\title{
Model-Based Design of a Plug-In Hybrid Electric Vehicle Control Strategy
}

\author{
Jonathan Charles King
}

Thesis submitted to the faculty of the Virginia Polytechnic Institute and State University in partial fulfillment of the requirements for the degree of

Master of Science

in

Mechanical Engineering

Chair: Douglas J. Nelson

Alexander Leonessa

Scott T. Huxtable

September 5, 2012

Blacksburg, VA

Keywords: model-based design, hybrid electric vehicle, plug-in, architecture selection, control system validation, simulation, software-in-the-loop, hardware-in-the-loop

Copyright 2012, Jonathan C. King 


\title{
Model-Based Design of a Plug-In Hybrid Electric Vehicle Control Strategy
}

Jonathan Charles King

\begin{abstract}
For years the trend in the automotive industry has been toward more complex electronic control systems. The number of electronic control units (ECUs) in vehicles is ever increasing as is the complexity of communication networks among the ECUs. Increasing fuel economy standards and the increasing cost of fuel is driving hybridization and electrification of the automobile. Achieving superior fuel economy with a hybrid powertrain requires an effective and optimized control system. On the other hand, mathematical modeling and simulation tools have become extremely advanced and have turned simulation into a powerful design tool. The combination of increasing control system complexity and simulation technology has led to an industry wide trend toward model based control design. Rather than using models to analyze and validate real world testing data, simulation is now the primary tool used in the design process long before real world testing is possible. Modeling is used in every step from architecture selection to control system validation before on-road testing begins.
\end{abstract}

The Hybrid Electric Vehicle Team (HEVT) of Virginia Tech is participating in the 2011-2014 EcoCAR 2 competition in which the team is tasked with re-engineering the powertrain of a GM donated vehicle. The primary goals of the competition are to reduce well to wheels (WTW) petroleum energy use (PEU) and reduce WTW greenhouse gas (GHG) and criteria emissions while maintaining performance, safety, and consumer acceptability. This paper will present systematic methodology for using model based design techniques for architecture selection, control system design, control strategy optimization, and controller validation to meet the goals of the competition. Simple energy management and efficiency analysis will form the primary basis of architecture selection. Using a novel method, a series-parallel powertrain architecture is selected. The control system architecture and requirements is defined using a systematic approach based around the interactions between control units. Vehicle communication networks are designed to facilitate efficient data flow. Software-in-the-loop (SIL) simulation with Mathworks Simulink is used to refine a control strategy to maximize fuel economy. Finally hardware-in-the-loop (HIL) testing on a dSPACE HIL simulator is demonstrated for performance improvements, as well as for safety critical controller validation. The end product of this design study is a control system that has reached a high level of parameter optimization and validation ready for on-road testing in a vehicle. 


\section{ACKNOWLEDGEMENTS}

I would first like to thank General Motors, the United States Department of Energy, and Argonne National Labs for sponsoring and organizing Advanced Technology Vehicle Competitions including EcoCAR 2. Participation in this program has shaped my education and graduate studies. I would also like to thank the Hybrid Electric Vehicle Team of Virginia Tech which, without the support of, I could not accomplish this study. Next I would like to thank my family for giving me the support to work through stress and hardships to complete my studies. Finally I would like to thank Dr. Nelson for his mentorship and friendship, and for sharing my passion for advanced vehicle powertrains. 


\section{TABLE OF CONTENTS}

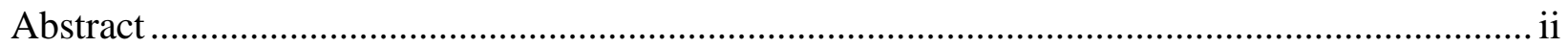

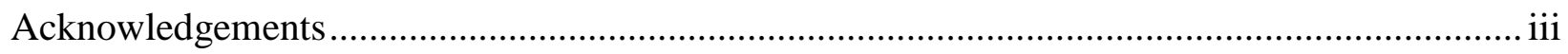

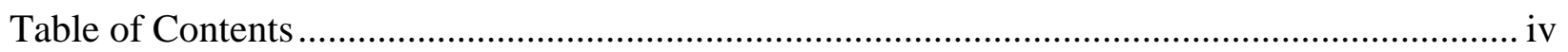

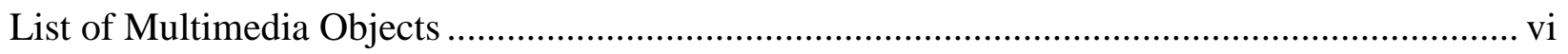

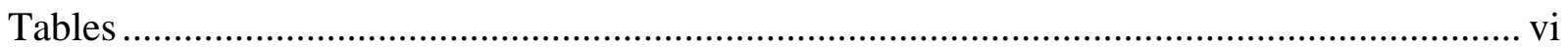

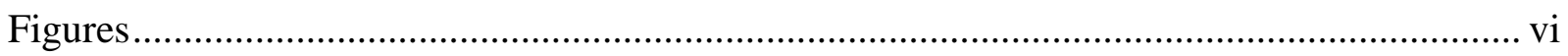

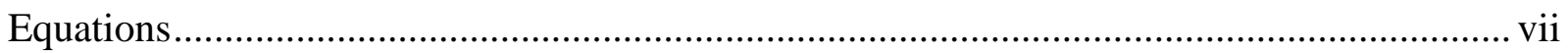

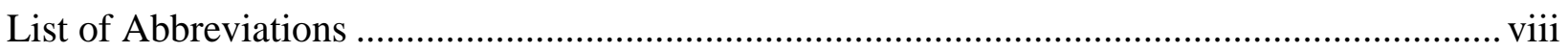

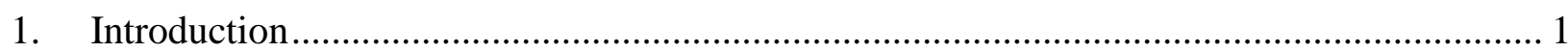

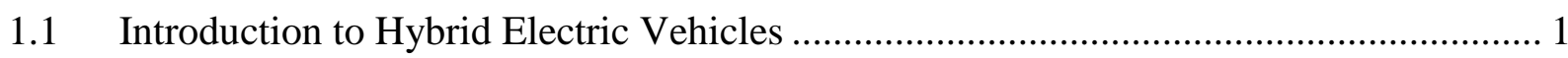

1.2 Motivation for Development of Vehicle Control Systems.............................................. 1

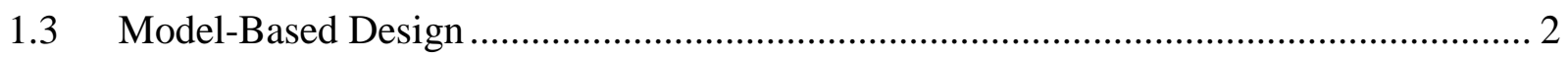

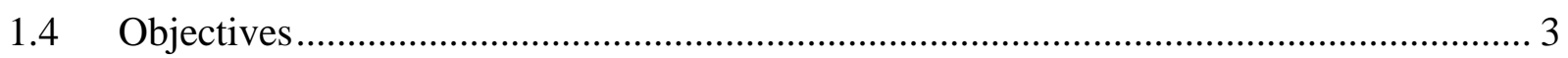

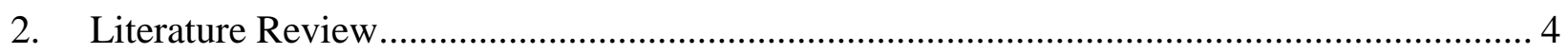

2.1 Mahapatra et al. Paper on Model-Based Design ........................................................ 4

2.2 Marco and Cacciatori Paper on Model-Based Design Techniques................................... 4

2.3 Katrašnik et al. Article on Energy Conversion Efficiency .............................................. 5

2.4 Alley Master's Thesis on Energy Flow and Losses in Hybrid Powertrains....................... 6

2.5 Pisu and Rizzoni Article on Supervisory Control Strategies ......................................... 6

2.6 Schacht Master's Thesis on Development of EcoCAR Vehicle Controls ......................... 8

2.7 Ramaswamy et al. Case Study in Hardware-In-the-Loop Testing .................................... 8

2.8 Deng et al. Paper on Controller Hardware-In-the-Loop Simulation ................................ 9

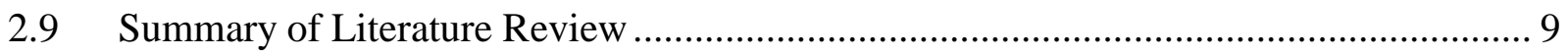

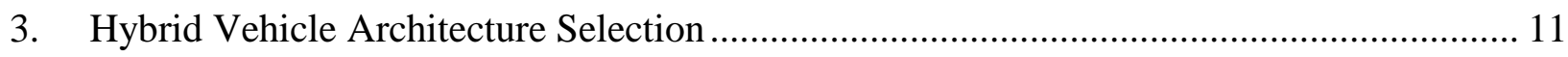

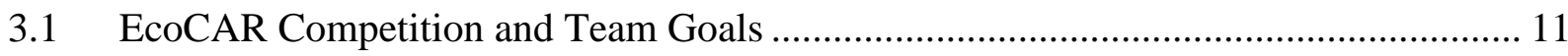

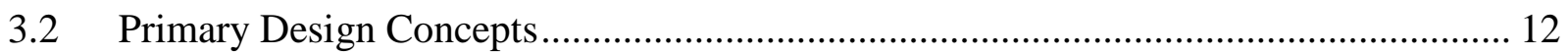

3.4 Energy Storage System Sizing ........................................................................... 14

3.4 Architecture Layout Selection........................................................................... 18

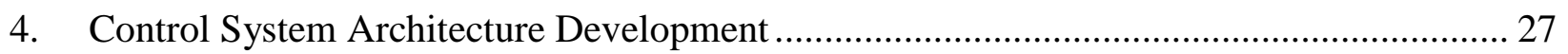

4.1 Expansion of Base Vehicle Control System .............................................................. 27

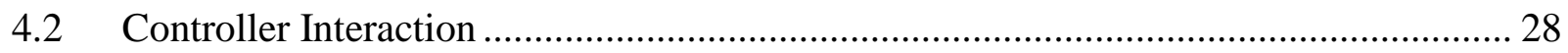

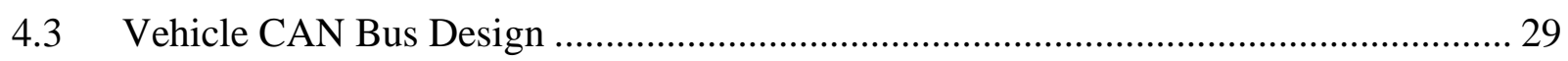

5. Hybrid Vehicle Supervisory Controller development ....................................................... 31 
$5.1 \quad$ Hybrid Vehicle Supervisory Controller Requirements .............................................. 31

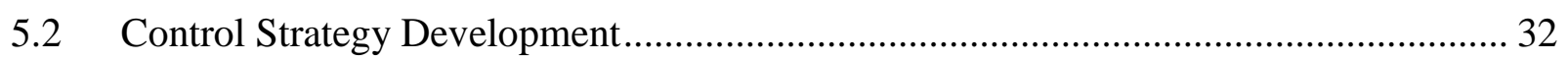

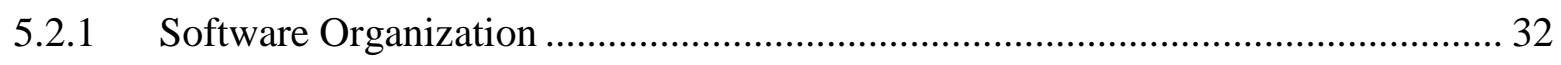

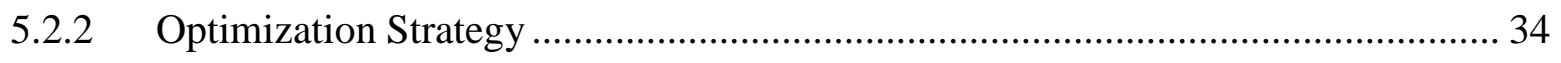

5.2.3 SIL Vehicle Model for Strategy Development ....................................................... 36

5.2.4 SIL Testing to Improve Optimization Strategy ........................................................ 38

5.2.5 HIL Hardware and Plant Model Development ..................................................... 42

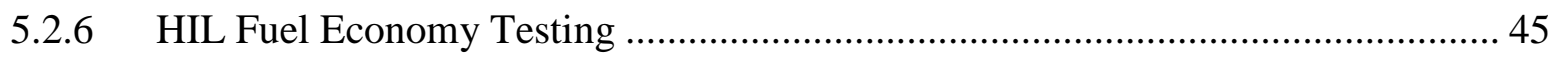

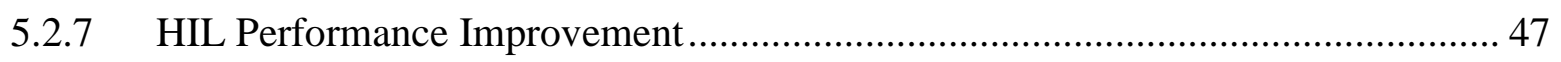

5.2.8 HIL Safety Critical and Diagnostic Testing...................................................... 50

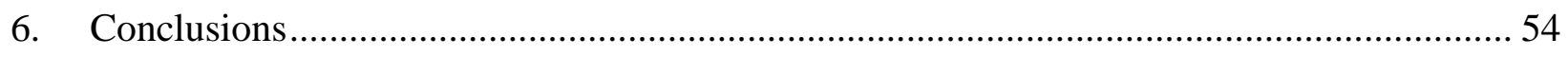

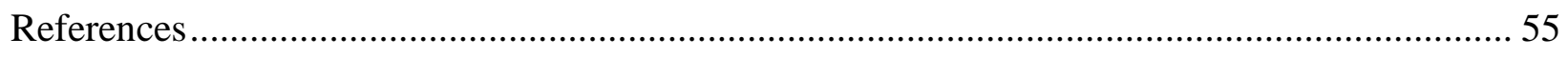

Appendix A: Table of Powertrain Control Modules............................................................ 57

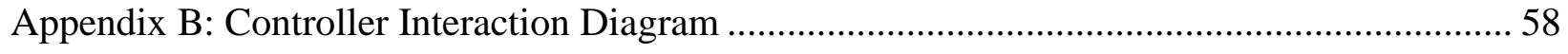

Appendix C: Results for SIL Testing Parameter Variation ............................................................. 60 


\section{LIST OF MULTIMEDIA OBJECTS}

\section{Tables}

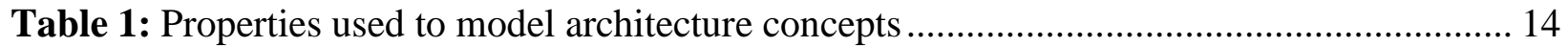

Table 2: Results for EV powertrain drive cycle simulation ......................................................... 17

Table 3: Comparison of powertrains using drive cycle simulation ........................................... 25

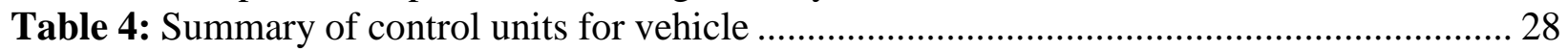

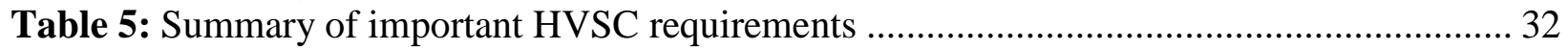

Table 6: Powertrain modes of operation ............................................................................. 34

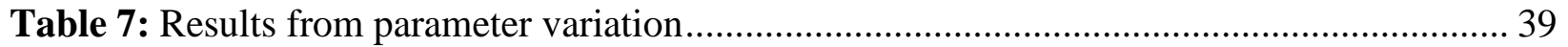

Table 8: Fuel economy results for full optimization strategy ................................................. 42

Table 9: Specifications for dSPACE Mid-Size Simulator ............................................................. 43

Table 10: Component models used in HIL plant model ........................................................... 45

Table 11: HIL energy consumption and fuel economy test results.............................................. 46

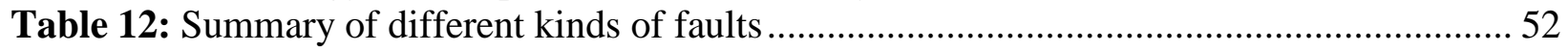

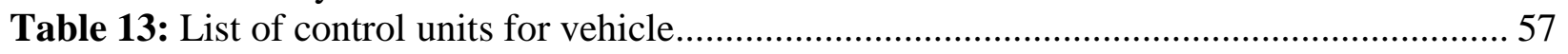

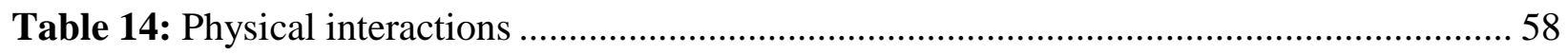

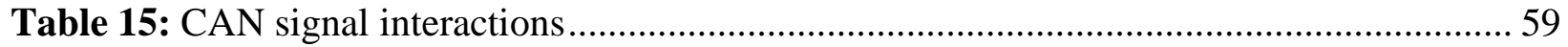

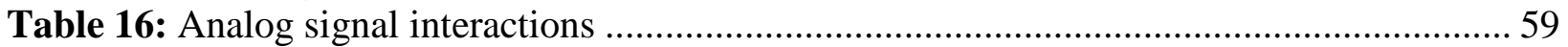

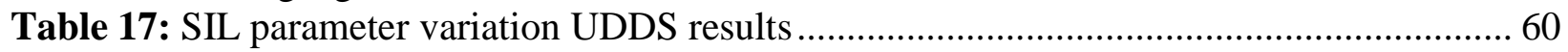

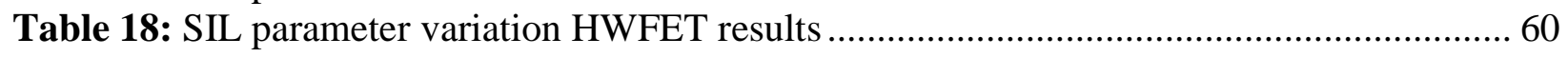

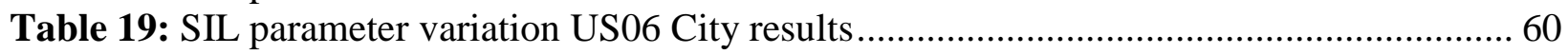

Table 20: SIL parameter variation US06 Highway results ...................................................... 61

\section{Figures}

Figure 1: Typical one-way commute of the average U.S. resident........................................... 12

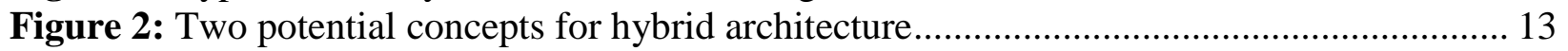

Figure 3: Charge depleting powertrain efficiency map ……….................................................. 15

Figure 4: Powertrain efficiency map with US06 city cycle plotted over..................................... 17

Figure 5: Powertrain efficiency map for series powertrain ....................................................... 20

Figure 6: Series-parallel powertrain mode selection map …………………………………..... 21

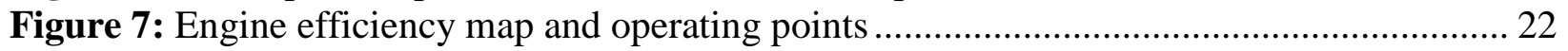

Figure 8: Series-parallel powertrain battery operating points …………………....................... 23

Figure 9: Series-parallel powertrain efficiency map.................................................................. 23

Figure 10: Comparison between series and series-parallel powertrain efficiency maps ............. 24

Figure 11: Controller interaction between HVSC, ECM, engine, and driver.............................. 29

Figure 12: Vehicle CAN bus design ..................................................................................... 30

Figure 13: Control system requirements based on HVSC and ECM interaction ......................... 31

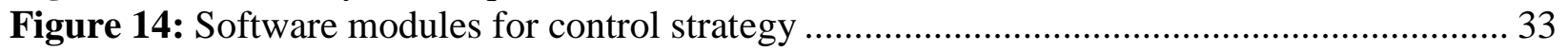

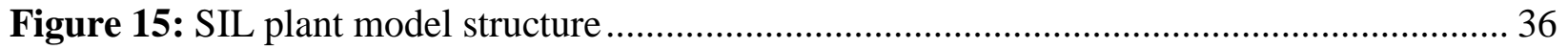

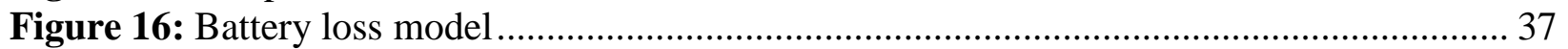

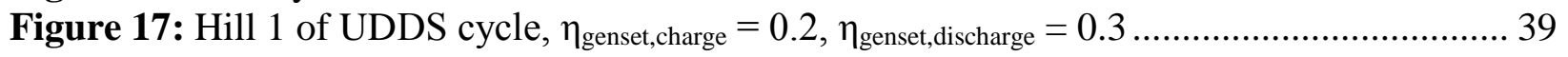

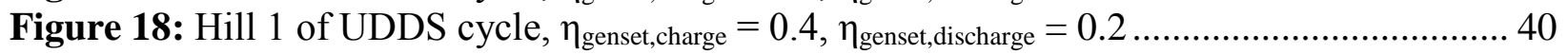

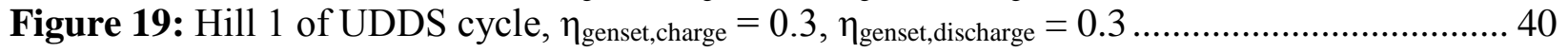




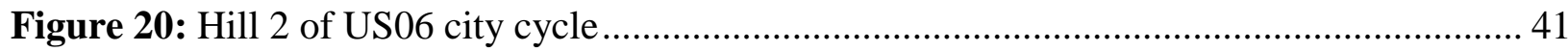

Figure 21: I/O and control system requirements that drive model requirements ..................... 44

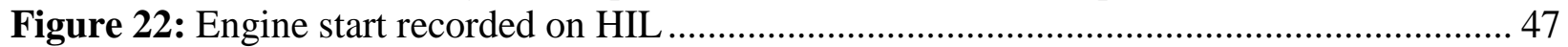

Figure 23: Acceleration data from HIL ..................................................................... 48

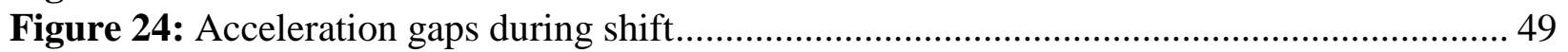

Figure 25: Vehicle acceleration during shift after algorithm changes ................................... 50

Figure 26: Response to simultaneous accelerator and brake input.................................... 51

Figure 27: Results from test of RTM CAN communication fault ....................................... 52

Figure 28: Controller interaction diagram ................................................................ 58

\section{Equations}

Equation 1: Basic EV Powertrain Efficiency ....................................................................14

Equation 2: Expanded EV Powertrain Efficiency ............................................................14

Equation 3: RTM Torque From Output Axle Torque ...........................................................15

Equation 4: RTM Speed From Output Axle Speed..........................................................15

Equation 5: Regenerative Braking Powertrain Efficiency ...............................................15

Equation 6: Tractive Effort From Road Load .......................................................................16

Equation 7: Output Axle Torque From Tractive Effort ......................................................16

Equation 8: Output Axle Speed From Vehicle Speed .......................................................16

Equation 9: Basic Charge Sustaining Powertrain Efficiency ....................................................18

Equation 10: Battery Discharging Powertrain Efficiency ...................................................18

Equation 11: Battery Charging Powertrain Efficiency.........................................................19

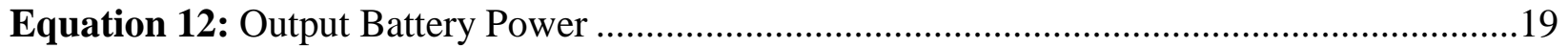

Equation 13: Drive Cycle Average Charging Efficiency …..............................................25

Equation 14: Drive Cycle Average Discharging Efficiency ................................................25

Equation 15: Drive Cycle Average Genset Efficiency..........................................................25

Equation 16: Battery Charging Fuel Consumption ............................................................35

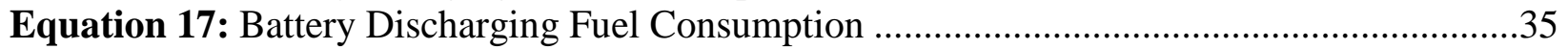

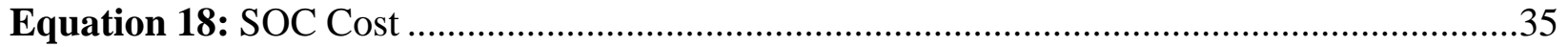

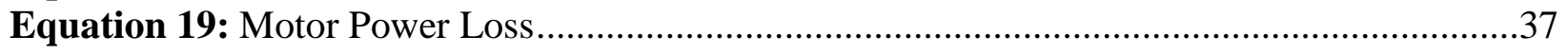

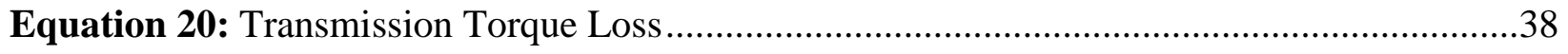




\section{LIST OF ABBREVIATIONS}

$\begin{array}{ll}\text { ABS } & \text { Antilock Braking System } \\ \text { AER } & \text { All-Electric Range } \\ \text { ANL } & \text { Argonne National Laboratory } \\ \text { APM } & \text { Auxiliary Power Module } \\ \text { ASM } & \text { Automotive Simulation Models } \\ \text { BCM } & \text { Battery Control Module } \\ \text { CAN } & \text { Controller Area Network } \\ \text { CD } & \text { Charge Depleting } \\ \text { CS } & \text { Charge Sustaining } \\ \text { DOD } & \text { Depth of Discharge } \\ \text { DOE } & \text { Department of Energy } \\ \text { DOF } & \text { Degrees of Freedom } \\ \text { EBCM } & \text { Electronic Brake Control Module } \\ \text { ECMS } & \text { Equivalent Consumption Minimization Strategy } \\ \text { ECU } & \text { Electronic Control Unit } \\ \text { EREV } & \text { Extended Range Electric Vehicle } \\ \text { ESS } & \text { Energy Storage System } \\ \text { EV } & \text { Electric Vehicle } \\ \text { FSM } & \text { Finite State Machine } \\ \text { GHG } & \text { Greenhouse Gas } \\ \text { GMIM } & \text { Generator Motor Inverter Module } \\ \text { HEV } & \text { Hybrid Electric Vehicle } \\ \text { HEVT } & \text { Hybrid Electric Vehicle Team } \\ \text { HIL } & \text { Hardware In the Loop } \\ \text { HVCM } & \text { High Voltage Charger Module } \\ \text { HVSC } & \text { Hybrid Vehicle Supervisory Controller } \\ \text { HWFET } & \text { Highway Fuel Economy Test } \\ \text { IBCM } & \text { Integrated Body Control Module } \\ \text { IO } & \text { Input/Output } \\ \text { MPG } & \text { Miles per Gallon } \\ \text { P2M } & \text { Position 2 Motor } \\ \text { PEU } & \text { Petroleum Energy Use } \\ \text { PSCM } & \text { Power Steering Control Module } \\ \text { PWM } & \text { Pulse Width Modulation } \\ \text { RTM } & \text { Rear Traction Motor } \\ \text { SIL } & \text { Software In the Loop } \\ \text { SOC } & \text { State of Charge } \\ \text { TCM } & \text { Transmission Control Module } \\ \text { TMIM } & \text { Traction Motor Inverter Module } \\ \text { UDDS } & \text { Urban Dynamometer Driving Schedule } \\ \text { WTW } & \text { Well to Wheel } \\ & \end{array}$




\section{INTRODUCTION}

\subsection{Introduction to Hybrid Electric Vehicles}

In 2011, 134 billion gallons of fuel was burned by passenger vehicles in the US [1]. This equates to $1.31 \times 10^{9}$ tons of greenhouse gasses released into the atmosphere and cost the average American family $\$ 4,155$ [2]. While petroleum has been the primary fuel for transportation use for decades there are many environmental, economical, and political reasons to reduce and ultimately replace petroleum as a major energy source. Passenger vehicles are not the sole consumer of petroleum fuel in the US but are a major contributor [3]. To combat this, legislation and standards such as Corporate Average Fuel Economy and the California zero-emission vehicle mandates put increasing pressure on auto-manufacturers to produce more efficient vehicles. While there are many technologies that are helping to increase the fuel economy of conventional vehicles, hybrid electric vehicles will play an important role in reducing petroleum energy use.

Hybrid electric vehicles come in a variety of forms and varying levels of electrification. In a general sense a hybrid vehicle is a vehicle that stores energy on board in two or more forms. In a typical hybrid electric vehicle one form is gasoline with an engine as a fuel converter. The other is a bidirectional electrical storage device, usually a battery. The size of the battery is an indicator of the level of electrification. A higher level of electrification generally comes with more potential to improve fuel economy.

There are several different ways that hybrid electric vehicles reduce fuel consumption. The first way is by eliminating idle fuel use. A conventional vehicle continues to burn fuel even when it is not moving. Hybrid electric vehicles can eliminate this by providing the capability to shut the engine off and quickly start it back up when needed. The next method of reducing fuel consumption is recapturing brake energy that otherwise would be wasted. This is made possible by introducing a bidirectional energy storage device on the vehicle. A third method of reducing fuel consumption is downsizing of the engine. The engine in a conventional vehicle is sized for peak demand, yet is usually operated at part load where it is less efficient. Hybrid electric vehicles can use more efficient electric machines to meet peak demand while sizing the engine to meet continuous demand therefore keeping the average load in higher efficiency zones. A fourth way hybrid vehicles reduce fuel consumption is by operating the engine more efficiently. Hybrid electric powertrains typically have degrees of freedom in what speed and output level the engine can be operated at while still meeting the driver demand. This offers the capability of running the engine in its most efficient zones for a wide range of vehicle conditions. The last way hybrid vehicles can reduce fuel use is by offsetting fuel with stored grid electricity. This is possible for plug-in vehicles that allow recharging and some level of electric-only driving capability.

\subsection{Motivation for Development of Vehicle Control Systems}

Control systems in vehicles have continuously evolved to meet the increasing demands from customers and governmental regulation. While control systems in modern vehicles have led to better performance, drivability, and safety, a large influence in the adoption of control systems 
for vehicles has been the push to meet fuel economy and emissions requirements. The modern hybrid electric vehicle is the state of the art in electronic vehicle control systems. The first electronic control units emerged out of the need for better engine control in order to meet fuel economy and emissions standards. Fuel injection allowed much more precise control of fuel delivery than traditional carburetors but required an electronic control unit (ECU) to control the fuel delivery. Engine control continued to evolve with the ECU eventually taking over tasks such as controlling ignition timing, cooling, exhaust gas recirculation, and the intake throttle. The next place ECU's emerged in vehicles was for transmission control. Traditional automatic transmissions used complicated hydraulic systems to control shift logic and execution. Electronic transmission control proved to be much more reliable and improved fuel economy through better shift control. Modern transmission controllers also achieve much faster shifts with superior drivability through precise clutch control. Another important place where ECU's emerged in vehicles was in brake systems. Antilock braking systems (ABS) provided improved safety by preventing the wheels from locking up in a panic stop situation. This helped the driver maintain control of the vehicle while braking. This later evolved into more advanced features such as dynamic stability control and traction control.

Along with the need for electronic control units in vehicles, the need for these control units to communicate with each other soon arose. By sharing information the control units were able to more effectively perform their tasks. The engine controller and transmission controller, for instance, could achieve much smoother shift quality if they communicated and coordinated engine torque modification during a shift. Stability control and traction control systems could also benefit from modifying engine output when activated. Various forms of vehicle communication networks emerged and facilitated real-time information transfer between ECU's. The modern standard for ECU communication is controller area network (CAN). CAN allows high speed transfer of information without heavy wiring harnesses. Rather than multiple ECU's reading the same sensor, one ECU can read a sensor, perform signal conditioning, then broadcast the information scaled in engineering units for any other ECU that requires the information. As the number of ECU's on a vehicle has continually increased vehicles have gone from having one to multiple CAN buses for information of different priorities.

At this point, while vehicles contained many networked ECU's that worked together, vehicle control systems were still not approached from the system level. Each component still largely operated on its own accord taking its primary commands from the driver. The final evolution in vehicle control systems is supervisory control. This has been largely influenced by hybrid vehicles. With the addition of new powertrain components that must work together seamlessly to achieve high fuel economy or even work at all, there comes the need for a control unit that makes decisions and commands the rest of the powertrain components accordingly. The engine controller, for instance, can no longer determine how much output the engine should make based on the driver demand alone. Torque split between the engine and electric machines must be decided and the engine and electric machine must act accordingly.

\subsection{Model-Based Design}

With the rise of complex hybrid powertrains and the complex control systems required to make them work, model-based design has become an essential tool in the design and validation of 
hybrid powertrains and control systems [5]. Modern computer simulation hardware has become powerful enough to execute complex vehicle models that can reproduce the behavior of a real vehicle with a high degree of realism while executing the model in real-time. This facilitates the design and validation of both powertrain components and control systems at the component, subsystem, system, or even vehicle level. In the design stages modeling can help make design decisions such as powertrain layout and component selection for the vehicle to meet the goals and specifications that are desired. With the vehicle architecture determined, model-based design provides a platform to develop the control system and strategies before any powertrain hardware is developed and built.

Model-based design is also extremely effective for validation purposes, especially for control systems. With widespread use of electronic control, a control malfunction in a modern hybrid vehicle could potentially cause the vehicle to accelerate without being prompted by the driver and even, depending on the powertrain, accelerate in the wrong direction. This means thorough validation of control systems before implementation in a vehicle is critical. The complex vehicle communication networks require analysis of communication reliability and implications of communication failure with individual components.

\subsection{Objectives}

The goal of this research is to demonstrate how model based design can be effectively used in the design of a hybrid electric vehicle powertrain and control system. The design will be followed from initial goals and requirements to the development and validation of the actual control system and control strategies. Methods and techniques will be presented at different steps in the vehicle development that make effective use of model-based design tools. The research will begin with selection of a hybrid vehicle architecture to meet team goals. A novel technique of comparing different vehicle architectures will be presented. The important feature of this technique is that it can compare completely different vehicle architectures without the need of developing actual control strategies and running second by second drive cycle simulations. It is based on evaluating the potential an architecture has to perform in different driving conditions. Next development of the control system architecture will be covered including the design of a dual CAN bus structure. The research will then go into the design of a control strategy to minimize fuel consumption. Software-in-the-loop (SIL) simulation will be used to examine fuel economy results. Finally, hardware-in-the-loop (HIL) simulation will be used to validate the vehicle control system for performance, safety, and fuel economy. 


\section{LITERATURE REVIEW}

\subsection{Mahapatra et al. Paper on Model-Based Design}

A paper by Mahapatra et al. [5] offers several insights into the motivation for and advantages of using model-based design as an integral tool throughout the design and implementation process. Mahapatra says that while model based design is traditionally only used for controller development, one of the goals of the paper is to demonstrate how model-based techniques can be used throughout the design process. The paper goes on to discuss general challenges in HEV system design. According to Mahapatra the key aspect of model-based design is the ability to continually verify that design requirements are being met at each step of the way.

The paper follows the development of a hybrid vehicle that uses two electric machines and a planetary power splitting device. While this architecture is distinctly different from the architectures that will be considered for this research, there is still much insight to be gained from this paper. Mahapatra describes how different steps of design require models with varying levels of abstraction and fidelity. The model-based design process is described as a process of continually elaborating simulation models from a concept to a detailed system design that can verify performance. The overall goal is to ensure first pass success when a prototype is built.

The paper suggests starting with a high level system model. The subsystems in the model are then each passed on to various specialists who refine the models while also refining and updating requirements. Detailed models are then integrated back into the system level model and verified by simulation. This is described as an iterative process that converges to an optimal design. Code generation is described as the next step to facilitate testing on a target processor as well as accelerating simulation and doing HIL testing.

The paper also gives some description about the models used. The models of the mechanical powertrain components use the Mathworks SimDriveLine toolkit for calculations. Mathworks SimPowerSystems is used for some electrical components. Mahapatra discusses the tradeoffs of creating highly detailed models and suggests against models with excessive detail. He describes some of the simplified subsystem models used for simulation. The control strategy developed for the vehicle is a state machine type architecture programmed using Mathworks Stateflow.

This research will address some of the short comings of Mahapatra's paper by describing in more detail system design of the vehicle control system. For instance interaction and communication between vehicle ECUs will be examined. This paper will also present in detail a control strategy aimed at minimizing fuel consumption. This paper will also describe in detail HIL testing using dSPACE Automotive Simulation Models (ASM).

\subsection{Marco and Cacciatori Paper on Model-Based Design Techniques}

A paper by Marco and Cacciatori [6] aims to show how use of model based design techniques can be used to reduce complexity and development time of HEV systems. The paper focuses on two main areas, architecture and component selection and control algorithm design. The paper discusses differences between online and offline simulation, as well as forward looking and 
backward looking simulation models during initial simulation and component selection phase. Two case studies are presented as examples for architecture selection using simulation. For the first, a backward looking model is used in the development of a fuel cell hybrid sports car to examine tradeoffs between parameters such as vehicle weight, powertrain efficiency and aerodynamics. The model requires a generic control strategy to run drive cycles for measuring fuel economy. The results provide a sensitivity analysis for varying the parameters to fuel economy. The second case study looks to compare actual powertrain component selection choices. In particular, simulation is used to choose between different gearing configurations for the traction motor and selection of the motor itself.

While the methods presented can be effective they have some shortcomings. While the paper looks at component selection, it does not address choosing between distinctly different architectures. Another important issue is that the simulations used by Marco and Cacciatori require control strategies to operate the powertrain. At the architecture selection point in design however, a detailed control strategy has usually not been developed. This means a simple strategy must be created for each architecture just for the purpose of determining if that architecture is a desirable option. The goal should be to determine the potential that a given vehicle architecture has of improving fuel economy without looking at the actual control strategy.

The paper then goes on to discuss control architecture and strategy development. Universal modeling languages SysML and UML are presented as tools for this process. A visual model is developed to show interaction of the requirements of the control system between the driver and the vehicle. Mathworks Simulink is then used to implement the actual control strategy. The Wren Project is introduced as a tool to facilitate interchangeability of control functions between different powertrain concepts but is not described in detail. The paper does not actually present a detailed control architecture or strategy. The current work aims to directly demonstrate how model-based design tools have actually been used to develop and refine a control system.

\subsection{Katrašnik et al. Article on Energy Conversion Efficiency}

An IEEE article by Katrašnik et al. [7] presents analysis on conversion efficiency for both series and parallel hybrid powertrains. This is important to this research because choosing between these powertrain options is an important step during architecture selection. The article mentions an important limitation in lookup table based models traditionally used for simulations. Lookup table based engine models, for instance, do not account for dynamics and transients. Turbo charged engines cannot be effectively modeled in this way. The article therefore points to forward looking dynamic models as the most effective for simulation. The article presents two approaches of analyzing powertrain efficiency, analytical and through simulation. The analytical approach uses energy balance equations to present a solution for calculating the powertrain efficiency. The equations however use somewhat arbitrary efficiency constants and the article offers no explanation of how to derive the constants.

The simulation software used is a thermodynamic and fluid mechanics code developed by Katrašnik. The article goes into detail about the parameters for each of the component models for the series and parallel architecture. Rather than running vehicle drive cycle simulations, 
simulations are run for the European Transient Cycle engine dynamometer test, using the engine load as a powertrain load. This was done to compare the hybrid powertrain to the baseline conventional powertrain without the influence of gear shift strategies and vehicle parameters. For the simulation a thermostatic type control strategy was used for the series hybrid. The control strategy for the parallel was not described in detail but offered several modes of operation. The article does not address how the control strategy affects the powertrain efficiency or support the control strategies used. This is a limitation that this research aims to address. Comparing different architectures independent of a specific control strategy is important to identifying whether one architecture is superior to another. The findings of the paper are that overall the parallel powertrain offered better fuel economy. The series powertrain offered an advantage in cycles featuring frequent rapid decelerations and transients. Another finding was that the hybrid powertrain efficiency was very sensitive to the efficiencies of the electric machines and storage devices, thus emerging electric machines with higher efficiency offer promise in increasing fuel economy of hybrid powertrains.

\subsection{Alley Master's Thesis on Energy Flow and Losses in Hybrid Powertrains}

This master's thesis by Alley introduces a new tool and method for analyzing losses throughout a hybrid electric powertrain system. The purpose of the tool developed, called VTool, is to facilitate better understanding of a powertrain architecture and provide a means of comparing the potential of two different architectures for fuel economy. Like the method that will be presented in the current work, the VTool method allows the comparison of different architectures without the need to develop a real-time control strategy. Alley uses "Sovran" coefficients to characterize a drive cycle and vehicle glider properties to characterize the drive cycle demands on the powertrain over a cycle. The tool can than calculate how much fuel energy it would take to meet the demands. The effects of the control strategy are summarized into a single parameter called the Power Split Fraction. This parameter indicates how much energy from the engine goes directly to meeting driver demand versus the fraction of energy that gets stored in the battery pack then later discharged. The VTool method provides some advantages and disadvantages compared to the method proposed in the current research. One advantage is that it requires less work and can rapidly be used to study the energy flows and losses in the system. An advantage of the method introduced in the current research is that it provides more insight into what control techniques might be effective when the selected architecture moves into control development.

Another interesting component of VTool is the use of drive cycle average efficiencies. VTool makes use of multiple average component efficiencies in order to calculate energy consumption. Alley uses test data collected from a vehicle for these parameters and tunes them to validate the model against the collected data. The current research uses drive cycle average efficiencies to determine the value of stored battery energy. These parameters are estimated during architecture selection through iteratively running the model. Later they will be used as tunable parameters to tweak behavior of the control strategy.

\subsection{Pisu and Rizzoni Article on Supervisory Control Strategies}

Pisu and Rizzoni authored an article [8] that compares some supervisory control techniques for hybrid electric vehicles. The paper uses a pre-transmission belt coupled parallel hybrid electric 
vehicle to analyze the impact of different control strategies. The electric machine is an $18 \mathrm{~kW}$ continuous, $42 \mathrm{~kW}$ peak induction machine. While this powertrain has some similarities to the powertrain that will be examined for the current work, larger electric machines and thus a higher degree of hybridization will give the control strategy in the current work much more impact in the fuel economy. This article still offers some useful insight. The vehicle model used for simulating the control strategies is outlined first. The mathematical models for all the vehicle components are presented. A curve fit model is used for engine fuel consumption. A similar method is used for the electric motor. While initial modeling for the current research will use simple lookup table based models, further development will be done using dynamic simulation models.

The article then goes into four different proposed control strategies. Pisu and Rizzoni state that since the parallel powertrain is a pre-transmission architecture the gear shifting strategy can be separated from the torque split strategy. This may be a reasonable assumption on a vehicle with a low degree of hybridization, but for a vehicle with more powerful electric machines the gear ratio is important to efficiency and is a degree of freedom that should be examined. The first control strategy described is a finite-state machine (FSM) that is rule and event driven and operated the powertrain in discrete states such as acceleration, deceleration, cruise, and recharge. The advantage of this method is simplicity and low computational complexity. The disadvantage however is that this method is not directly based on fuel economy. The strategy is mainly effective for maintaining battery SOC within limits, but does not directly aim to reduce fuel consumption.

The second strategy is called the equivalent consumption minimization strategy (ECMS). This strategy forms a cost function with the goal of minimizing fuel consumption at each point in time. It works by equating energy used from the battery to fuel that was consumed to charge the battery. Energy being stored into the battery can be deducted from fuel being consumed at the present time since that stored energy will offset fuel use. This method is sensitive to how electric energy is related to fuel. An equivalence factor is derived for this purpose that changes based on driving conditions. This method is very similar to the control strategy that will be proposed in this paper. This paper will however use the strategy to explore all modes of operation including transmission gear, rather than having a separate gear shift strategy. The article then goes on to describe an adaptive version of the ECMS strategy.

The last two strategies described are called $\mathcal{H}_{\infty}$ control and dynamic programming. The $\mathcal{H}_{\infty}$ control method is based on a state space closed loop control model. Dynamic programming analyzes all possible torque split combinations at each point in time to find the optimal trajectory of battery SOC that gives the highest fuel economy. These methods are not practical for invehicle use because it requires a high level of offline computational complexity and prior knowledge of the drive cycle to develop the optimal solution. The article summarizes by discussing the pros and cons of the different control methods. ECMS is found to offer the best compromise delivering fuel economy close to the optimal solution. 


\subsection{Schacht Master's Thesis on Development of EcoCAR Vehicle Controls}

The Master's thesis by Schacht [9] covers development of the Ohio State University vehicle for the EcoCAR competition. The architecture has some similarities with the vehicle used for this research and some key differences. Both have a high power electric machine on the rear axle. On the front both architectures have an engine and electric motor that can be used in series mode or deliver torque to the front axle. The Ohio State vehicle can decouple the front electric motor from the engine and provide electric assist in electric-only mode. The vehicle used for this research cannot disconnect the electric motor from the engine, but has multiple gear ratios for parallel operation, where the Ohio State vehicle only has one gear. The electric motor on the front for the Ohio State vehicle is also much bigger, offering $82 \mathrm{~kW}$ peak, versus $27 \mathrm{~kW}$ for the vehicle in this research.

A detailed description of the vehicle supervisory control system is included. There are many similarities between the control system of the Ohio State vehicle and the control system designed in this research. The control system architecture is very similar with distributed component controllers and a supervisory controller interpreting driver demand and commanding powertrain components, communicating via a multiple CAN bus structure. The control hardware selected for the supervisory controller was a MicroAutoBox just like the controller in this research. While the CAN bus structure is presented, the process of designing this structure and verification of reliability is not addressed. This is one of the goals of this research.

Schacht then goes into the actual design of the control software that runs on the supervisory controller. At the highest level the control software utilizes a rule based control system to control flow between discreet modes. Within the operation modes an optimization strategy is run to choose an operating point. This is also similar to the strategy employed for this research but there is major difference. While the strategy used by Schacht uses rule based control to choose operating mode, the strategy developed for this research only uses rule based control for choosing high level operating state (e.g. charge depleting vs. charge sustaining). Selection of operating mode and of an operating point within a mode is done using an optimization strategy. Schacht used a rule based system, primarily a vehicle speed criteria, to choose between series and parallel modes. In series mode, a load following strategy is used to choose an engine generator operating point while in parallel mode the ECMS strategy described in the Pisu and Rizzoni article [8] is used to choose torque split. The strategy in this research uses an algorithm similar to ECMS to choose between series and parallel mode and the operating point within the mode. The parallel mode for the vehicle architecture used in this research also has multiple gear ratios to choose from for parallel operation. This is another variable for the strategy to optimize.

\subsection{Ramaswamy et al. Case Study in Hardware-In-the-Loop Testing}

A paper by Ramaswamy et al. [10] provides an excellent example of using HIL testing to refine a supervisory controller for a hybrid electric vehicle. The paper shows how implementation of HIL has helped Ford Motor Company in design of ECU's for highly complex hybrid vehicles. The paper says implementation of HIL testing has been quick and effective, as errors are found earlier in development where the cost of correcting them is much lower. The testing strategy 
employed progresses from desktop to HIL, dynamometer, and finally to on-road testing. Each step brings additional real components to the system to replace models.

The criteria for selecting the HIL system were that it needed to have the computing power to execute a complete vehicle plant model as well as other control units that the unit in testing must communicate with. The system should also have fault insertion under simulation control so that faults can be tested during automatic drive cycles. Extensive CAN communication support was also needed as that was a primary form of communication for the vehicle to be tested. A dSPACE midsize HIL simulator similar to the system being used for this research was chosen by Ford Motor Company to implement the HIL testing system. This HIL system used for this research is very similar and offers the same features such as automated fault insertion and load simulation.

The paper describes two testing methods for HIL, open loop and closed loop. In open loop testing, rather than actually running a vehicle simulation, inputs to the ECU are fed as constants or preset traces. This testing method can be useful for testing low level system I/O functionality. Closed loop testing uses a vehicle model that simulates the actual sensors and feedback the ECU should receive and responds to the ECU actuator commands. This is the typical general purpose testing method. The paper says that while they did not initially feel that open loop testing would be very useful it proved to be extremely effective in the initial stages of the development of the vehicle when the plant hardware design was not yet finalized. This research will focus on closed loop HIL testing and validation. While Ramaswamy stayed very high level and did not detail the actual HIL system setup, this paper will go much more in depth with the design of the test setup.

\subsection{Deng et al. Paper on Controller Hardware-In-the-Loop Simulation}

A paper by Deng et al. [11] is a case study in the use of controller HIL simulation to design the power management strategy for a fuel cell vehicle. While this vehicle architecture is distinctly different from what will be examined for this research, the control system design challenges are very similar and the same controller HIL testing techniques can be employed. Both vehicles have a unidirectional fuel converter and a bidirectional energy storage device of which SOC must be managed. The simulation hardware used to run the plant models is a Real-Time Digital Simulator which provides multiple parallel processors and a number of digital and analog I/O channels. The HIL system is used to test two different energy management strategies on a hardware controller. Through HIL new issues were highlighted that did not show up in software only testing. Current and voltage spikes caused by the time delay in interpreting the physical sensor signals and control signals appeared. This is an example of how HIL provides better validation through increased realism. While the paper provides a good high level basis on HIL testing techniques this research will go much more in depth into how HIL was used to validate a full vehicle control system.

\subsection{Summary of Literature Review}

This literature review explores prior work into the key areas being addressed in this research. The first important topic covered is use of model based design for hybrid electric vehicles. From the paper by Mahapatra a method of keeping requirements closely linked with algorithm 
development is demonstrated. The paper by Marco and Cacciatori explores the potential for using model based design at the architecture selection phase of development. The article by Katrašnik shows some of the tradeoffs between series and parallel vehicle architectures. This research will look at balancing the two to develop a powertrain that addresses the shortcomings of both. The next area explored is control strategies for reducing fuel consumption in hybrid vehicles. The prior work provides a good basis for developing a new real-time control strategy. The final topic explored is HIL testing. The prior work explores many of the concepts and advantages of HIL testing. This research will specifically highlight these methods in action. 


\section{HYBRID VEHICLE ARCHITECTURE SELECTION}

\subsection{EcoCAR Competition and Team Goals}

The Hybrid Electric Vehicle Team of Virginia Tech (HEVT) is competing in the three year EcoCAR 2 competition, organized by Argonne National Laboratory (ANL) and sponsored by General Motors (GM) and the US Department of Energy (DOE). Fifteen collegiate teams from the US and Canada are competing in EcoCAR 2, which is the latest in a series of Advanced Vehicle Technology Competitions. The goal of the competition is re-engineer a Chevrolet Malibu to reduce environmental impact while maintaining the consumer appeal. Teams will each receive an identical 2013 Chevrolet Malibu as a base vehicle. The competition lasts three years and roughly follows GM's vehicle development process. The first year of competition is primarily a design year, ending with the project initiation approval event where teams showcase a complete vehicle design. The second year is a build year where a "mule" or prototype vehicle is developed with the final event being vehicle design review. The third and final year is refinement where the vehicle is refined to a $99 \%$ production ready vehicle, ending with the vehicle testing complete event. The design of this vehicle will be the case study that this research is based on. With the first year of the competition having just been completed this research will show how model-based design tools have been used in several key ways through the year.

The major goals of the competition are to reduce well-to-wheels (WTW) petroleum energy use, reduce WTW greenhouse gas and criteria emission, and maintain safety, performance, and consumer acceptability. Apart from the competition design goals and targets, HEVT has identified several specific team goals. The first is to reduce petroleum energy use by $80 \%$. The choice to focus on petroleum energy reduction is made because that is a benefit that a consumer can directly see. While lowering emissions is important, the benefit is not as obvious as the direct financial impact a consumer will see from petroleum energy reduction.

The second major team goal is to have an all-electric range (AER) of at least 35 miles based on a 4-cycle drive schedule weighting (an approximation of EPA 5-cycle weighting developed for the EcoCAR 2 competition). This goal is set for several reasons. Electric-only driving is a big consumer pleaser because electric powertrains offer superior drivability to any conventional powertrain. The smooth torque delivery and lack of shifting provides an unparalleled driving experience. Electric powertrains are also exceptionally quiet. The high efficiency of electric powertrains also has a big potential to save consumers money. While per kWh of fuel energy the cost of electricity and gasoline is very similar the electric powertrain will use the energy stored onboard with nearly three times the efficiency, thus costing about a third as much to operate. The target of 35 miles was chosen because that range has the potential to allow many consumers to do all of their daily driving without using any gasoline. Figure 1 shows the distribution of average daily driven miles for US commuters. 


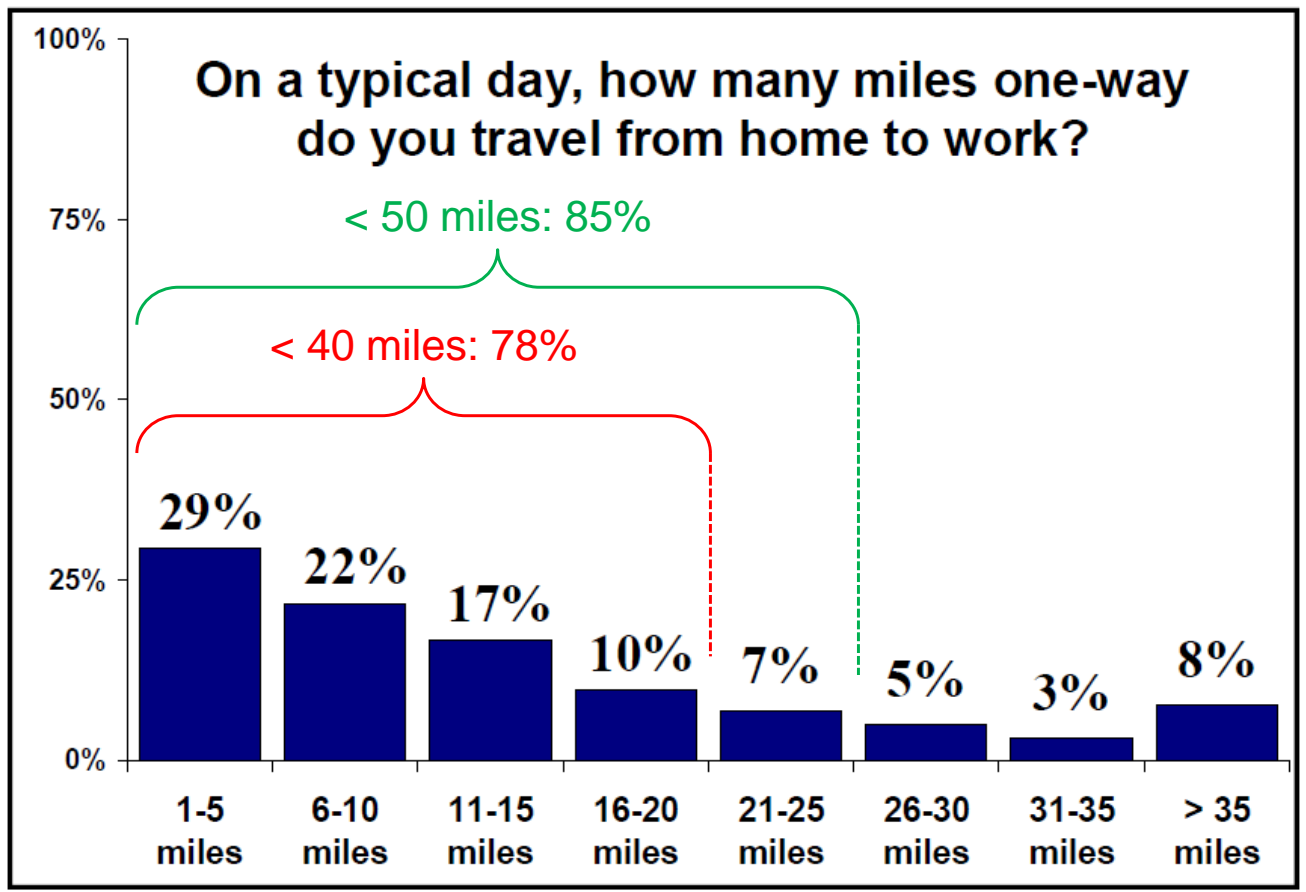

Source: US Department of Transportation, Bureau of Transportation Statistics, Omnibus Household Survey. Aggregated data cover activities for the month prior to the survey.

Figure 1: Typical one-way commute of the average U.S. resident

This chart shows that a vehicle with a 35 mile AER has the potential to allow between $68 \%$ and $78 \%$ of US commuters to do their daily traveling without using any gasoline. This does not include the increased potential of those who have the capability to charge at their place of work or business.

\subsection{Primary Design Concepts}

The first important step in the vehicle design was hybrid architecture selection. There are several design constraints that helped narrow down choices to potential solutions. The first is driven by the requirement to have a long AER. This means the vehicle must have a large energy storage system (ESS) and a powertrain capable of full performance in all-electric operation. The next constraint is that the vehicle must be designed and built by a student team within the three year time frame of the competition. This means the design must primarily use of off the shelf components potentially with some modification. As far as fuel sources, diesel will not be considered due to the lack of necessary resources to develop and calibrate an exhaust aftertreatment emissions control system for a diesel engine. Hydrogen was excluded from consideration due to limited hydrogen fueling availability and safety capabilities of the available facilities. Apart from resources to successfully design a hydrogen vehicle, the design compromises that would be forced by the integration challenges of a hydrogen vehicle directly contrasted team goals such as maintaining five passenger seating capacity and cargo space [12]. 
With these design constraints in mind two powertrain concepts were chosen for further consideration. The first was a series hybrid extended-range electric vehicle (EREV). The vehicle would have a $125 \mathrm{~kW}$ traction motor and a large ESS to store grid electricity. The range extender would be a $2.4 \mathrm{~L}$ E85 engine coupled to a $75 \mathrm{~kW}$ generator. The second concept was a seriesparallel EREV that had the capability of both series and parallel operation. This vehicle would have a $125 \mathrm{~kW}$ traction drive and ESS just like the series concept. The vehicle would also have a $2.4 \mathrm{~L} \mathrm{E} 85$ engine coupled to a smaller generator of $27 \mathrm{~kW}$. The engine and generator would also be mated to a 6 speed automatic transmission driving the front axle. With the transmission in neutral the vehicle could operate as a series hybrid and with the transmission in gear parallel hybrid operation is possible [13]. Figure 2 shows a schematic of how the two architectures would be laid out in the vehicle.

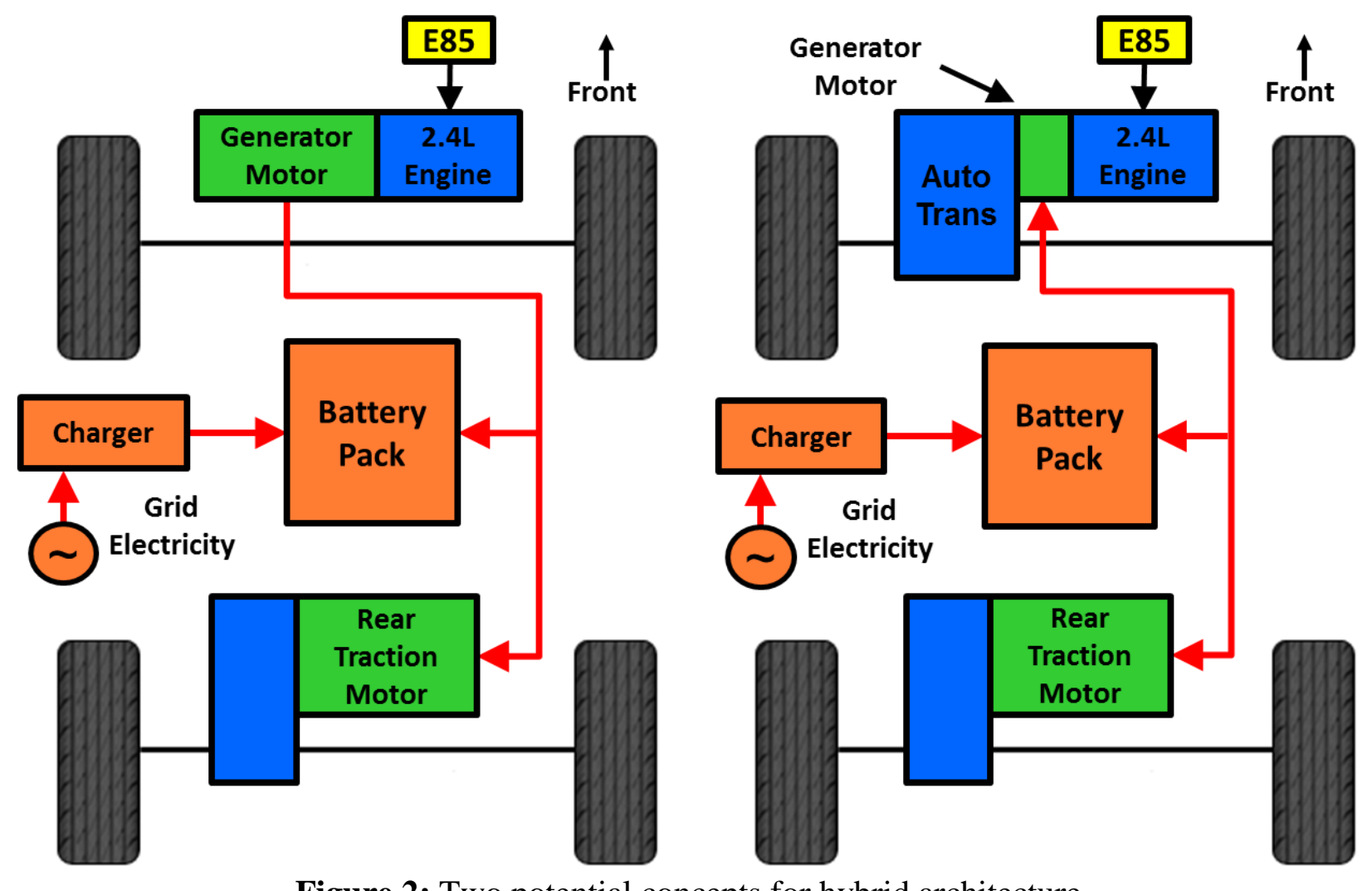

Figure 2: Two potential concepts for hybrid architecture

Both architectures utilize a rear traction motor (RTM) as the primary source of electric drive. There are 2 key differences in the architectures. The first difference is that the generator in the second architecture, referred to as the position 2 motor (P2M) is smaller than the generator in the series concept. This means in series operation will have less potential for efficiency due to less capability to load the engine. The other key difference is the parallel capability of the second concept through the automatic transmission. This parallel path has the potential to reduce losses by giving engine power a more efficient path to the wheels. This is particularly advantageous on the highway where the load on the engine is high enough for good efficiency and the energy conversions required by series operation become a disadvantage. Parallel capability also means the powertrain does not need to rely on the continuous capability of the generator motor for gradeability. Parallel mode also has much more performance potential with the capability to 
combine the engine, generator, and traction motor torque for tractive effort, as opposed to the series powertrain which can only use the traction motor. Table 1 shows the parameters that will be used to model each architecture. The series-parallel architecture is modeled with slightly more mass to account for the added weight of the transmission, only some of which is offset by the smaller generator.

Table 1: Properties used to model architecture concepts

\begin{tabular}{|l|l|l|}
\hline \multicolumn{3}{|c|}{ Vehicle Glider Properties } \\
\hline Architecture: & Series EREV & Series-Parallel EREV \\
\hline Test Mass: & $2000 \mathrm{~kg}$ & $2050 \mathrm{~kg}$ \\
\hline Drag Coefficient/Frontal Area Product: & $0.76 \mathrm{~m}^{2}$ & $0.76 \mathrm{~m}^{2}$ \\
\hline Coefficient of Rolling Resistance: & 0.01 & 0.01 \\
\hline Tire Radius: & $0.324 \mathrm{~m}$ & $0.324 \mathrm{~m}$ \\
\hline \multicolumn{2}{|c|}{ Powertrain Properties } \\
\hline Traction Motor Peak Power: & $125 \mathrm{~kW}$ & $125 \mathrm{~kW}$ \\
\hline Traction Motor Peak Torque: & $300 \mathrm{Nm}$ & $300 \mathrm{Nm}$ \\
\hline Traction Motor Gear Ratio: & 7.59 & 7.59 \\
\hline Generator Peak Power: & $75 \mathrm{~kW}$ & $27 \mathrm{~kW}$ \\
\hline Generator Continuous Power: & $41 \mathrm{~kW}$ & $20 \mathrm{~kW}$ \\
\hline Accessory Load: & $600 \mathrm{~W}$ & $600 \mathrm{~W}$ \\
\hline
\end{tabular}

\subsection{Energy Storage System Sizing}

The next step in the architecture design process is ESS sizing. This is performed next because the primary purpose of ESS sizing is to meet the AER requirement and both architecture concepts have similar all-electric performance characteristics. The technique used for sizing the ESS involves determining the stored energy needed to complete given drive cycles. This information can then be used to determine the energy needed to meet a required range with a given drive cycle weighting. The first step in this process is to develop an expression for powertrain efficiency so that a map characteristic of the powertrain can be developed. Equation 1 shows the fundamental equation for powertrain efficiency for a charge depleting (CD) hybrid vehicle for a given operating point of torque and speed.

$$
\eta_{P T}=\frac{P_{T r}}{P_{B a t t, i n t}}
$$

The numerator has tractive power out with the denominator being internal battery power required. This can be further expanded to the result given in equation 2 .

$$
\eta_{P T}=\frac{T_{o} \omega_{o}}{\left(P_{R T M, e l e c}\left(T_{R T M}, \omega_{R T M}\right)+P_{a c c y}\right) / \eta_{B a t t}\left(P_{R T M, e l e c}\left(T_{R T M}, \omega_{R T M}\right)+P_{a c c y}\right)}
$$

Equation 2 shows that the tractive power can be calculated as the product of output torque $\left(T_{o}\right)$ and axle speed $\left(\omega_{o}\right)$. The internal battery power required is equal to the RTM electrical power and accessory power divided by the battery discharge efficiency. The RTM electrical power is a function of the torque and speed of the motor. Actual test data for the motor was used for this 
term. The rear transaxle has a gear ratio of 7.59 and is modeled with $3 \mathrm{Nm}$ of spin-loss at the input. This method of formulating the losses is valid for both positive and negative output torque. Equations 3 and 4 therefore show how to calculate $T_{R T M}$ and $\omega_{R T M}$ from $T_{o}$ and $\omega_{o}$.

$$
\begin{gathered}
T_{R T M}=\frac{T_{o}}{7.59}+3 \\
\omega_{R T M}=7.59 \cdot \omega_{0}
\end{gathered}
$$

The battery discharge efficiency is a function of the battery power, which is equal to the sum of motor power and accessory power. The battery discharge efficiency is also a function of internal resistance and open circuit voltage of the battery pack which depend on the size of the pack. An assumption must therefore be made for the model to be run. In this case an internal resistance of $0.08 \Omega$ and open circuit voltage of $350 \mathrm{~V}$ is used. A similar relationship can be made for the regenerative braking case, though the output and input are reversed. This is shown in equation 5.

$$
\eta_{P T}=\frac{\left(P_{R T M, e l e c}\left(T_{R T M}, \omega_{R T M}\right)+P_{a c c y}\right) \cdot \eta_{B a t t}\left(P_{R T M, e l e c}\left(T_{R T M}, \omega_{R T M}\right)+P_{a c c y}\right)}{T_{o} \omega_{o}}
$$

Figure 3 shows an efficiency map generated using the powertrain efficiency equations above. The map includes both propel and regenerative braking and maps the entire forward operating range of the $\mathrm{EV}$ powertrain.

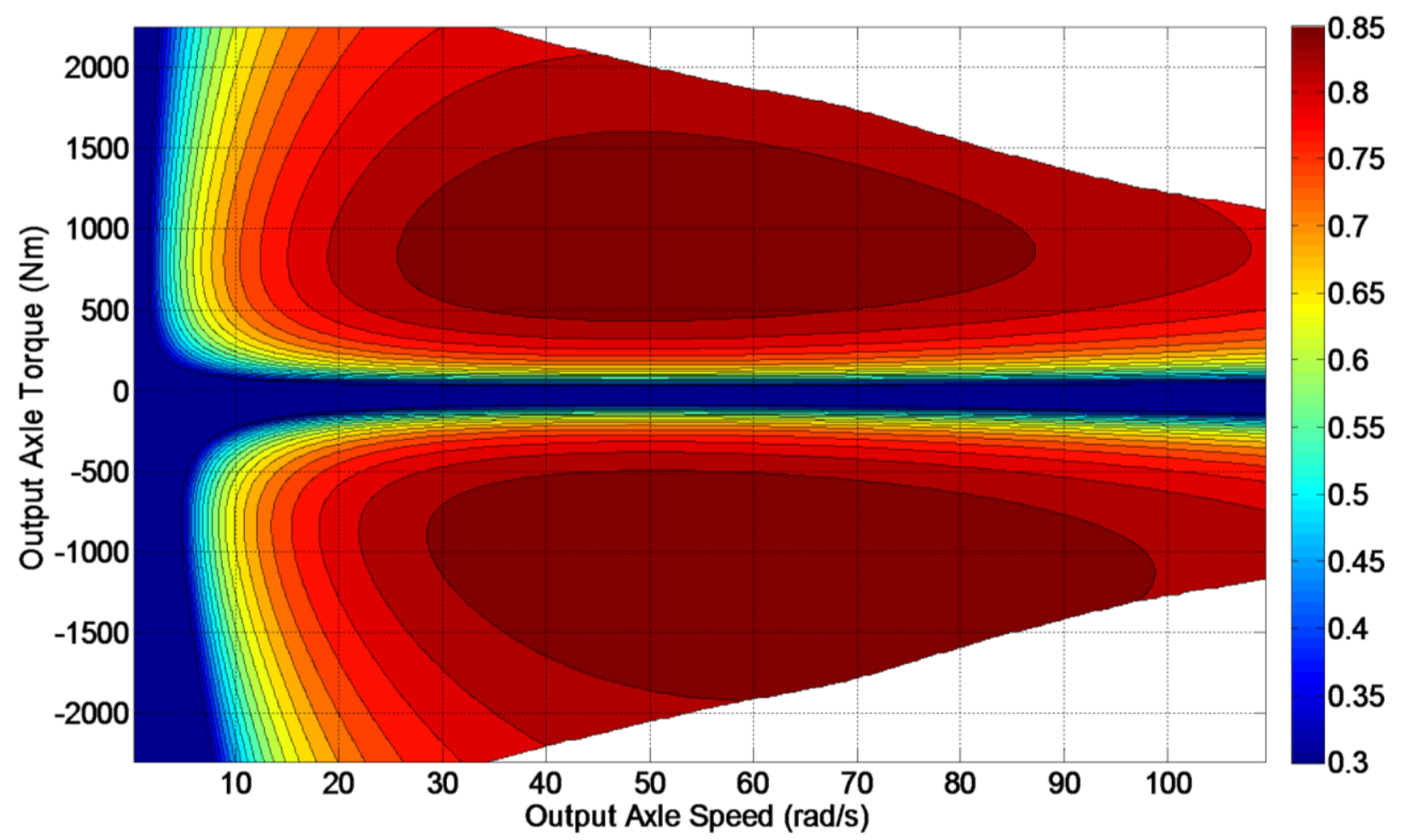

Figure 3: Charge depleting powertrain efficiency map 
The next step is to determine the requirements of a given drive cycle on the powertrain. This is done using the vehicle glider properties to determine for each second of the drive schedule where on the map the operating point falls. Given a drive schedule with a velocity versus time trace, the acceleration at each point necessary to meet the trace can be determined. This acceleration can then be used to calculate the tractive effort needed to meet the drive schedule at each point in time. This is effectively a backward facing modeling technique where given the powertrain output, the input required is calculated. Equation 6 shows how to use the vehicle glider properties to calculate the required tractive effort based on a force balance on the vehicle.

$$
F_{t r}=M_{I} a+M g c_{r r}+\frac{1}{2} \rho C_{d} A V^{2}
$$

In this equation $M_{I}$ is the inertial mass that accounts for rotating driveline components in the momentum of the vehicle and $a$ represents the acceleration from the drive trace. The second term represents the rolling resistance force, where $M$ is the test mass of the vehicle, $g$ is the acceleration due to gravity and $c_{r r}$ is the coefficient of rolling resistance. The final term represents aerodynamic drag where $\rho$ is the density of air, $C_{d}$ is the drag coefficient, $\mathrm{A}$ is the frontal area of the vehicle and $V$ is the vehicle velocity. Equations 7 and 8 show how the required tractive effort and vehicle speed can be related to the output axle torque and speed of the powertrain based on the kinematic relationship using the wheel radius, $r_{w}$.

$$
\begin{gathered}
T_{o}=F_{t r} r_{w} \\
\omega_{o}=\frac{V}{r_{w}}
\end{gathered}
$$

With the drive schedule converted into axle speed and torque points it can then be related to the powertrain efficiency map. Figure 4 shows the EV powertrain efficiency map with the US06 city cycle superimposed. All points of negative tractive effort have been scaled by a regen braking fraction to represent how much braking torque is available for recapture. This is ultimately a function of the powertrain capabilities and control strategy but an approximation of 0.5 is used to simplify the model. This assumption is made because with the traction motor on the rear axle the potential to recover braking energy is lower since most braking is on the front axle. 


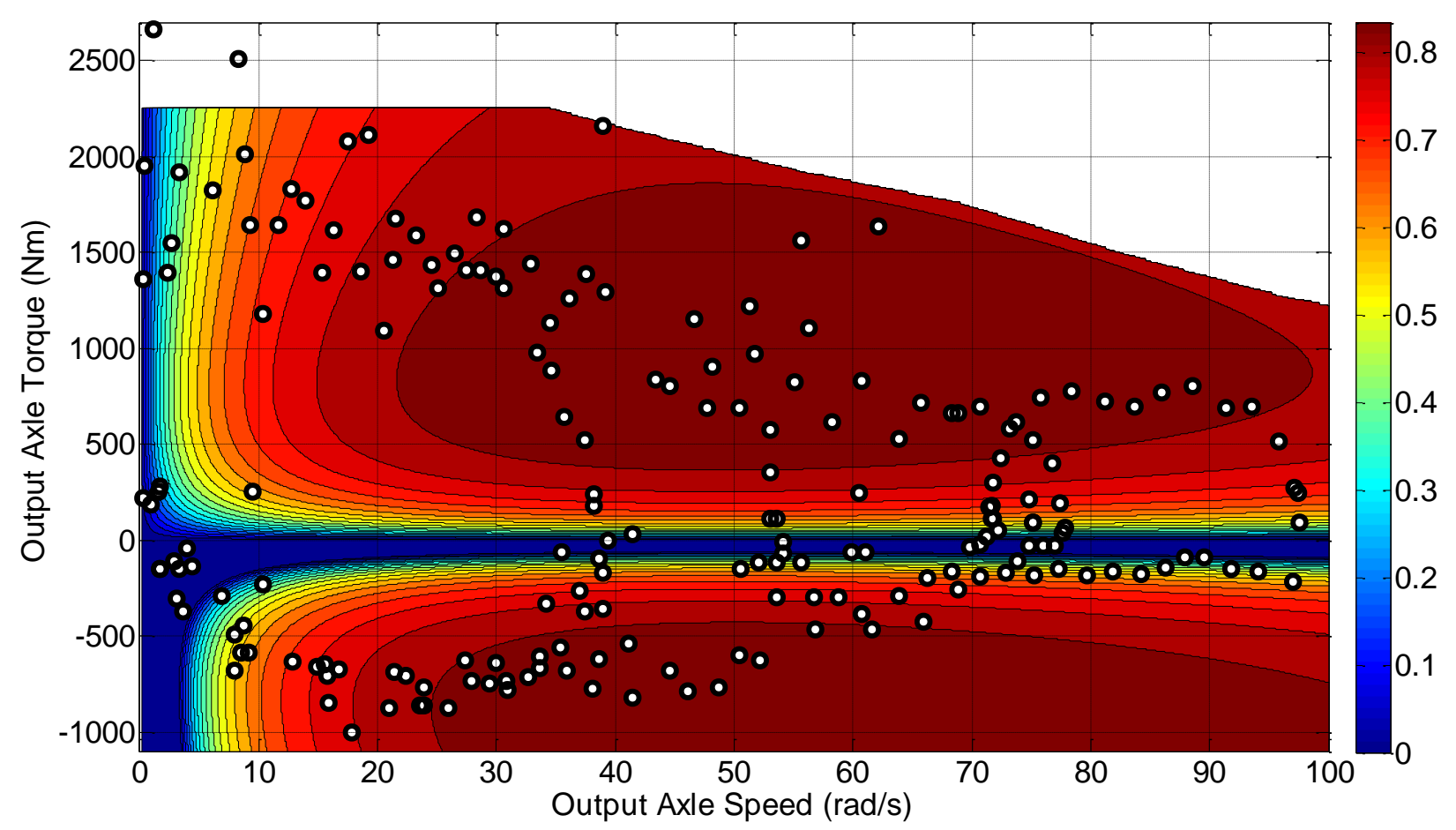

Figure 4: Powertrain efficiency map with US06 city cycle plotted over

Note that two points lie outside the powertrain capability. A drive cycle is still a valid certification run as long as the vehicle stays within $2 \mathrm{mph}$ of the trace. Two points slightly outside the powertrain capability therefore is acceptable. The final step is to use the powertrain efficiency to determine total battery energy used during the cycle. This energy is calculated by integrating the battery power for each operating point over one second.

Table 2: Results for EV powertrain drive cycle simulation

\begin{tabular}{|l|l|l|l|l|c|}
\hline Drive Cycle & 505 & HWFET & US06 City & US06 Hwy & 4-Cycle \\
\hline Energy Consumed (Wh) & 1148.6 & 3141.6 & 852.9 & 2608.0 & - \\
\hline Cycle Distance (mi) & 3.59 & 10.26 & 1.77 & 6.24 & - \\
\hline Energy Consumed (Wh/mi) & 319.8 & 306.3 & 481.3 & 418.2 & 385.1 \\
\hline Energy Req. for 35 mi (kWh) & 11.19 & 10.72 & 16.84 & 14.64 & 13.48 \\
\hline Energy Req. for 40 mi (kWh) & 12.79 & 12.25 & 19.25 & 16.73 & 15.40 \\
\hline
\end{tabular}

The results show that to achieve the desired 35 mile EV range based on 4-Cycle drive cycle weighting a battery pack with $13.48 \mathrm{kWh}$ of usable energy is required. A123 Systems sponsors the EcoCAR 2 competition offering teams a choice from 4 battery pack options each with a different energy capacity and cell configuration. The battery needs to supply the required energy for the EV range within an acceptable depth of discharge (DOD) where performance would still be adequate. Other criteria such as thermal properties are also taken into account. The final selected battery pack is the largest option offered by A123 Systems. With seven modules, each having 15 cells in series and 3 in parallel, it offers a capacity of $18.8 \mathrm{kWh}$ with $15.1 \mathrm{kWh}$ usable at the chosen $80 \%$ DOD. With this pack an EV range of nearly 40 miles should be possible. The characteristics of this battery pack will be used for all further modeling purposes. 


\subsection{Architecture Layout Selection}

With the two concepts presented and the ESS sized, a method for evaluating the potential efficiency of each architecture is needed. Both concepts use the same powertrain for charge depleting operation. They differ only in charge sustaining capabilities. The goal for selection is therefore to choose the architecture with the potential for better charge sustaining fuel economy. A traditional technique for determining which architecture can achieve superior fuel economy would be to run drive cycle simulations. The disadvantage of this technique however is a control strategy must be developed in order to run the simulation. A poor or non-optimized control strategy might misrepresent the potential an architecture has, especially when comparing two schematically different architectures. The comparison method still needs to take drive cycle into account, as fuel economy is sensitive to driving schedule. A novel method has been created for performing this analysis. The technique used earlier for ESS sizing is actually a simplified version of this technique. The full method will be presented here.

The first step in the process, just as with the steps taken for battery sizing, is to establish an expression for the powertrain efficiency. Equation 9 shows the fundamental powertrain efficiency equation for a charge sustaining vehicle.

$$
\eta_{P T}=\frac{T_{o} \omega_{o}}{P_{\text {eng,fuel }}\left(T_{e}, \omega_{e}\right)}
$$

In this case, while the numerator is still tractive power, the denominator is now fuel power since in charge sustaining operation fuel is the only energy source with ultimately a zero net change in stored battery energy (in an ideal case). The fuel power is a function of the torque and speed the engine is operating at for the operating point. This equation only works however for an operating point that has zero current going in or out of the battery. As a hybrid vehicle, the capability to utilize energy storage to improve efficiency is important. The powertrain efficiency equation therefore needs to take charge and discharge of the battery into account. This can be done by relating stored battery energy to fuel energy. Charging the battery is saving fuel in the future while discharging the battery is using fuel burned in the past. Equation 10 represents the powertrain efficiency of an operating point that involves discharging the battery.

$$
\eta_{P T}=\frac{T_{o} \omega_{o}}{P_{\text {eng,fuel }}\left(T_{e}, \omega_{e}\right)+\frac{P_{\text {Batt }, \text { out }}}{\eta_{\text {Batt }}\left(P_{\text {Batt }, \text { out }}\right) \cdot \widetilde{\eta}_{\text {Batt }, \text { Chg }} \cdot \widetilde{\eta}_{\text {Gen }}}}
$$

The output power of the battery is divided by the discharge efficiency of the battery which is a function of that battery power. This gives the power being dissipated from the internal energy of the pack. This is also divided by the drive cycle average battery charging efficiency to determine how much power was put into the terminals to get the required stored energy. A drive cycle average is used for this value because the energy was stored sometime in the past at varying efficiency. Finally a drive cycle average marginal generating efficiency is used to calculate how much fuel was burned to put that energy into the battery. This generating efficiency represents any path of engine power to the battery, whether it is a generator directly coupled to the engine or a parallel through-the-road path. The concept of marginal efficiency is very important. A given operating point might use some fuel propel the vehicle while charging the battery at the 
same time. Marginal efficiency represents the efficiency of only the additional fuel that went to charging the battery.

The following is an example of calculating the marginal efficiency. For a given operating point, $20 \mathrm{~kW}$ of output is required of the engine. It can do so at $25 \%$ efficiency. Alternatively the engine can output $30 \mathrm{~kW}$ at $29 \%$ efficiency with $10 \mathrm{~kW}$ to be stored in the battery. An electric machine can convert this extra power to electricity at $90 \%$ efficiency. This means the engine will burn about $23.4 \mathrm{~kW}$ of extra fuel to put $9 \mathrm{~kW}$ into the battery. In this case the marginal efficiency of the extra energy put into the battery is $38.4 \%$. To find a drive cycle average, all positive battery power can be integrated and divided by the total extra fuel burned.

The drive cycle average values pose a problem in evaluation. These average efficiencies are dependent on what operating points are chosen during the drive cycle. Changing the efficiency values will in turn change what points are selected. A solution must therefore be found iteratively. This will be done later when drive cycles are evaluated.

Equation 11 shows the powertrain efficiency equation for charging the battery.

$$
\eta_{P T}=\frac{T_{o} \omega_{o}}{P_{\text {eng,fuel }}\left(T_{e}, \omega_{e}\right)+\frac{P_{\text {Batt }, o u t} \cdot \eta_{\text {Batt }}\left(P_{\text {Batt }, o u t}\right) \cdot \widetilde{\eta}_{\text {Batt }, \text { Dis }}}{\widetilde{\eta}_{\text {Gen }}}}
$$

In this case the energy charged into the battery represents fuel saved in the future. The battery power, $P_{\text {Batt,out }}$, is a negative value and is multiplied by the charging efficiency at the current power level and by the drive cycle average discharging efficiency to find how much power will later be available on the high voltage bus. This is then divided by the marginal drive cycle average generating efficiency to find, on average, how much fuel power it would have taken to get that same power to the high voltage bus. In this way electrical power is equated to the fuel it saved. Both equations 10 and 11 are generic to any hybrid electric vehicle powertrain with electrical energy storage and a fuel converter. The calculation of $P_{\text {Batt,out }}$ is the part that is unique to a specific powertrain. Equation 12 shows how to calculate the battery power for both powertrain concepts being considered.

$$
P_{\text {Batt }, \text { out }}=P_{\text {RTM,elec }}+P_{\text {Gen,elec }}+P_{\text {accy }}
$$

For the series-parallel powertrain $\mathrm{P}_{\mathrm{Gen}}$ would be replaced by $P_{P 2 M}$. For both powertrains, a given desired output torque and speed operating point has many combinations of RTM torque, generator torque, and engine torque that could achieve the desired torque. The next step in the evaluation process is to establish the possible modes of operation and operating degrees of freedom (DOF) that can be used and optimize the efficiency of each point to generate an efficiency map. This step was omitted during battery sizing because for both powertrain options there were zero DOF in charge depleting operation. There was only one way to achieve a desired torque at a given speed. A vehicle with multiple electric machines available for propulsion during charge depleting operation would need to take this step.

For the series powertrain there is only one mode of operation and the torque and speed of the RTM are set by the output torque and speed. For the engine generator system, or genset, the 
speed of the engine and generator are linked. If the assumption is made that for a given point the genset is operating at steady state, the torque of the engine and generator are equal and opposite. This leaves two degrees of freedom, the torque and speed of the genset. A 2D map can be made over the torque and speed domains that indicates for every point the fuel input and DC power output. This takes both engine and generator losses into account. This can be simplified by observing that there are many torque and speed combinations that work out to the same DC output power level, but only one of those points gives the lowest fuel consumption for a given power level. The system can therefore be reduced to one DOF in genset power [14].

For each possible operating point the powertrain efficiency can be calculated for each level of genset power to determine the best power level to operate the genset for that powertrain operating point. With the best genset level and corresponding powertrain efficiency calculated an efficiency map for the powertrain Figure 5 shows the map generated for the series hybrid powertrain.

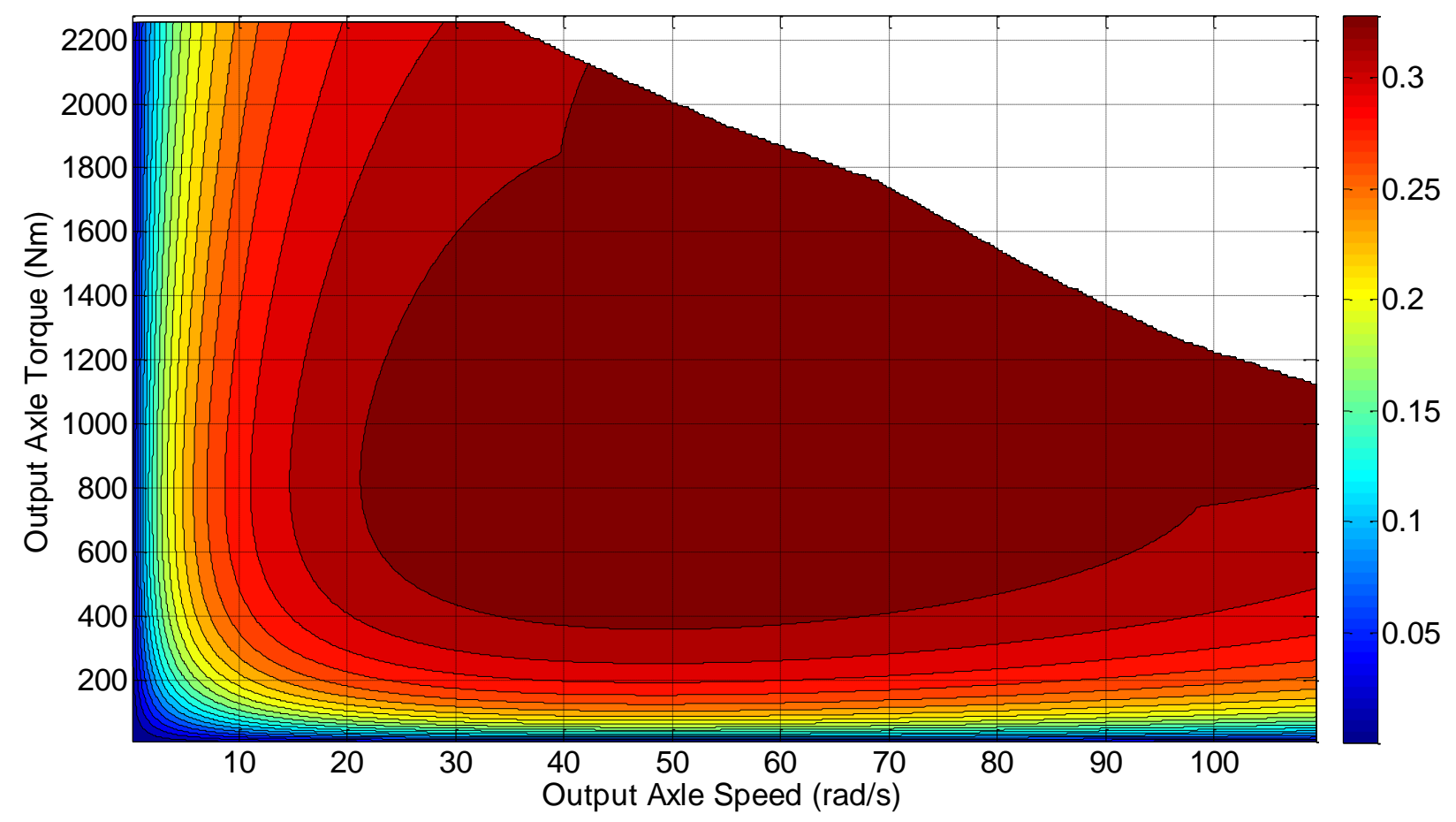

Figure 5: Powertrain efficiency map for series powertrain

The data shows that generally higher speed and higher output torque leads to higher powertrain efficiency. The peak efficiency for the series powertrain is $34.44 \%$, observed at output speed $49.5 \mathrm{rad} / \mathrm{s}$ and with output torque of $842.5 \mathrm{Nm}$. A kink in the efficiency contour is observed near $1800 \mathrm{Nm}$ at about $40 \mathrm{rad} / \mathrm{s}$ and likewise at $100 \mathrm{rad} / \mathrm{s}$ near $800 \mathrm{Nm}$. This is a ripple along the constant power line where the power required for the traction motor exceeds the output capability of the genset and therefore necessarily discharges energy from the battery pack.

The series-parallel powertrain has two modes of operation and a few more DOF. For this powertrain, all modes of operation and all possible points in each mode must be considered to optimize every powertrain operating point. The series mode can be optimized just like the series 
only powertrain. It must then be compared to the parallel powertrain for each point. The parallel powertrain mode has 3 effective DOF which can be expressed a number of different ways. The first DOF is the transmission gear ratio which sets the speed of the engine and P2M. The other two DOF are power split between the engine and battery, and electrical power split between the RTM and P2M. Since all the engine and motors are commanded in torque however a more direct way to express the DOF is gear ratio, engine torque and $\mathrm{P} 2 \mathrm{M}$ torque. With these values set the RTM torque is fixed by the output torque requirement. To generate a map, all possible modes were considered, varying all degrees of freedom to test the entire range for each operating point. Figure 6 shows a map of which operating mode and gear was selected as best over the operating range of the powertrain.

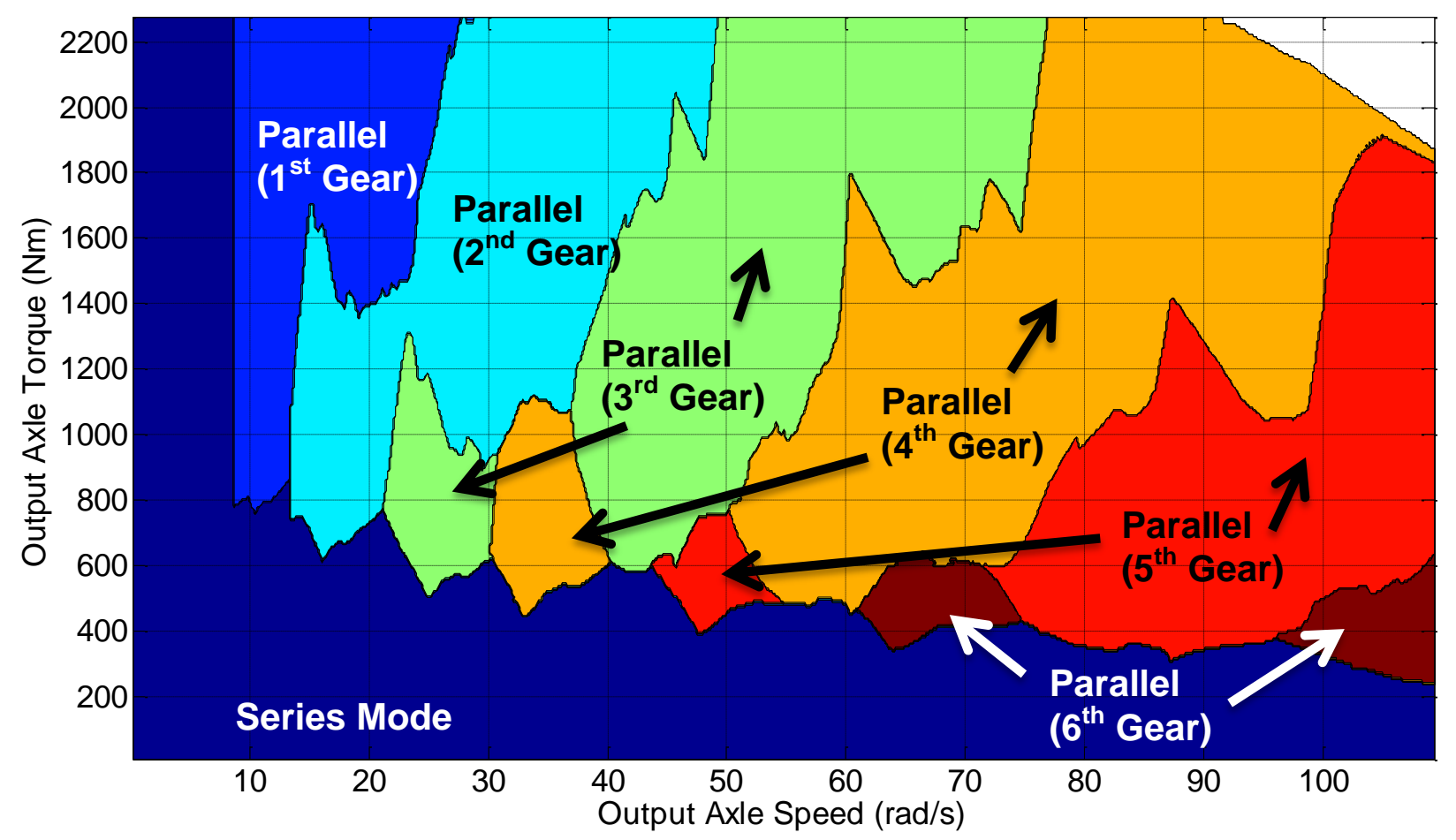

Figure 6: Series-parallel powertrain mode selection map

Note the regions in Figure 6 do not represent a shift map tuned for drivability. The modes selected were based only on what gave the highest potential fuel economy for the given operating point. Series mode was always favored for low output torque because at these points the strategy chose to shut off the engine and discharge the battery. Series mode is also chosen exclusively at low speed since the lack of a torque converter means parallel mode is not possible at lower speed. $1^{\text {st }}$ gear is first utilized from axle speed of $8.69 \mathrm{rad} / \mathrm{s}$, about $6 \mathrm{mph}$. For mid-range output torque $2^{\text {nd }}, 3^{\text {rd }}$, and $4^{\text {th }}$ gears are all shifted into as soon as the axle speed is fast enough. Near $40 \mathrm{rad} / \mathrm{s}$ however, $3^{\text {rd }}$ gear becomes favorable over $4^{\text {th }}$ creating a peculiar "island" where 4 th gear is selected between two regions of $3^{\text {rd }}$ gear. Similar islands of $5^{\text {th }}$ and $6^{\text {th }}$ gear also exist for mid-range output torque. A similar effect is also observed at high torque, though isolated islands are not created. If a line of increasing speed for constant torque of $1600 \mathrm{Nm}$ were followed, for instance, a shift from $3^{\text {rd }}$ to $4^{\text {th }}$ gear would be followed by a downshift back to $3^{\text {rd }}$ before 
returning to $4^{\text {th }}$ gear. This behavior can be explained by observing the engine operation points shown in Figure 7.

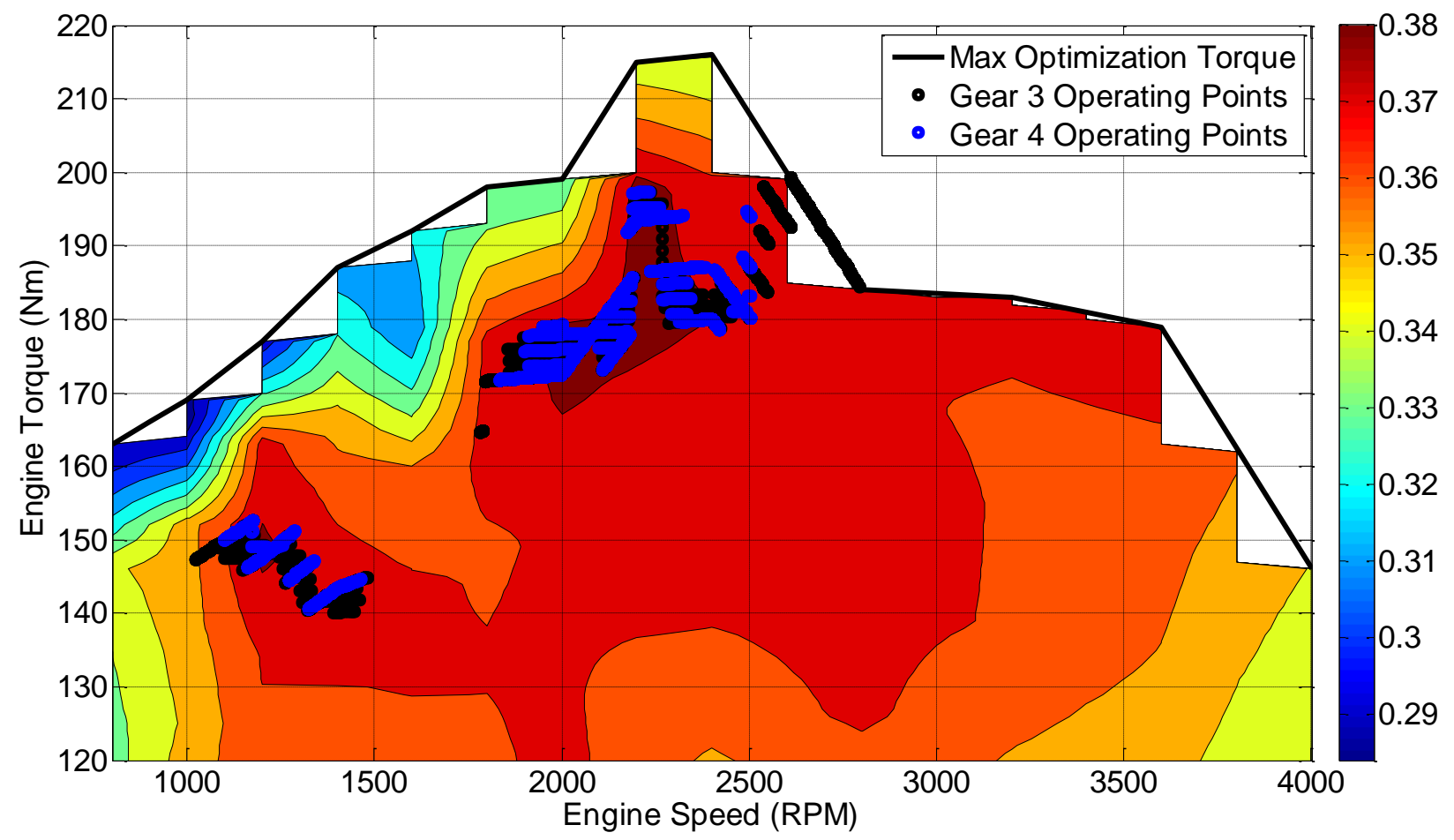

Figure 7: Engine efficiency map and operating points

The plot shows operating points chosen during the mapping superimposed on the engine efficiency map. The efficiency map comes from Test 18 efficiency data. The black line is not the maximum torque the engine is capable of, but it is the region the optimization routine is limited to due to the limited efficiency data. The data covers the region where the engine should be operated for best efficiency so this limitation is acceptable. The data shows that there are two islands of best efficiency, one around 1200 RPM and the other centered around 2100 RPM.

The points show where the optimization chose to operate the engine for the mid-range output torque region of the mapping for the times $3^{\text {rd }}$ or $4^{\text {th }}$ gear were chosen. The gear islands are caused by the optimization attempting to keep the engine in high efficiency zones. The island of $4^{\text {th }}$ gear between $30 \mathrm{rad} / \mathrm{s}$ and $40 \mathrm{rad} / \mathrm{s}$, for instance, is to avoid operating the engine at the lower efficiency region between 1500 RPM and 1800 RPM.

Regions where battery charging and discharging were chosen can be seen in Figure 8. 


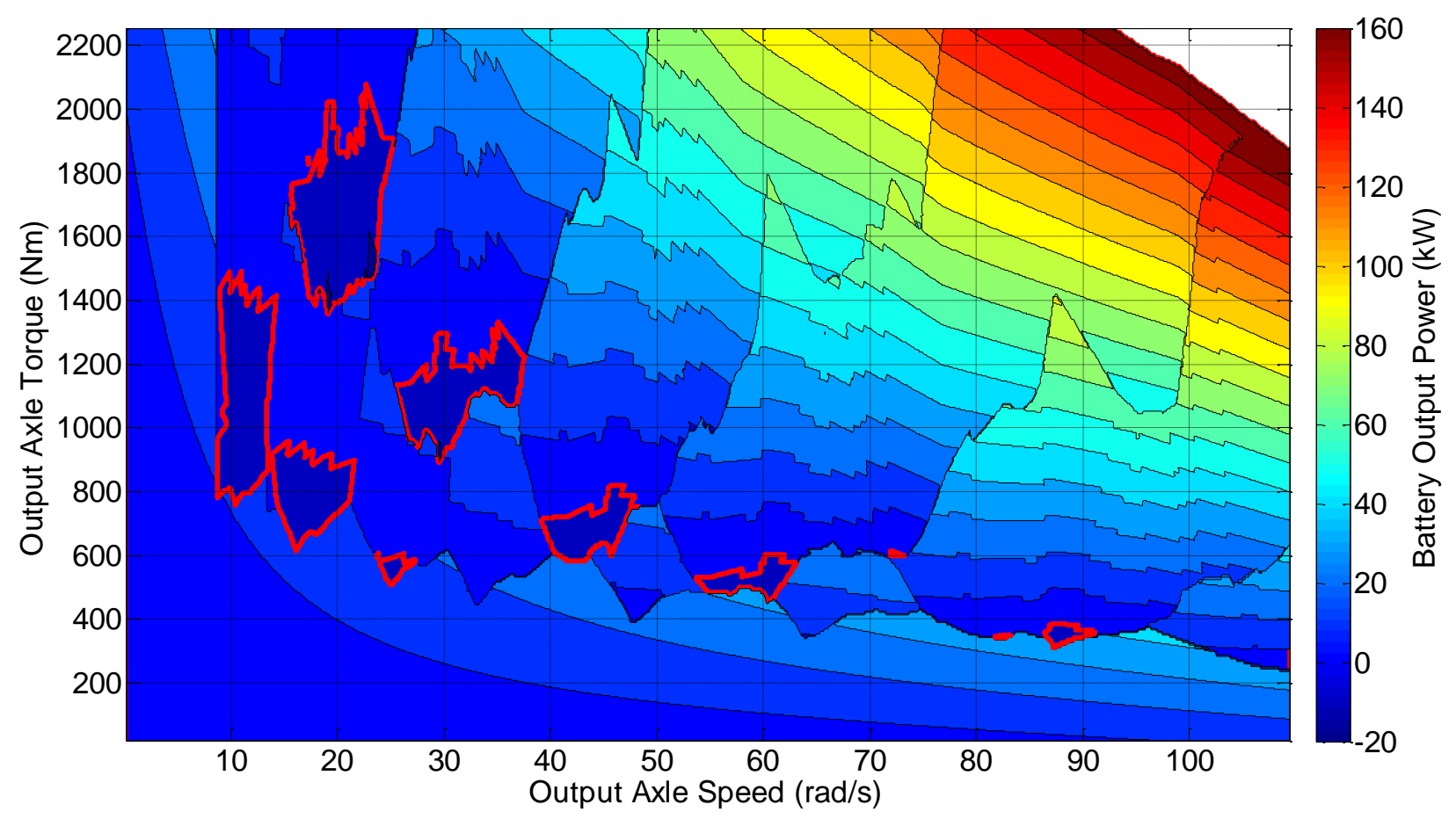

Figure 8: Series-parallel powertrain battery operating points

The contours in Figure 8 loosely match the gear selection contours. The regions where the battery is charged are highlighted in red. At the low torque end of each gear region, battery charging is selected. As torque goes up more discharging is chosen. Figure 9 shows the corresponding efficiency map for the points selected in Figure 8.

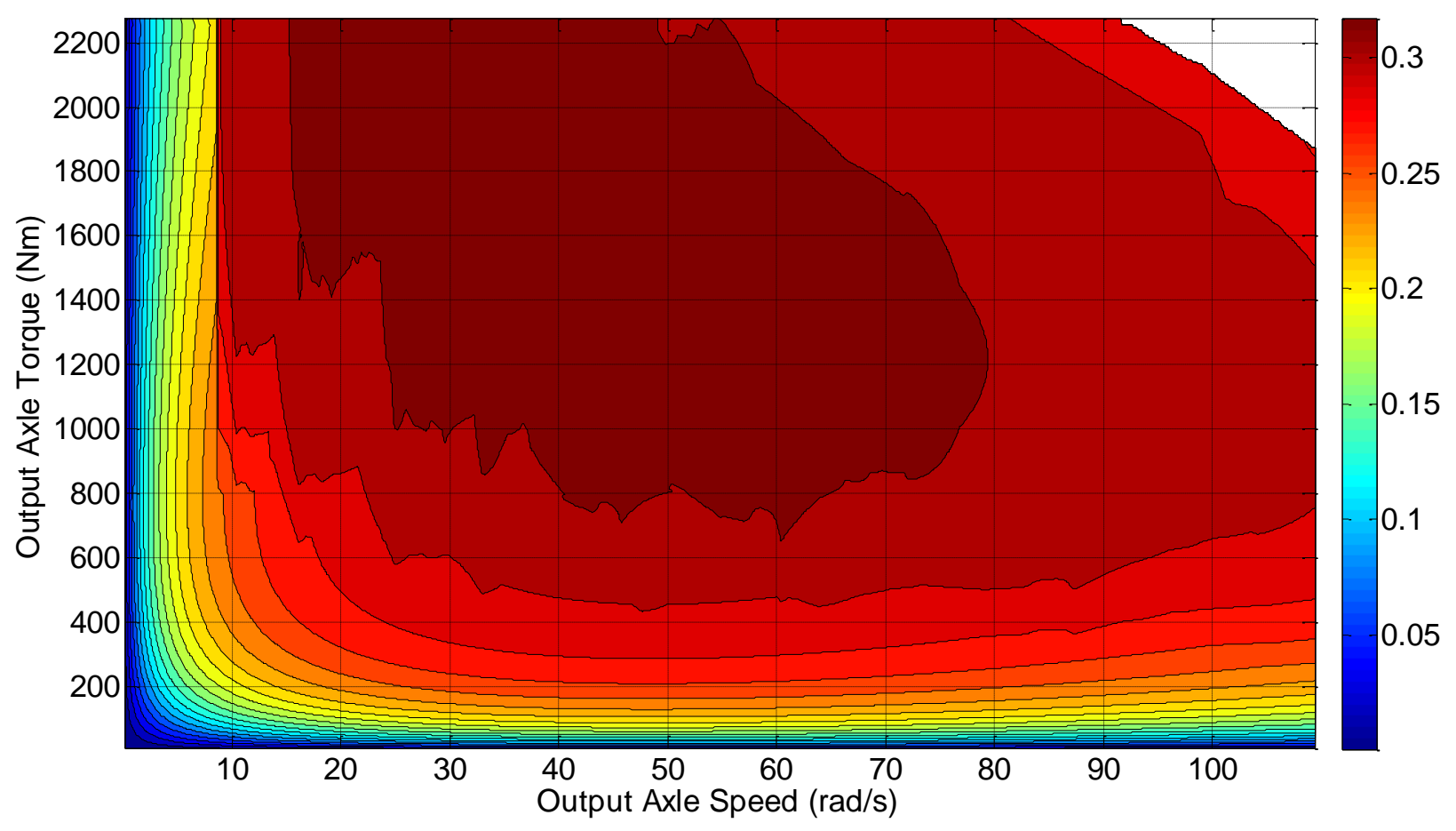

Figure 9: Series-parallel powertrain efficiency map 
With this complete the efficiency maps of the two powertrains can be compared to each other to identify regions where one powertrain is superior to the other. Figure 10 shows the comparison between the two maps by subtracting the series powertrain efficiency from the series-parallel powertrain efficiency map.

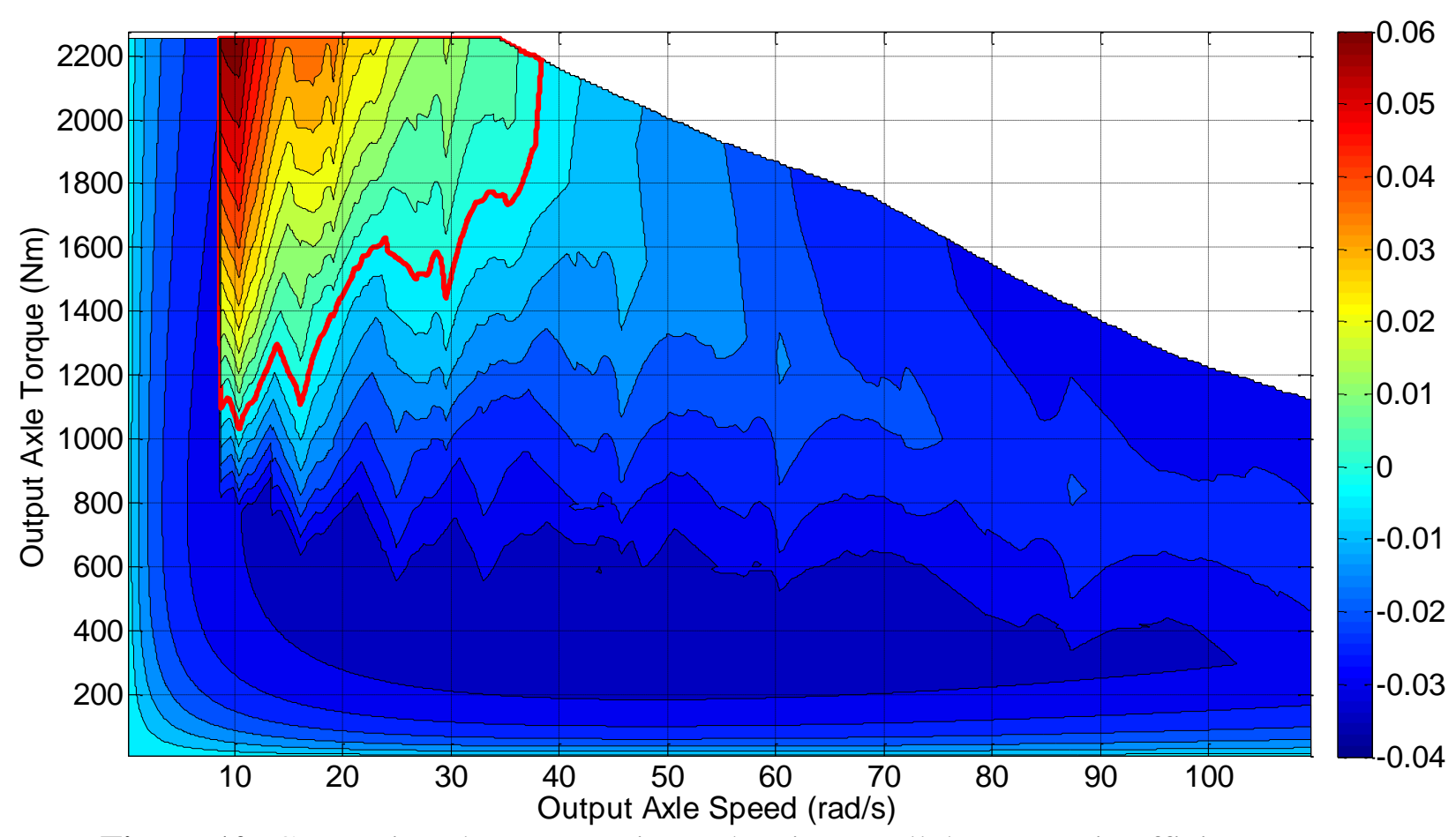

Figure 10: Comparison between series and series-parallel powertrain efficiency maps

Positive values indicate where the series-parallel powertrain is more efficient while negative values mean the series powertrain is more efficient. The red contour indicates the zero-boundary where the efficiencies are equal. Figure 10 shows that while the series powertrain has a wider range of higher efficiency, it only beats the parallel powertrain by a small margin. The seriesparallel powertrain on the other hand beats the series powertrain by a wide margin in the lower speed high torque areas. The results of this comparison will vary slightly depending on what numbers are used for the drive cycle average efficiency parameters. In this case a 4-cycle average is used for the numbers obtained using the drive cycle method described next.

Just as with battery sizing, the two powertrain options can also be compared with drive cycles to show how different driving situations will affect them. As mentioned earlier, the drive cycle average efficiencies can also now be calculated. For every operating point, battery charging or discharging power at the terminals and internal is integrated to find the efficiency. For points where energy is going into the battery and the engine output is more than what is needed to meet the output torque, the extra engine fuel is integrated for calculation. Extra engine fuel can be determined by first finding how much fuel it would take to only meet the given operating point with zero battery energy in the most efficient mode to do so. Equations 13, 14, and 15 show calculation of drive cycle average charging efficiency, discharging efficiency, and genset efficiency respectively. 


$$
\begin{gathered}
\tilde{\eta}_{\text {Batt,Chg }}=\frac{E_{\text {Batt,int }}^{-}}{E_{\text {Batt,out }}^{-}} \\
\tilde{\eta}_{\text {Batt,Dis }}=\frac{E_{\text {Batt,out }}^{+}}{E_{\text {Bat }, \text { int }}^{+}} \\
\tilde{\eta}_{\text {Gen }}=\frac{-E_{\text {Batt }, \text { out }}^{-}}{E_{\text {fuel,extra }}}
\end{gathered}
$$

Note that the calculation for genset efficiency in equation 15 uses the sum of all energy charged into the battery, which includes energy from regenerative braking. This properly accounts the value of stored battery energy against fuel and regenerative braking. Energy from regenerative braking is "free" energy that would have otherwise been lost. It therefore increases the marginal genset efficiency. Table 3 shows a summary of the results for drive cycle simulations

Table 3: Comparison of powertrains using drive cycle simulation

\begin{tabular}{|l|l|l|l|l|l|}
\hline \multicolumn{7}{|c|}{ Series-Parallel Powertrain } \\
\hline Drive Cycle & 505 & HWFET & US06 City & US06 Hwy & 4-Cycle \\
\hline Fuel Energy Consumed (Wh/mi) & 808.3 & 730.8 & 1100.4 & 1004.4 & 928.1 \\
\hline Fuel Economy (MPGge) & 41.8 & 46.3 & 30.7 & 33.7 & 36.4 \\
\hline $\begin{array}{l}\text { Drive Cycle Average Battery } \\
\text { Charge Efficiency }\end{array}$ & $98.4 \%$ & $98.1 \%$ & $98.6 \%$ & $98.1 \%$ & $98.2 \%$ \\
\hline $\begin{array}{l}\text { Drive Cycle Average Battery } \\
\text { Discharge Efficiency }\end{array}$ & $99.8 \%$ & $99.9 \%$ & $98.3 \%$ & $98.2 \%$ & $98.9 \%$ \\
\hline $\begin{array}{l}\text { Drive Cycle Average Genset } \\
\text { Efficiency }\end{array}$ & $31.5 \%$ & $30.3 \%$ & $31.7 \%$ & $27.4 \%$ & $30.0 \%$ \\
\hline \multicolumn{7}{|c|}{ Series Powertrain } \\
\hline Drive Cycle & 505 & HWFET & US06 City & US06 Hwy & $4-$ Cycle \\
\hline Fuel Energy Consumed (Wh/mi) & 771.6 & 778.7 & 1067.5 & 1078.2 & 951.8 \\
\hline Fuel Economy (MPGe) & 43.8 & 43.4 & 31.7 & 31.4 & 35.5 \\
\hline $\begin{array}{l}\text { Drive Cycle Average Battery } \\
\text { Charge Efficiency }\end{array}$ & $96.8 \%$ & $96.9 \%$ & $97 . .2 \%$ & $97.6 \%$ & $97.2 \%$ \\
\hline $\begin{array}{l}\text { Drive Cycle Average Battery } \\
\text { Discharge Efficiency }\end{array}$ & $99.9 \%$ & $99.9 \%$ & $98.3 \%$ & $98.5 \%$ & $99.1 \%$ \\
\hline $\begin{array}{l}\text { Drive Cycle Average Genset } \\
\text { Efficiency }\end{array}$ & $39.4 \%$ & $38.2 \%$ & $46.5 \%$ & $40.0 \%$ & $40.5 \%$ \\
\hline
\end{tabular}

The results show that the series powertrain did better on both city cycles while the series-parallel powertrain was superior on the highway cycles. The series powertrain also generally achieved higher average genset efficiency, meaning the fuel to DC electrical power path was more efficient. The results show that with a 4 cycle weighting the series-parallel powertrain offers better potential fuel economy. Based on these results as well as all the other advantages offered, the series-parallel powertrain will be used for further vehicle development. 
It is important to note that what has been developed here is not a control strategy that can be used to operate a vehicle. The powertrain points selected may or may not have kept battery SOC within appropriate limits and/or resulted in a charge balanced cycle. The points also may not have resulted in good drivability along with other concerns. The results do not necessarily represent what the architecture should actually achieve if built. The results only represent the potential the architecture has with a good control strategy. The real world fuel economy will likely be lower due to other considerations the control strategy must make apart from fuel economy. The goal of this step is to determine which architecture to proceed through development with, including developing a full control strategy and predicting fuel economy with a dynamic vehicle model. 


\section{CONTROL SYSTEM ARCHITECTURE DEVELOPMENT}

\subsection{Expansion of Base Vehicle Control System}

With the vehicle architecture defined the next important task is to develop the control architecture. With all of the complex subsystems on a vehicle, a distributed control system is the most effective design. This allows the reuse of components and their accompanying ECUs in various vehicles without having to validate the controller base functionality for each vehicle application (though system level validation is still necessary). Using a different engine and transmission in a vehicle for instance does not require re-validation of chassis control systems such as the antilock braking system (ABS) and stability control systems. Only system level validation such as the interaction between the engine and the stability control system during a stability control intervention will need to be done. Another advantage of a distributed control system is that ECUs can be placed near the sensors and actuators that they are responsible for. If the control system consisted of a single ECU extensive wiring would need to be run to reach sensors and actuators. A distributed control system cuts down on wiring and the reliability issues associated with it.

The main weakness of a distributed control system is the reliance on communication networks in the vehicle. If the network is reliable and robust the system will perform as designed. Failure of the communication network however could cripple system functionality. Each ECU must therefore be designed to continue operating despite failure of communication with other ECUs when possible. If the communication failure results in loss of critical signals the ECU must fail gracefully and maintain the safety of the system. For a conventional vehicle, most systems can continue to operate despite loss of communication with others. The transmission can continue to operate for instance without signals from the engine, though shifts will likely be rougher and the shift pattern will have to rely on vehicle speed alone without knowledge of the accelerator pedal position. For a hybrid vehicle however communication can be much more critical.

While a conventional vehicle has no main ECU that serves as a supervisor giving commands to other ECUs, a hybrid vehicle requires this type of controller to facilitate the joint operation of the various powertrain components. This hybrid vehicle supervisory controller (HVSC) is responsible for interpreting driver demand, responding to component level fault conditions reported by other ECUs, detecting system level fault conditions, determining mode of operation, and commanding powertrain components. Loss of communication with a powertrain component means the HVSC no longer has information on the component and cannot verify that it is operating as intended. The HVSC therefore can no longer rely on that component and must shut it down.

As HEVT will be using a 2013 Chevy Malibu as a base vehicle some components and control modules will be kept while new ones will be added. Table 4 shows a summary of the important powertrain and chassis control units that will be used in the vehicle. 
Table 4: Summary of control units for vehicle

\begin{tabular}{|c|c|c|c|}
\hline \multicolumn{4}{|c|}{ Existing Control Units } \\
\hline Component & $\mathbf{E C U}$ & Supplier & Primary Roles \\
\hline $\begin{array}{l}\text { 6-Speed } \\
\text { Automatic } \\
\text { Transmission }\end{array}$ & $\begin{array}{l}\text { Transmission } \\
\text { Control Module } \\
\text { (TCM) }\end{array}$ & $\begin{array}{l}\text { General } \\
\text { Motors }\end{array}$ & $\begin{array}{l}\text { - Receive gear command from HVSC } \\
\text { - Operate transmission clutches to achieve } \\
\text { desired gear }\end{array}$ \\
\hline Vehicle Chassis & $\begin{array}{l}\text { Integrated Body } \\
\text { Control Module } \\
\text { (IBCM) }\end{array}$ & $\begin{array}{l}\text { General } \\
\text { Motors }\end{array}$ & $\begin{array}{l}\text { - Report key position } \\
\text { - Operate chassis systems (lights, horn, ect.) }\end{array}$ \\
\hline Brake System & $\begin{array}{l}\text { Electronic } \\
\text { Brake Control } \\
\text { Module } \\
(\mathrm{EBCM})\end{array}$ & $\begin{array}{l}\text { General } \\
\text { Motors }\end{array}$ & $\begin{array}{l}\text { - Report drive applied brake pedal pressure } \\
\text { to HVSC } \\
\text { - Operate ABS } \\
\text { - Report ABS state to HVSC }\end{array}$ \\
\hline \multicolumn{4}{|c|}{ New Control Units } \\
\hline Component & ECU & Supplier & Primary Roles \\
\hline $\begin{array}{l}\text { 2.4 L Flex Fuel } \\
\text { Engine }\end{array}$ & $\begin{array}{l}\text { Engine Control } \\
\text { Module (ECM) }\end{array}$ & $\begin{array}{l}\text { General } \\
\text { Motors }\end{array}$ & $\begin{array}{l}\text { - Receive torque command from HVSC } \\
\text { - Operate engine fuel delivery, ignition, and } \\
\text { emissions control } \\
\text { - Report engine speed and achieved torque } \\
\text { to HVSC }\end{array}$ \\
\hline $\begin{array}{l}125 \mathrm{~kW} \text { Rear } \\
\text { Traction Motor }\end{array}$ & $\begin{array}{l}\text { Traction Motor } \\
\text { Inverter Module } \\
\text { (TMIM) }\end{array}$ & UQM & $\begin{array}{l}\text { - Receive torque command from HVSC } \\
\text { - Control motor 3-phase current } \\
\text { - Report motor speed and achieved torque to } \\
\text { HVSC }\end{array}$ \\
\hline $\begin{array}{l}30 \mathrm{~kW} \mathrm{P2} \\
\text { Generator } \\
\text { Motor }\end{array}$ & $\begin{array}{l}\text { Generator } \\
\text { Motor Inverter } \\
\text { Module } \\
\text { (GMIM) }\end{array}$ & Kollmorgen & $\begin{array}{l}\text { - Receive torque command from HVSC } \\
\text { - Control motor 3-phase current } \\
\text { - Report motor speed and achieved torque to } \\
\text { HVSC }\end{array}$ \\
\hline $\begin{array}{l}18.9 \mathrm{kWh} \\
\text { Energy Storage } \\
\text { System }\end{array}$ & $\begin{array}{l}\text { Battery Control } \\
\text { Module (BCM) }\end{array}$ & $\begin{array}{l}\text { A123 } \\
\text { Systems }\end{array}$ & $\begin{array}{l}\text { - Receive contactor command from HVSC } \\
\text { - Operate battery contactors } \\
\text { - Report current limits to HVSC }\end{array}$ \\
\hline
\end{tabular}

Appendix A contains a more complete version of this table.

\subsection{Controller Interaction}

With the control units needed for the control system established, the interaction between these controllers, the driver, and the powertrain must be analyzed. Important data flows should be determined so that an effective communication network can be developed. This can be done effectively be creating a controller interaction diagram. Figure 11 shows a partial controller interaction diagram for the HVSC, ECM, engine, and driver. 


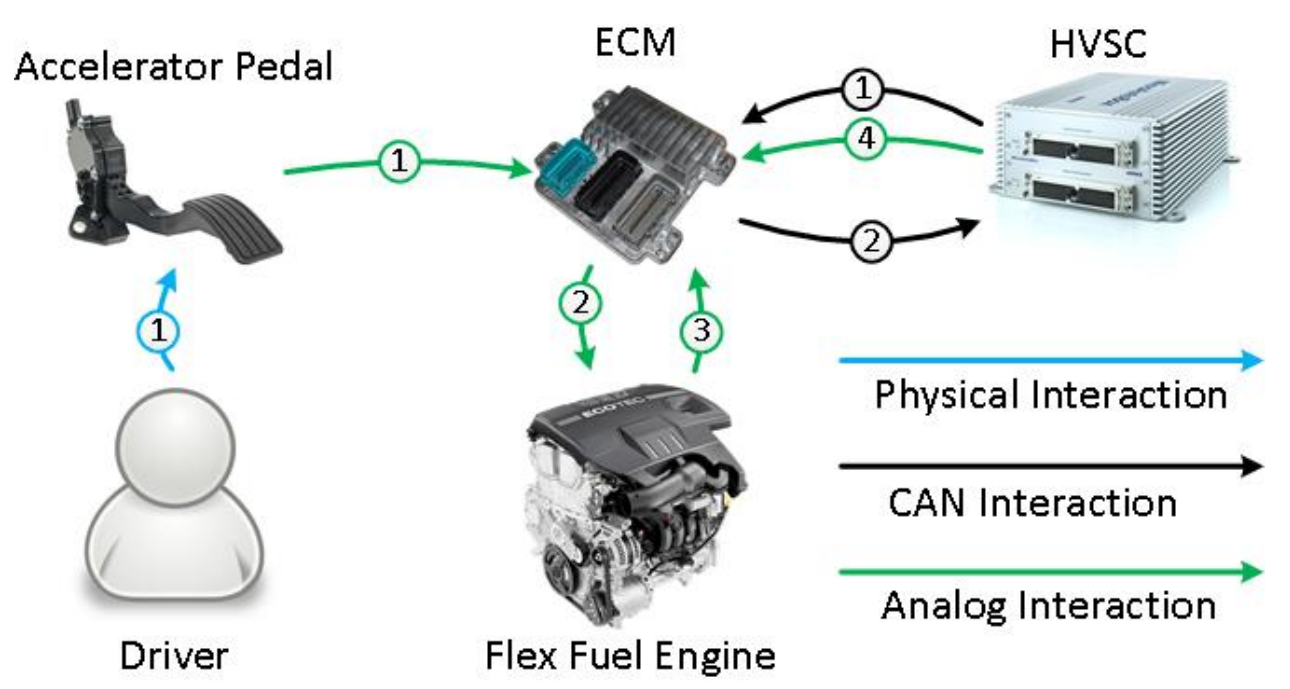

Figure 11: Controller interaction between HVSC, ECM, engine, and driver

Different colored arrows represent different types of interaction. Physical interaction (1) represents the driver pushing on the accelerator pedal. Analog interaction (1) passes this signal to the ECM. Analog interaction (2) represents all the actuators such as ignition and injectors the ECM controls on the engine. Analog interaction (3) contains all the sensor signals that the ECM reads from the engine such as cam angle sensors, oxygen sensors, intake airflow sensors, ect. Analog interaction (4) contains the analog signals the HVSC uses to control the $12 \mathrm{v}$ starter and to shut the engine off. CAN interaction (1) contains command signals the HVSC uses to control engine torque while CAN interaction (2) contains feedback signals such as engine speed and achieved engine torque. Appendix B contains a complete controller interaction diagram for all important powertrain and chassis control systems. Building a complete interaction diagram with all components, ECUs and signals proves useful for identifying critical information flow paths and will be used a later points in development.

\subsection{Vehicle CAN Bus Design}

The controller interaction diagram can be used to effectively design vehicle CAN buses to facilitate effective data flow. Control modules with high priority data should be on the same CAN bus. Safety critical signals may warrant redundant CAN signals to verify data transfer. Figure 12 shows the design that has been developed for the vehicle. 


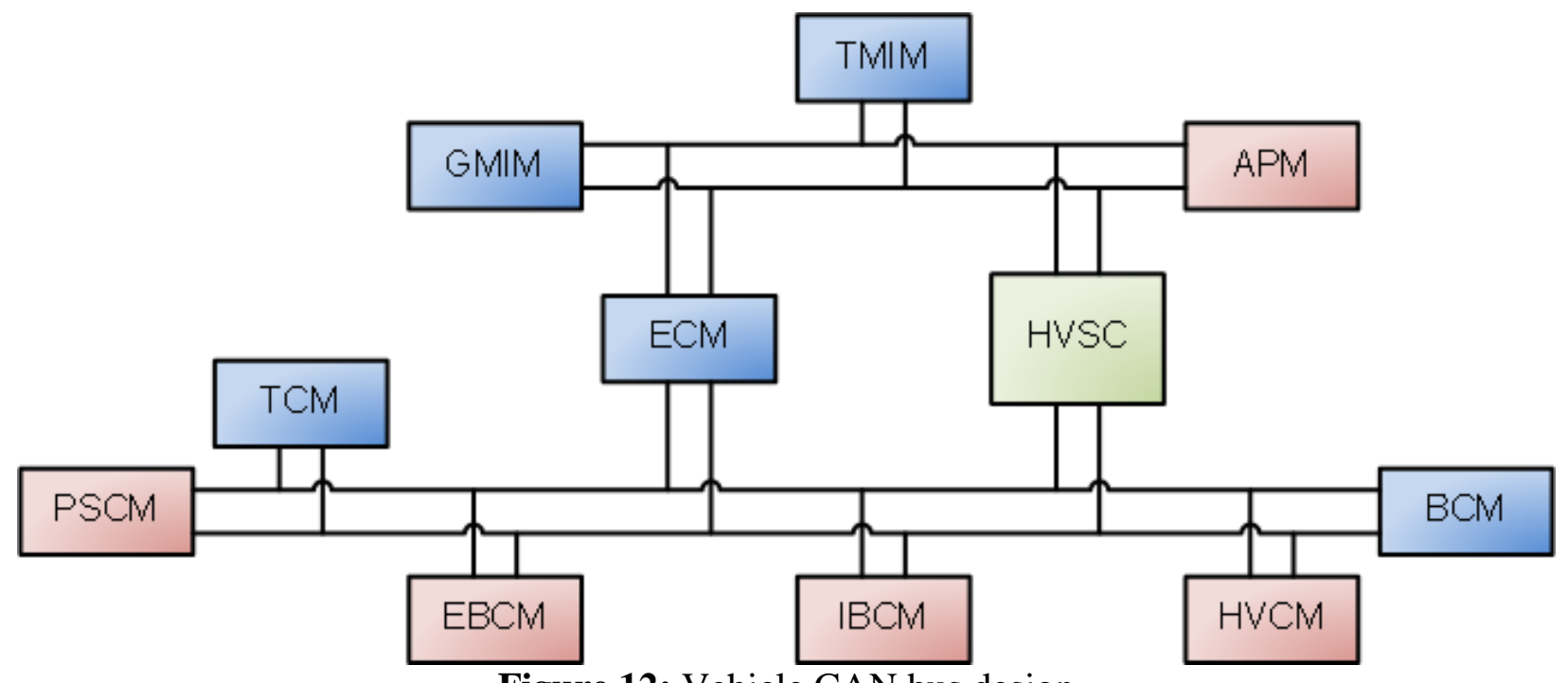

Figure 12: Vehicle CAN bus design

The red modules are for chassis systems, the blue are for powertrain components and the HVSC is in green. The design consists of two buses with the HVSC acting as an information gateway between the buses. The main CAN bus has all chassis control systems as well as some powertrain components including the transmission and the energy storage system. All torque producing components are on the powertrain CAN bus as they require faster communication to provide rapid torque command and feedback. The ECM is connected to both CAN buses to provide redundancy in the torque command from the HVSC. It also must interact with the TCM to coordinate gear shifts. 


\section{HYBRID VEHICLE SUPERVISORY CONTROLLER DEVELOPMENT}

\subsection{Hybrid Vehicle Supervisory Controller Requirements}

With the control system architecture designed, the focus shifts to developing and validating the individual ECUs that makeup the control system. Many of these ECUs can be sourced from other non-hybrid applications, as they are specific to their components not the vehicle as a whole. The HVSC however is unique to the hybrid powertrain and has the important role of making all the other components work together. The last section of this research will focus on the development and validation for the HVSC of the plug-in hybrid electric vehicle.

The first step to HVSC development is to define the requirements of the controller. One place requirements can be pulled from is the control system architecture. Using the controller interaction hierarchy each signal the HVSC must read and interpret brings a set of requirements for correctly interpreting and verifying the validity of that signal. Each signal the HVSC must generate brings requirements for how to decide what should be output for that signal. Each of these low level requirements then give rise to higher level requirements ultimately reaching the few high level goals of the controller. Figure 13 shows an example of this process, working from the HVSC interaction with the ECM to the high level goals and responsibilities of the HVSC.

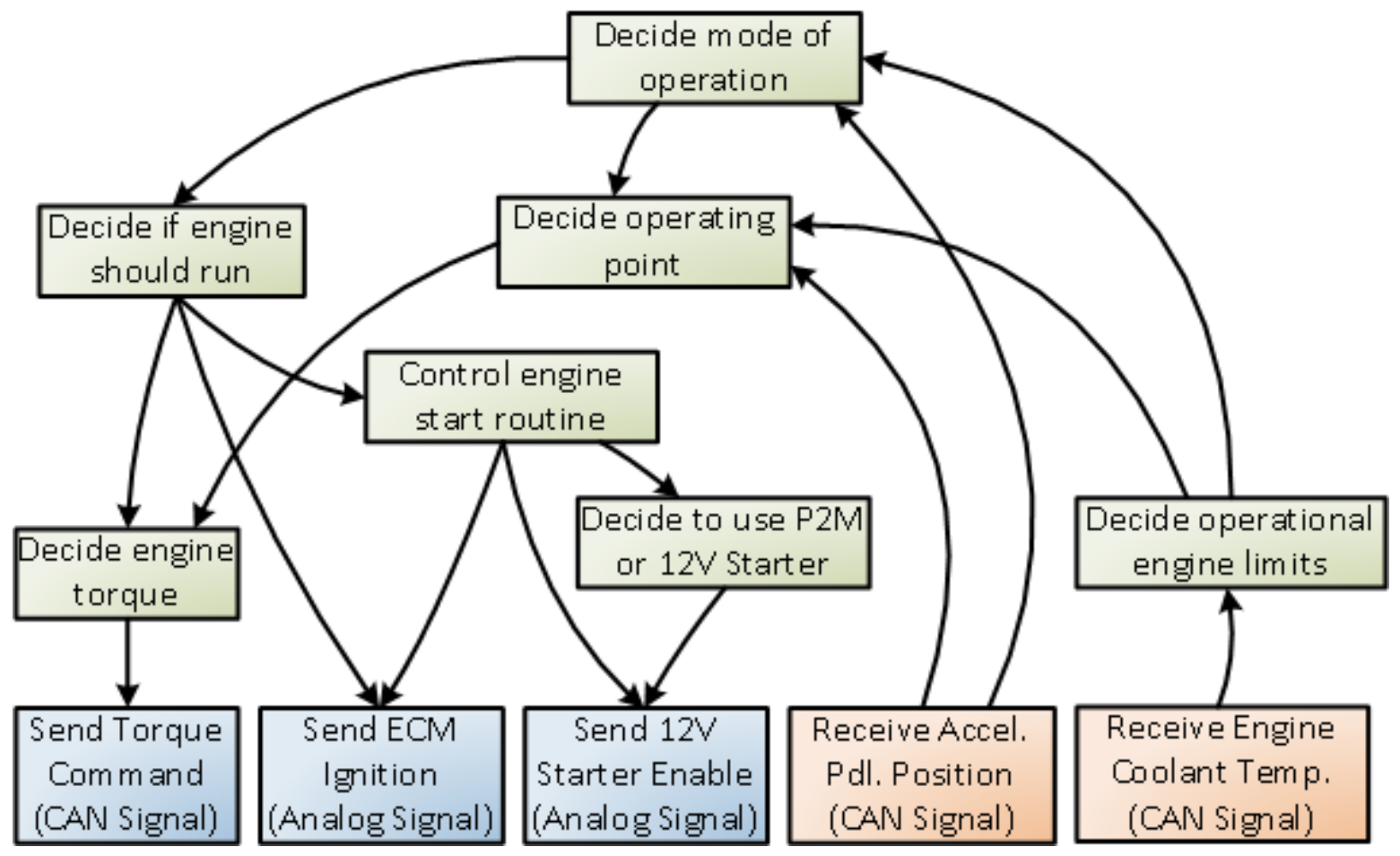

Figure 13: Control system requirements based on HVSC and ECM interaction

The example in this figure shows only some of the interactions and some of the requirements that come from those interactions. Receiving CAN signals would also bring requirements to verify that the CAN communication link is still active and working correctly. Reading analog signals would bring requirements for making sure analog signals are within range of acceptable values. Requirements can also be found using a top-down approach, starting with the high level roles 
and functionality and breaking them down into specific requirements. All requirements from low to high level can then be collected and categorized by the related control function or component. Table 5 summarizes some of the important requirements of the HVSC.

Table 5: Summary of important HVSC requirements

\begin{tabular}{|l|l|}
\hline Related Component/Function & Requirements \\
\hline Flex Fuel Engine & $\bullet$ Decide and command engine torque \\
& $\bullet$ Control engine start routine \\
$\bullet$ Maintain engine within temperature limits
\end{tabular}

Throughout development of the software that will run on the HVSC these requirements will need to be constantly reviewed to ensure they are being addressed. Specific algorithms that address each requirement and the development/testing status of those algorithms should be maintained to ensure proper validation of the strategy. These requirements will also later be used for developing models for testing and validation of the HVSC.

\subsection{Control Strategy Development}

\subsubsection{Software Organization}

Control strategy development often poses several challenges to those designing hybrid electric vehicles. The complexity and scale of a control strategy for a modern hybrid electric vehicle requires the effort of teams of various sizes. It is important to develop the strategy in a way that promotes readability and understandability. For this project Mathworks Simulink and Stateflow were chosen to develop the control software. Simulink and Stateflow are widely used in the industry due to the versatility they offer. As a visual based programming language, Simulink promotes readability of code and eliminates syntax errors. Using Real-Time Workshop C code can be generated from the Simulink model allowing a wide variety of embedded hardware to be targeted without changing the model.

Another challenge of working in a large team is facilitating parallel workflows. Team members need to be able to work on separate control functions without breaking functionality between the functions. This can be made possible by dividing the code into logical code modules with well- 
defined inputs, outputs, and requirements. The algorithms for each module can then be developed in parallel. The strategy developed for this research has been divided into four main modules: I/O, Diagnostics, Selection, and Execution. Figure 14 shows the organization and data flow between these modules.

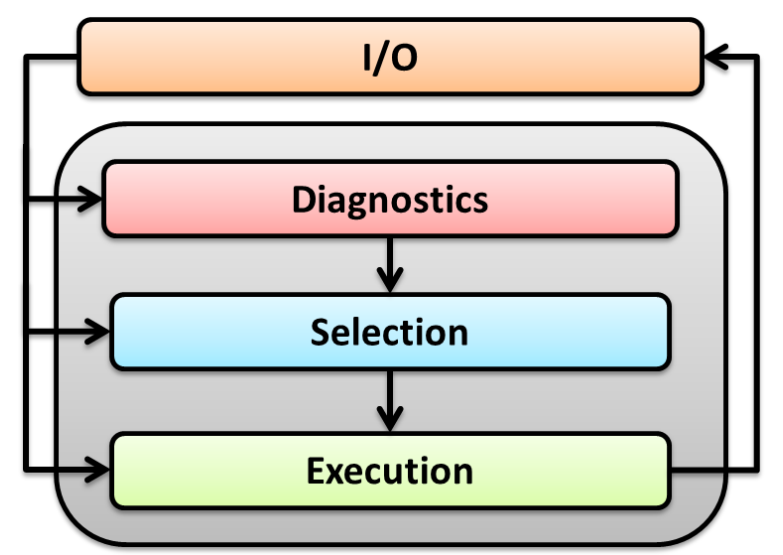

Figure 14: Software modules for control strategy

The I/O module is responsible for all signal conditioning and CAN messaging. All data passed between the I/O module and other modules is scaled in engineering units. Within the $\mathrm{I} / \mathrm{O}$ module those scaled signals are converted to and from their physical representation. This module is the only one that is platform specific. If it was desired to run the software on different hardware, a different I/O module could be used that correctly interfaces with that hardware. The I/O module could also be replaced with a vehicle model to facilitate SIL testing.

The Diagnostics module is responsible for analyzing all the input signals and detecting problems. It first checks for signal validity issues, making sure all values are within logical ranges. Where possible, signals are also compared with each other to verify accuracy. Engine speed reported by the ECM, for instance, can be compared with P2M speed reported by the GMIM and transmission input speed reported by the TCM. After signals are validated the diagnostics modules looks for component issues reported by respective controllers. This includes problems such as overheating components, or components outside of functional limits. The implication of component statuses on the system is assessed and operational limits are determined. The Diagnostics reports to the other software modules allowable modes of operation and individual component limits, such as motor torque limits and battery charge and discharge power limits.

The Selection module determines the vehicle state and mode of operation and finds the optimal torque/power split to meet the driver demand in the most efficient manner. As the vehicle is an electric vehicle first and a conventional hybrid second, there are two high level states the vehicle can operate in: charge depleting and charge sustaining. The selection between these states utilizes a state machine decision structure. The primary criteria for transitioning between these states is the battery SOC. With a high SOC, charge depleting is selected in which only electric power is used to propel the vehicle. If the SOC falls below a threshold the transition to charge sustaining is made where engine power is utilized to maintain the battery SOC within a target window. Within these states there are several possible modes of operation. Table 6 summarizes the possible modes of operation. 
Table 6: Powertrain modes of operation

\begin{tabular}{|l|l|l|}
\cline { 2 - 3 } \multicolumn{1}{l|}{} & Engine Off & Engine On \\
\hline Mode 1 & Mode 1, Engine off & $\begin{array}{l}\text { Mode 1, Engine On } \\
\text { (Series Hybrid Operation) }\end{array}$ \\
\hline $\begin{array}{l}\text { Mode 2 } \\
\text { (Transmission in Neutral) }\end{array}$ & (RTM Only) & $\begin{array}{l}\text { Mode 1, Engine On } \\
\text { (Parallel Hybrid Operation) }\end{array}$ \\
\hline
\end{tabular}

In the charge depleting state the powertrain can be operated in mode 1 engine off or mode 2 engine off. In mode 2 engine off, then engine would be spinning unfueled, incurring high losses. This mode is therefore only useful for performance assist in all-electric mode. In the charge sustaining state all modes of operation are available. An online optimization strategy is used to select between them. This strategy will be described in the next section.

The final module is the execution module which takes the desired mode and operating point determined by the selection module and decides actual torques and actuator commands to send to components. The execution module must handle transients and transitions when going from one mode to another. This module is also responsible for auxiliary systems such as cooling pumps and fans.

\subsubsection{Optimization Strategy}

The core of the control strategy is the selection strategy that determines how to operate the powertrain to reduce fuel consumption while meeting the driver demand. This section will present the design of a strategy using an online optimization technique. At every instance in time, or time step, the control strategy must determine how exactly to operate the powertrain. The main constraint for a given time step is output axle speed which is fixed at that point in time by the vehicle speed. The target is output axle torque which is fixed by the driver demand. Driver demand is typically determined by looking at vehicle speed and the accelerator pedal position input, but can also come from other sources. Cruise control, for instance, could be active and determining the desired output torque to track a desired speed. Regardless of the source, the goal of the optimization strategy is to meet a desired output torque at the current vehicle speed in a way that will minimize fuel consumption, not just instantaneously, but over a cycle. While at a given point in time the future of the cycle is unknown, the control strategy must determine whether to do things such as charging the battery assuming that charge will be used up at some point in the future.

For a given output torque $\left(\mathrm{T}_{\mathrm{o}}\right)$ and output speed $\left(\mathrm{N}_{\mathrm{o}}\right)$ the hybrid powertrain has many different ways it could operate. This was explored earlier during the architecture selection phase. As determined earlier in charge depleting there are zero DOF and in charge sustaining there are two modes of operation, one with $1 \mathrm{DOF}$ and the other with $3 \mathrm{DOF}$. The mode of operation dictates the powertrain configuration, in this case whether the transmission is in neutral or in gear allowing a path for engine torque to the ground. An operating point determines what specific combination of torque to use to achieve the desired output torque. 
Two approaches to selecting the mode and operating point for a given time step are offline optimization and online optimization. Offline optimization involves predetermining a mode and operating point over the range of possible $\left(\mathrm{T}_{\mathrm{o}}, \mathrm{N}_{\mathrm{o}}\right)$ combinations and storing that information in lookup tables. These lookup tables are stored on the HVSC and at run time are used to choose mode and operating point. For online optimization the HVSC runs calculations in real-time to find the best mode and operating point. These two techniques both offer advantages and disadvantages. The main advantage of the offline method is that it does not require much computing power. This means for a production vehicle a lower cost ECU can be used. The disadvantage is that every additional variable desired to be included in the optimization brings an exponential increase in lookup table size and complexity. An important variable to include for instance is battery SOC, as that must be maintained within certain limits. Online optimization allows for consideration of any dynamic variable. Another advantage to online optimization is that adaptable parameters can be included. The disadvantage is the need for an ECU with enough computing power to run the optimization in real-time.

The strategy presented in this research runs an online optimization strategy that is based upon minimizing a fuel consumption equation. Just as with the method used in architecture selection, the equation for fuel consumption needs to take battery power into account. Equations 16 and 17 show the fuel consumption equations for charging and discharging of the battery respectively.

$$
\begin{aligned}
& P_{\text {fuel }}=P_{\text {eng,fuel }}\left(T_{e}, \omega_{e}\right)+\frac{P_{\text {Batt,out }} \cdot \eta_{\text {Batt }}\left(P_{\text {Batt }, \text { out }}\right)}{\widetilde{\eta}_{\text {Gen,Dis }}}+P_{\text {Cost }} \\
& P_{\text {fuel }}=P_{\text {eng,fuel }}\left(T_{e}, \omega_{e}\right)+\frac{P_{\text {Batt }, \text { out }}}{\eta_{\text {Batt }}\left(P_{\text {Batt }, \text { out }}\right) \cdot \widetilde{\eta}_{\text {Gen }, \text { Chg }}}+P_{\text {Cost }}
\end{aligned}
$$

The equations are for the most part the same as the denominator as the powertrain efficiency equations used during architecture selection with two main differences. The first difference is the drive cycle average efficiencies. For the charging equation the drive cycle average discharge efficiency and genset efficiency have been lumped into one number. The same is done for the discharging equation. These two parameters can be used as tunable and/or adaptable parameters that affect the behavior of the strategy.

The second change is the addition of $P_{\text {Cost }}$. This represents the total "cost" associated with a given operating point. Costs are calculated from a variety of sources and are used to influence the strategy to achieve desired behavior, especially when the desired behavior is not necessarily best for fuel economy. The first area where the cost is used is for SOC control. If the battery SOC is approaching a boundary, a cost function can be used to influence the strategy away from operating points that continue to approach the battery. The SOC cost is calculated using equation 18.

$$
P_{\text {SOC Cost }}=C F(S O C) \cdot P_{\text {Batt }, \text { out }}
$$

The battery power is multiplied by a cost factor which is a function of battery SOC. Different cost factor functions will be tested to determine how they impact fuel consumption and the SOC vs. time trace. 
The next area where cost is used is for transition costs. For a given time step a certain operation mode may be found to be more efficient than the current mode of operation. The transition to the new mode of operation cannot happen instantaneously however, and there may be some increase in fuel consumption while the transition is in progress. It is therefore only worth making the transition if the new mode of operation can beat the current one by a reasonable margin. This is especially important when considering shutting off the engine. Since as a charge sustaining hybrid it is inherent that at some point in the future the engine will need to be turned back on the cost doing an engine start must be considered before shutting it off.

\subsubsection{SIL Vehicle Model for Strategy Development}

In order to do initial testing of the optimization strategy, a SIL testing technique was used. The goal was to test only the selection strategy without the rest of the functions of the control strategy. In order to do this a vehicle model needed to be developed. The first step in model development is identifying the requirements of the model to determine what level of detail is needed. The requirements of the model can be directly derived from the requirements of the algorithm being tested. In this case, as the goal was to test the selection strategy, a model that would be simple enough to operate without the execution software model but be able to predict fuel economy was needed.

The model was developed in Mathworks Simulink and consists of simplified component models that makeup the powertrain. Figure 15 shows the layout and signal flow through the model.

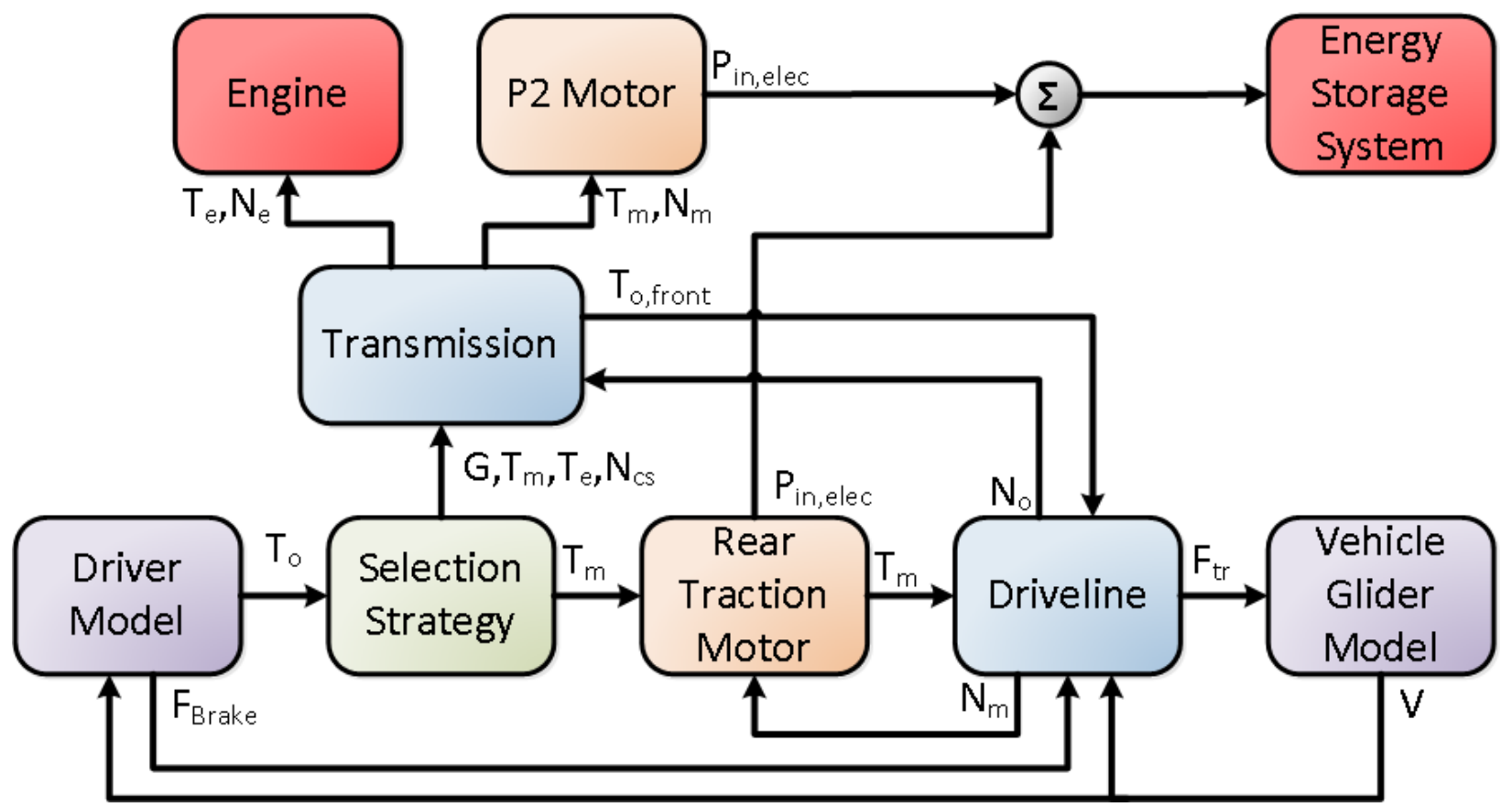

Figure 15: SIL plant model structure

The driver model generates an output torque request to match an input driving schedule. When negative tractive effort is needed a regen braking fraction is used to split between negative output 
torque and braking force. The selection strategy then operates to determine transmission gear and motor torques. When the transmission is in neutral the selection block can also dictate crankshaft speed. This allows the selection strategy to operate series mode without the need of execution strategies to control the engine generator system. The transmission model forwards the torque and speed to the engine and motor models. The RTM and P2M models send the input electrical power needed to the ESS model. The driveline receives all torques and braking force and calculates tractive effort. This is finally transmitted to the vehicle glider model where the vehicle velocity is calculated and fed back to the other models.

The ESS model is an $18.8 \mathrm{kWh}$ battery pack. The nominal pack voltage is $340 \mathrm{~V}$ and internal resistance is modeled as a constant $0.08 \Omega$. Figure 16 shows the representation of the battery pack used in the model.

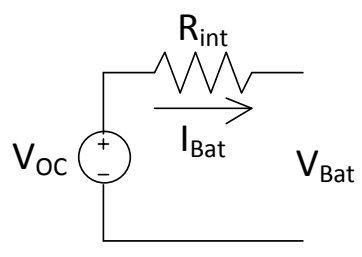

Figure 16: Battery loss model

Losses are calculated based on $\mathrm{I}^{2} \mathrm{R}$ losses due to the internal resistance. The model does not include any thermal dynamics, as that is beyond the scope of the strategy being tested.

The primary traction drive is a $125 \mathrm{~kW}$ rear traction motor (RTM) modeled after the UQM PP125 drive system. The model for this motor is a simple loss model that calculates the electrical input power required to meet the current torque command. Losses for the motor are calculated using a model from Larminie and Lowry [15] given in equation 19.

$$
P_{\text {Loss }}=k_{c} T^{2}+k_{i} \omega+k_{\omega} \omega^{3}+C
$$

The parameters of this equation have been tuned to closely match the characteristics of the UQM drive system. The motor drives the rear axle with a gear reduction of 7.59:1. The driveline for the RTM is modeled with $3 \mathrm{Nm}$ of spin loss on the motor input side.

The P2M model is based on early design data of a motor intended for the vehicle. This motor is being developed by Kollmorgen and preliminary specifications have been used for the model. The motor will be capable of about $27 \mathrm{~kW}$ peak and $21 \mathrm{~kW}$ continuous electrical output when generating. A simple loss model for this motor was developed using a scaled version of equation 1 to calculate losses.

The engine model is a simple loss model parameterized with fuel flow test data from the $2.4 \mathrm{~L}$ Chevrolet LE9 flex fuel engine. It calculates the fuel power required to meet the torque command at the given speed. This fuel power data comes from LE9 test 18 motoring efficiency data. The data is limited to between 750 and 4000 RPM. The fuel data also does not go up to the max torque for most of the speeds tested. These limitations are acceptable however as the data covers the region the engine will be operated within for efficiency. 
When the transmission is in gear, it is modeled with torque loss from the input. A loss model is developed as a function of input torque and speed to closely match efficiency data provided for the transmission from General Motors, given in Equation 20.

$$
T_{\text {Loss }}=C 0+C 1 \cdot \frac{T_{i}}{200}+C 2 \cdot \frac{N_{i}-2000}{2000}
$$

In this equation $T_{i}$ represents the input torque to the transmission and $N_{i}$ represents the input shaft speed in RPM. The coefficients have been tuned to closely match the characteristics of the 6T40 transmission in most of the gears that will be used in the vehicle.

\subsubsection{SIL Testing to Improve Optimization Strategy}

With the model developed, testing of the selection strategy could begin. The model was used to run drive cycles to calculate fuel consumption and record the selected mode and operating points during the cycle. The first goal was to make the selection algorithm operate well for series mode alone. As described earlier, series mode is simplified to a single DOF problem with genset output power being the only variable. Genset operation has been optimized by finding the point that has the lowest fuel consumption for a given level of DC output power. Since the plant model does not dynamically model the speed of the engine-generator system it is assumed that the system is always at the desired speed chosen by the selection strategy, remaining along the best efficiency line. While this assumption is not realistic, dynamic control of the genset speed is beyond the scope of the selection strategy being tested.

The drive cycle average efficiency parameters were designed to impact the behavior of the strategy so an analysis was done to see how they impacted the fuel economy. The genset/discharge efficiency parameter affected how the strategy valued charging the battery pack. Lower genset/discharge efficiency means more fuel can be saved by charging the battery pack, encouraging charging. The genset/charge efficiency parameter changes the value of discharging the battery. Lower genset/charge efficiency means it took more fuel to put energy into the battery pack thus discouraging using the stored energy.

The two parameters were varied between 0.2 and 0.4 and testing was done over several different drive cycles including the urban dynamometer driving schedule (UDDS), highway fuel economy test (HWFET), and US06 city and highway. Table 7 summarizes some of the interesting results from the parameter variation. A complete list of results can be found in Appendix C. 
Table 7: Results from parameter variation

\begin{tabular}{|l|l|l|l|l|}
\hline \multicolumn{5}{|c|}{ UDDS } \\
\begin{tabular}{|l} 
Genset/Charge \\
Efficiency
\end{tabular} & $\begin{array}{l}\text { Genset/Discharge } \\
\text { Efficiency }\end{array}$ & $\begin{array}{l}\text { Fuel Economy } \\
\text { (MPGge) }\end{array}$ & $\begin{array}{l}\text { Average Engine } \\
\text { Efficiency }\end{array}$ & $\begin{array}{l}\text { Total Battery } \\
\text { Losses (kJ) }\end{array}$ \\
\hline 0.2 & 0.3 & 34.5 & $34.3 \%$ & 18.25 \\
\hline 0.4 & 0.2 & 34.8 & $34.7 \%$ & 246.45 \\
\hline 0.3 & 0.3 & 36.5 & $36.6 \%$ & 68.65 \\
\hline \multicolumn{5}{|l|}{ HWFET } \\
\hline $\begin{array}{l}\text { Genset/Charge } \\
\text { Efficiency }\end{array}$ & $\begin{array}{l}\text { Genset/Discharge } \\
\text { Efficiency }\end{array}$ & $\begin{array}{l}\text { Fuel Economy } \\
\text { (MPGge) }\end{array}$ & $\begin{array}{l}\text { Average Engine } \\
\text { Efficiency }\end{array}$ & $\begin{array}{l}\text { Total Battery } \\
\text { Losses (kJ) }\end{array}$ \\
\hline 0.2 & 0.3 & 37.1 & $35.5 \%$ & 7.82 \\
\hline 0.4 & 0.2 & 36.9 & $34.8 \%$ & 194.83 \\
\hline 0.3 & 0.3 & 37.9 & $36.7 \%$ & 59.05 \\
\hline
\end{tabular}

The results show some interesting effects from the parameters. The first example is using genset/charge efficiency of 0.2 and genset/discharge efficiency of 0.3 . This resulted in close load following behavior with very low battery losses, but lower engine efficiency and low fuel economy. Figure 17 shows an example of the results with these parameters.

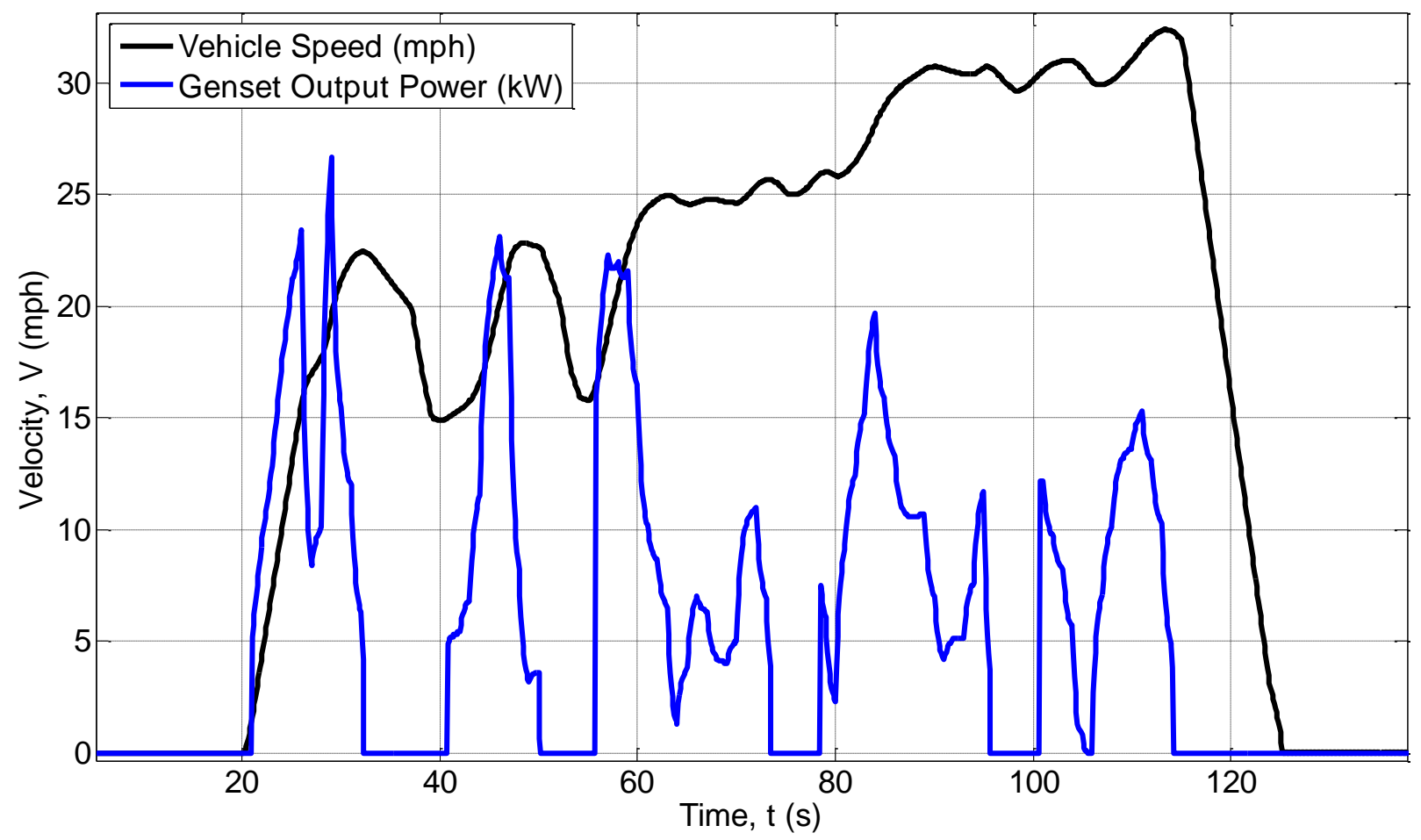

Figure 17: Hill 1 of UDDS cycle, $\eta_{\text {genset,charge }}=0.2, \eta_{\text {genset,discharge }}=0.3$

For the second example, genset/charge efficiency of 0.4 and genset/discharge efficiency of 0.2 were used. This produced the opposite behavior, with the strategy choosing to discharge the battery during high load then charge at a high rate when no load was present. This resulted in slightly higher engine efficiency but the highest battery losses. Figure 18 shows the results from these parameters. 


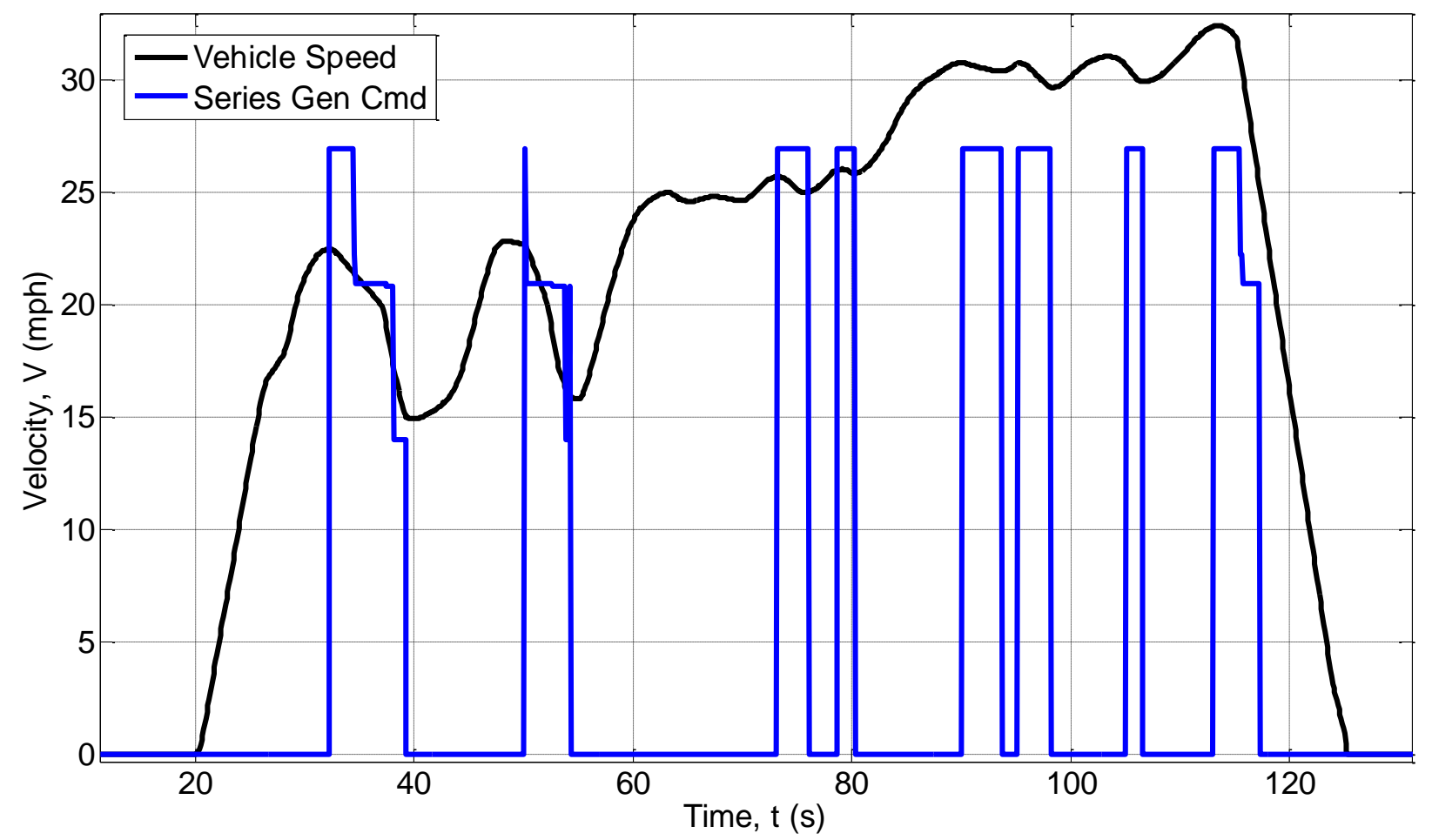

Figure 18: Hill 1 of UDDS cycle, $\eta_{\text {genset,charge }}=0.4, \eta_{\text {genset,discharge }}=0.2$

The third example achieved the best results with both efficiency parameters at 0.3. Figure 19 shows some of the results with these parameters.

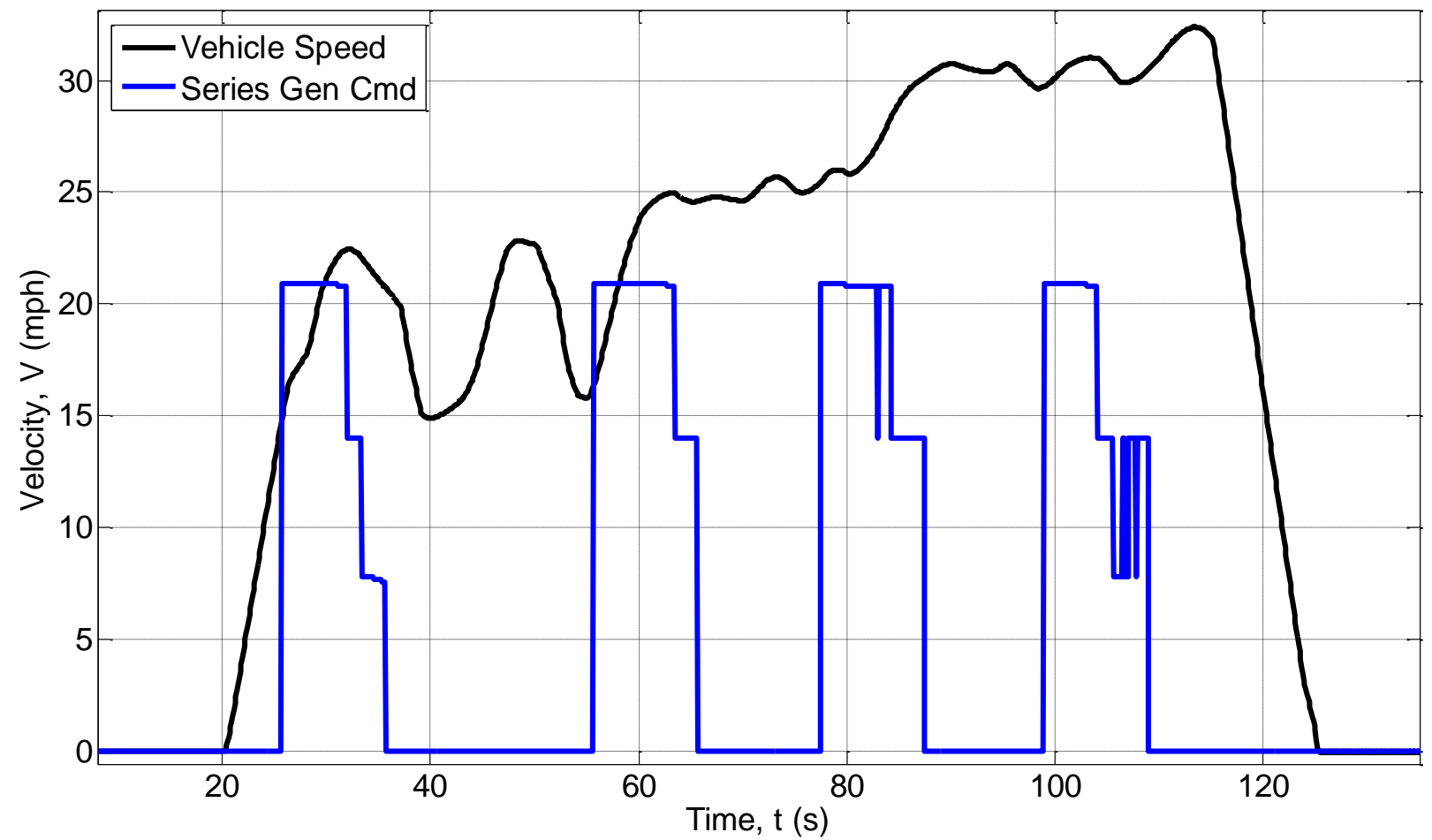

Figure 19: Hill 1 of UDDS cycle, $\eta_{\text {genset,charge }}=0.3, \eta_{\text {genset,discharge }}=0.3$ 
This case had the best balance between engine efficiency and battery losses, with the engine run at higher load but only when the load was high on the powertrain. Having the parameters both at 0.3 consistently produced the best results on all of the drive cycles producing similar results.

With series mode working well, the parallel mode was then included in the strategy. The optimization tested operating points in gears three through six. The first two were avoided only for drivability concerns. To simplify the optimization the P2M was not used in parallel mode since the RTM has a much higher power capability. Therefore the only DOF was torque split between the engine and RTM. Initially the strategy produced un-desired behavior. The strategy would rapidly switch back and forth between gears. To eliminate this behavior, a transition cost was added to the fuel consumption equation. The cost was calculated based on the change in speed required by the engine to accomplish the shift. This had the effect of preventing a gear shift unless there was a reasonable margin of efficiency improvement offered by a different gear. Another change to the strategy was the requirement that a different gear be selected as the best for multiple consecutive time steps before a transition to that gear is actually made. These strategy changes had the effect of making gear changes less frequent, producing smoother operation. Figure 20 shows an example of the gear selection during the second hill of a US06 city cycle.

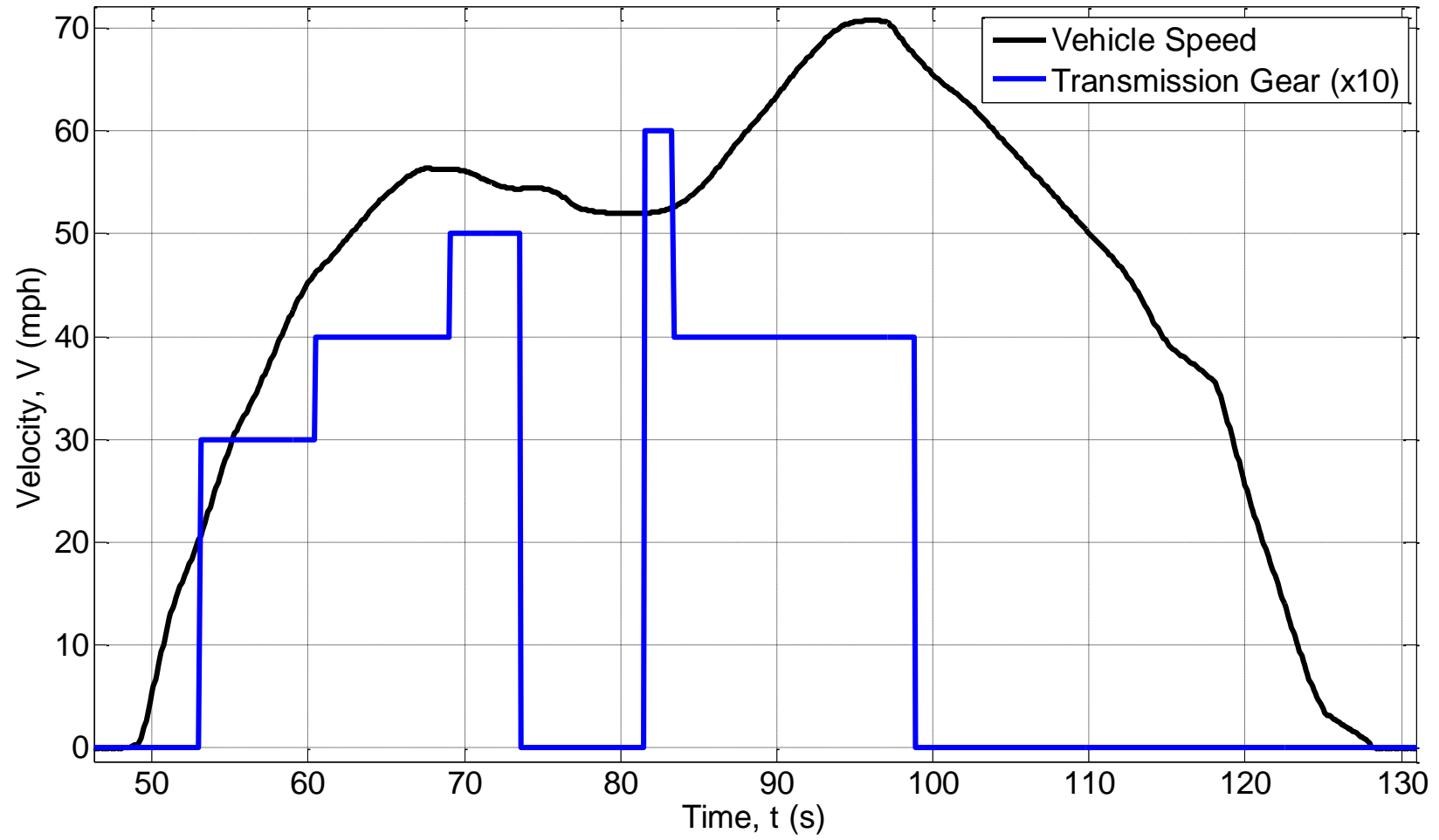

Figure 20: Hill 2 of US06 city cycle

Figure 20 shows that parallel mode is selected during acceleration while series mode, indicated by gear being zero, is selected while decelerating. The parallel modes improved the fuel economy for all drive cycles tested. Table 8 summarizes the fuel economy results under the full strategy. 
Table 8: Fuel economy results for full optimization strategy

\begin{tabular}{|l|l|l|l|l|c|}
\hline Drive Cycle & $\mathbf{5 0 5}$ & HWFET & US06 City & US06 Hwy & 4-Cycle \\
\hline Battery Losses (kJ/km) & 7.24 & 4.43 & 31.57 & 5.08 & - \\
\hline Average Engine Efficiency & $37.5 \%$ & $37.8 \%$ & $37.2 \%$ & $37.3 \%$ & - \\
\hline CS Fuel Economy (MPGge) & 37.6 & 40.2 & 24.0 & 29.8 & 31.5 \\
\hline CD Energy Cons. (Wh/mi) & 327.2 & 307.3 & 525.3 & 416.7 & 392.8 \\
\hline CD Range @ 80\% DOD (mi) & 46.2 & 49.2 & 28.8 & 36.3 & 38.5 \\
\hline
\end{tabular}

The results are comparable to those found by HEVT, modeling the same architecture using a simulation package called Autonomie [16]. HEVT found the CD energy consumption to be 368.9 Wh/mi and CS fuel economy to be 35.8 MPGge, both using a 4-cycle average.

\subsubsection{HIL Hardware and Plant Model Development}

With the selection strategy validated, a testing method is needed to validate the supervisory controls as a whole. This method needs to not only test the software algorithms but also the control hardware and I/O. While the SIL plant model proved useful for rapid design and testing of the selection strategy it was purposely made with low fidelity to allow fast simulations in a desktop environment. The model was also simplified to test only the scope of requirements for the selection strategy. A new model and testing method is needed to test the entire HVSC software and hardware.

Controller HIL is a powerful tool that enables a high level of controller validation even before the actual vehicle and/or components are available for testing. In an HIL testing environment the simulation runs in real-time and the controller being tested operates exactly how it would in the real vehicle without being aware it is in a simulated environment. The exact behavior of how the controller will function in the real vehicle can therefore be determined. A controller validated on a well-designed HIL system should be able to transition directly to in-vehicle testing with no modification.

To successfully execute HIL testing, a simulation target to run the model must be selected and an HIL plant model must be developed. The requirements of the HIL simulation target and model are derived directly from the requirements of the controller being tested and the goals of the test. An important universal requirement in an HIL environment is that the simulation must run in real-time. This means the simulation target must have enough computing power to calculate each time step of the simulation within the actual amount of time that elapses during that time step. Conversely, this means the model cannot be too computationally intensive to be executed in realtime. Ideally, the model should be designed with only enough fidelity to test all needed requirements. A simulation with enough computing power to execute the model in real-time can then be selected. If a simulation target with the necessary computing power is not available, however, tradeoffs may need to be made in the model to reduce the complexity and fit the available computing power.

The rest of the requirements for the simulation target hardware come from the necessary I/O. This can be determined by revisiting the controller interaction diagram discussed during the 
control system architecture development phase. By counting the interactions, the exact number of digital and analog $\mathrm{I} / \mathrm{O}$ signals that need to be generated by the simulator can be determined. The CAN bus structure can be used to determine how many CAN interfaces the simulation target needs to reproduce the CAN bus structure that will be used in the vehicle. For the EcoCAR 2 competition, teams were donated a dSPACE midsize simulator for use as a simulation target. The key specifications of the simulator are summarized in Table 9.

Table 9: Specifications for dSPACE Mid-Size Simulator

\begin{tabular}{|l|l|}
\hline Processor & $2.6 \mathrm{GHz}$ Quad Core AMD Opteron \\
\hline Memory & $256 \mathrm{MB}$ DDR-400 \\
\hline CAN channels & 2 High Speed \\
\hline Digital/PWM Outputs & 16 \\
\hline Digital/PWM Inputs & 38 \\
\hline Analog Outputs & $20,12-$ Bit Differential \\
\hline Analog Inputs & $16,14-$ Bit Differential \\
\hline Power Supply & $33 \mathrm{~V}$ Max, 33 A Max, 1 kW Max \\
\hline
\end{tabular}

The processing power offered by the simulator enables execution of high fidelity complex models in real-time. The simulator also offered a robust set of I/O adequate for completely testing the I/O of the HVSC. The included power supply will allow realistic simulation of the vehicle 12 volt system so that effects of fluctuation in the 12 volt system on other signals can be tested.

With the simulation target selected the HIL plant model needs to be developed. The particular goals of this testing environment are to validate the SIL results, predict real world fuel economy, and to test all HVSC requirements including proper behavior and response to driver inputs and safety critical systems and fault action strategy. Requirements for the model can be developed much the same way requirements for the control strategy were developed, using a bottom up approach from the controller I/O and a top-down approach from the high level functional needs.

The bottom up and top down approaches to generating model requirements meet in the middle at the component models. The component models together form the core of the HIL plant model and, while the interactions between the components are important, most of the computation work is in the components themselves. The fidelity of each component model is therefore very important and is driven by the requirements for that model. Figure 21 shows an example of how both HVSC I/O and control system requirements drive requirements for the ESS component model. 


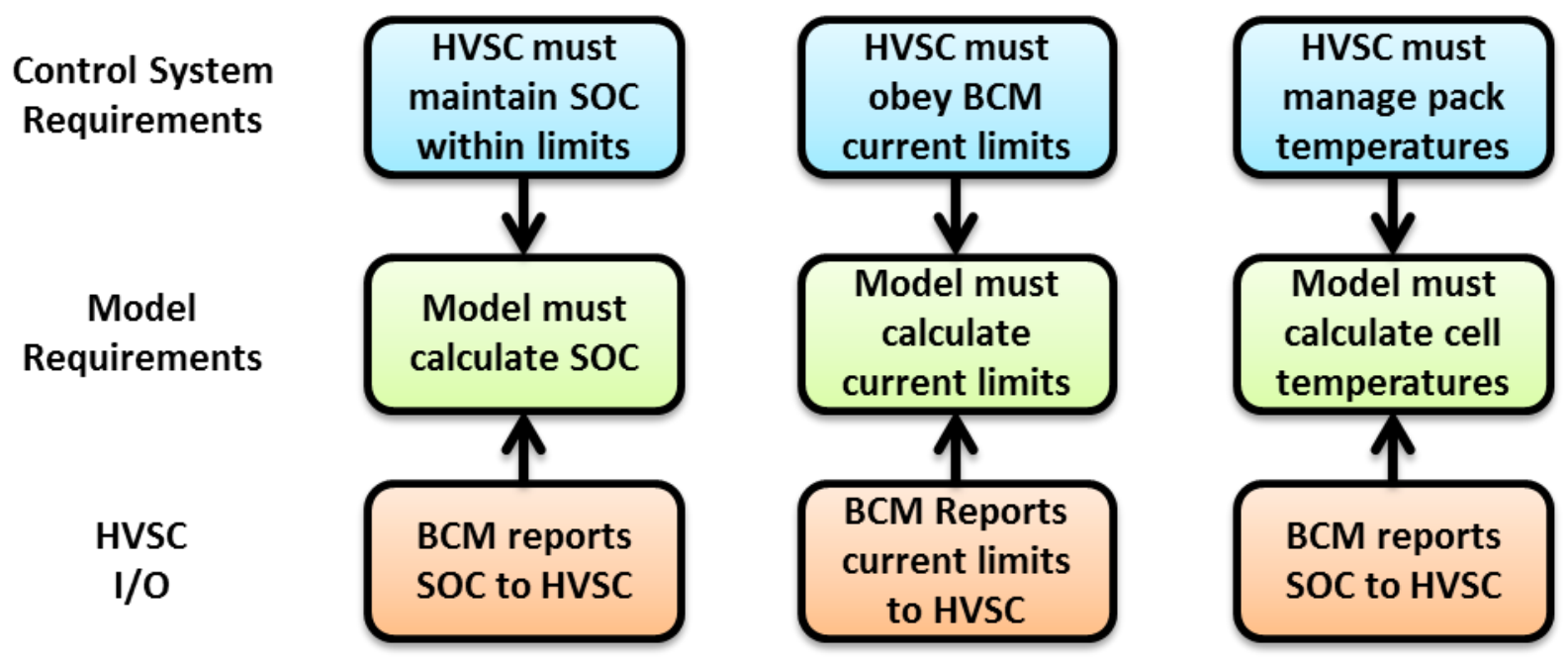

Figure 21: I/O and control system requirements that drive model requirements

Along with the simulator hardware, dSPACE donated their ASMs to EcoCAR participants. These simulation models were used for some components while other components used simpler models. Table 10 lists the components of the HIL plant models and their sources. 
Table 10: Component models used in HIL plant model

\begin{tabular}{|c|c|c|}
\hline Component & Model Source & Model Features \\
\hline 2.4 L Flex Fuel Engine & ASM (dSPACE) & $\begin{array}{l}\text { - High fidelity engine model with accurate } \\
\text { fuel consumption calculation } \\
\text { - Cooling system model with calculation for } \\
\text { coolant temperature } \\
\text { - Software ECU that generates signals real } \\
\text { ECU will generate }\end{array}$ \\
\hline $\begin{array}{l}\text { 6-Speed Automatic } \\
\text { Transmission }\end{array}$ & ASM (dSPACE) & $\begin{array}{l}\text { - High fidelity transmission model with } \\
\text { accurate fuel consumption calculation } \\
\text { - Software ECU that generates signals real } \\
\text { ECU will generate }\end{array}$ \\
\hline $\begin{array}{l}125 \mathrm{~kW} \text { Rear Traction } \\
\text { Motor, } 27 \mathrm{~kW} \text { P2 Motor }\end{array}$ & $\begin{array}{l}\text { Modified Autonomie } \\
\text { Model }\end{array}$ & $\begin{array}{l}\text { - Simple dynamic motor model using table } \\
\text { data for losses } \\
\text { - Thermal effects used to scale between peak } \\
\text { and continuous output capability }\end{array}$ \\
\hline $\begin{array}{l}18.9 \text { kWh } 360 \text { V Energy } \\
\text { Storage System }\end{array}$ & ASM (dSPACE) & $\begin{array}{l}\text { - High fidelity dynamic battery cell model } \\
\text { with accurate voltage and SOC calculation } \\
\text { - Cell thermal model } \\
\text { - Software ECU that generates signals real } \\
\text { ECU will generate }\end{array}$ \\
\hline Vehicle Glider Dynamics & ASM (dSPACE) & $\begin{array}{l}\text { - Calculates road load based on vehicle } \\
\text { properties and ambient conditions }\end{array}$ \\
\hline $\begin{array}{l}\text { DC-DC Converter/12 V } \\
\text { Vehicle Accessory Loads }\end{array}$ & New Model & $\begin{array}{l}\text { - Simple model using constant accessory load } \\
\text { assumption }\end{array}$ \\
\hline
\end{tabular}

The dSPACE ASMs are very high detail dynamic models and are suitable for the needs of most of the components. In some cases they had too much detail and other models were used instead. An example of a place where this was the case is the RTM. While dSPACE provided a generic ASM for an electric motor, the model did not come specifically parameterized to represent the UQM motor that will be used in the actual vehicle. Due to the high level of complexity of the motor ASM, it would have taken extensive work to parameterize the ASM for the UQM motor. Instead a model from Autonomie, a simulation package provided by ANL was used [16]. This model was much simpler yet still provided the needed functionality such as dynamic torque response and thermal effects. A disadvantage of the Autonomie model was that it did not calculate temperatures of the motor, inverter, or calculate coolant temperatures. This tradeoff was acceptable, however, as a detailed thermal model was not important for the requirements of the model. A simple thermal model could easily be added that would address requirements of testing the HVSC response to components approaching temperature limits.

\subsubsection{HIL Fuel Economy Testing}

With the HIL plant model development complete, the first goal of HIL testing is to get fuel economy results. The higher fidelity HIL plant model can produce much more accurate results that include the effects of the execution strategy, something the SIL model is not designed to do. 
Table 11 summarizes results from running the HIL model for both charge depleting and charge sustaining cases.

Table 11: HIL energy consumption and fuel economy test results

\begin{tabular}{|l|l|l|l|l|l|}
\hline Drive Cycle & $\mathbf{5 0 5}$ & HWFET & US06 City & US06 Hwy & 4-Cycle \\
\hline CD Energy Cons. (Wh/mi) & 403.39 & 353.78 & 755.46 & 467.96 & 475.79 \\
\hline CD Range @ 80\% DOD (mi) & 37.48 & 42.74 & 20.01 & 32.31 & 31.78 \\
\hline CS Fuel Economy (MPGge) & 37.7 & 44.8 & 20.88 & 33.53 & 32.8 \\
\hline
\end{tabular}

The HIL results are very similar to the SIL results, with the HIL achieving slightly higher CS fuel economy by about $4 \%$. The SIL model produced much lower CD energy consumption numbers however, using only $392 \mathrm{Wh} / \mathrm{mi}$ with 4-cycle weighting. Much of this difference can be attributed to regenerative braking. While the SIL model uses an assumption of $60 \%$ regenerative braking fraction, the control strategy on the HVSC does not yet incorporate regenerative braking. With regenerative braking turned off the model used $462 \mathrm{Wh} / \mathrm{mi}$, much closer to the HIL result. Adding regenerative braking will clearly improve the EV range of the vehicle.

Apart from just using the HIL to measure fuel economy over a cycle, it is also useful to test the fuel consumption implications of specific algorithms. One example of this is fuel use during an engine start. When the vehicle is operating in the charge sustaining state, there are times when shutting the engine off appears to be the most efficient option. As the goal is to sustain battery charge and the length of the current drive cycle is unknown to the real-time control strategy, it is a safe assumption that shutting the engine off means at some point in the future it will be started again. The selection strategy therefore weighs in the fuel that will be used in the future when considering if shutting the engine off is the best option. During SIL testing an approximation of $3.39 \mathrm{Wh}$ was used for the engine start fue, calculated based on the energy to spin up the inertia of the engine with the P2M. Using the HIL the actual fuel used during a start routine was measured. Figure 22 shows a data trace during an engine start. 


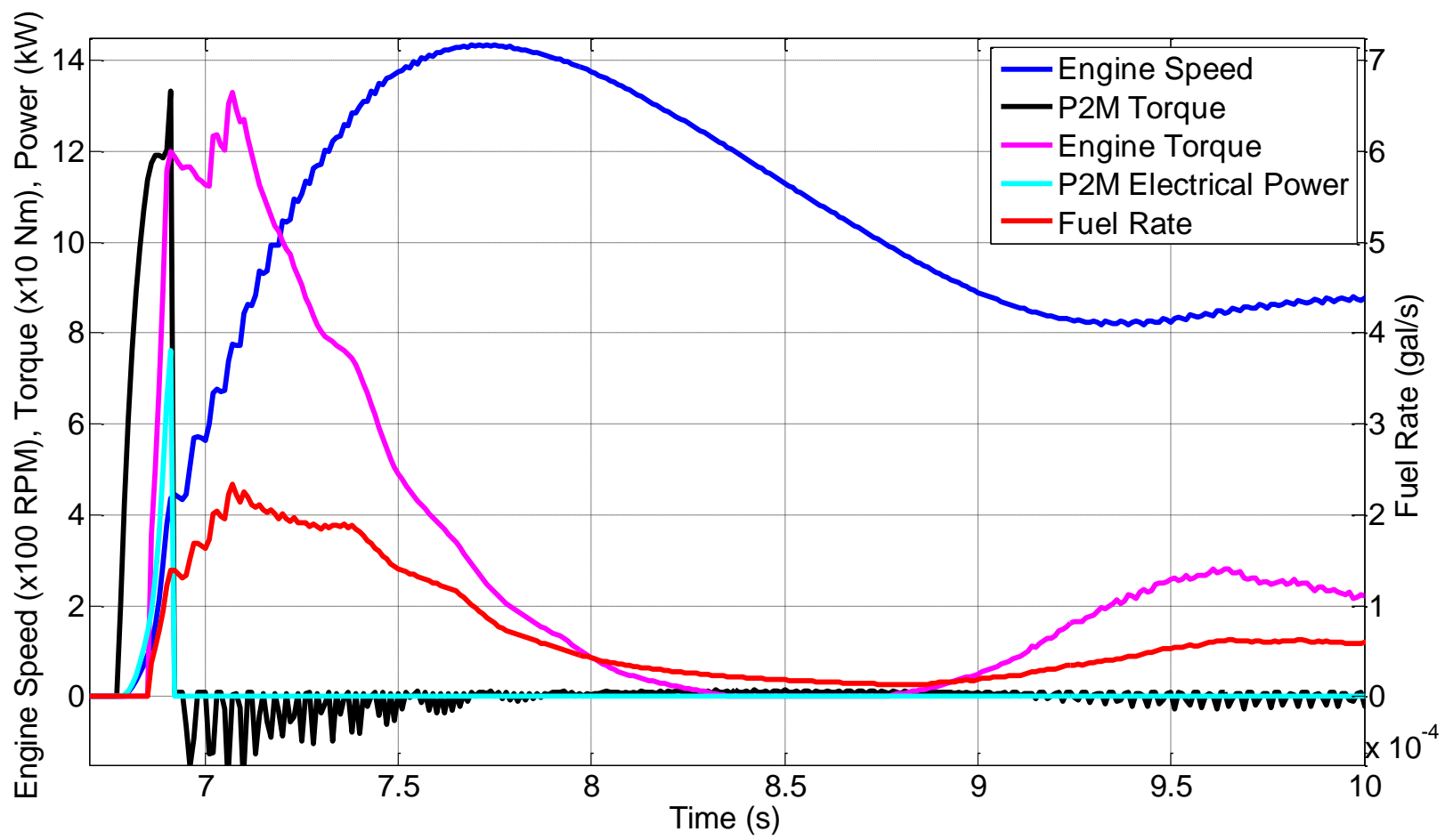

Figure 22: Engine start recorded on HIL

At the beginning of the engine start the $\mathrm{P} 2 \mathrm{M}$ is commanded torque for about $150 \mathrm{~ms}$ and uses a total of $0.0871 \mathrm{Wh}$ of battery energy. Using the relationship with $\eta_{\text {gen,chg }}$ this theoretically equals about $0.290 \mathrm{Wh}$ of fuel energy. While the engine takes about 3 seconds to settle at idle speed, it is immediately useful for producing torque once the speed has reached 1200 RPM, only $500 \mathrm{~ms}$ from initiating the engine start. Only the fuel used up to this point is therefore attributed to the engine start. The data shows $8.4 \times 10^{-5}$ gallons of fuel or $3.08 \mathrm{Wh}$ of fuel energy burned during the start. This means a total of about $3.37 \mathrm{Wh}$ of fuel energy is used during an engine start, close to the approximation used in the SIL plant model. The collected data also shows that fuel is used at a rate of about $6.10 \times 10^{-5} \mathrm{gal} / \mathrm{s}$ or $2.23 \mathrm{Wh} / \mathrm{s}$ of fuel energy when the engine idles. The engine start consumes about as much fuel as idling the engine for about 1.5 seconds.

\subsubsection{HIL Performance Improvement}

Apart from testing for fuel economy, the HIL is also used to test and improve vehicle performance and drivability. One example is using the HIL to measure the zero to $60 \mathrm{mph}$ and 50 $\mathrm{mph}$ to $70 \mathrm{mph}$ acceleration performance. Figure 23 shows the vehicle speed during the acceleration run for both charge depleting and charge sustaining. 


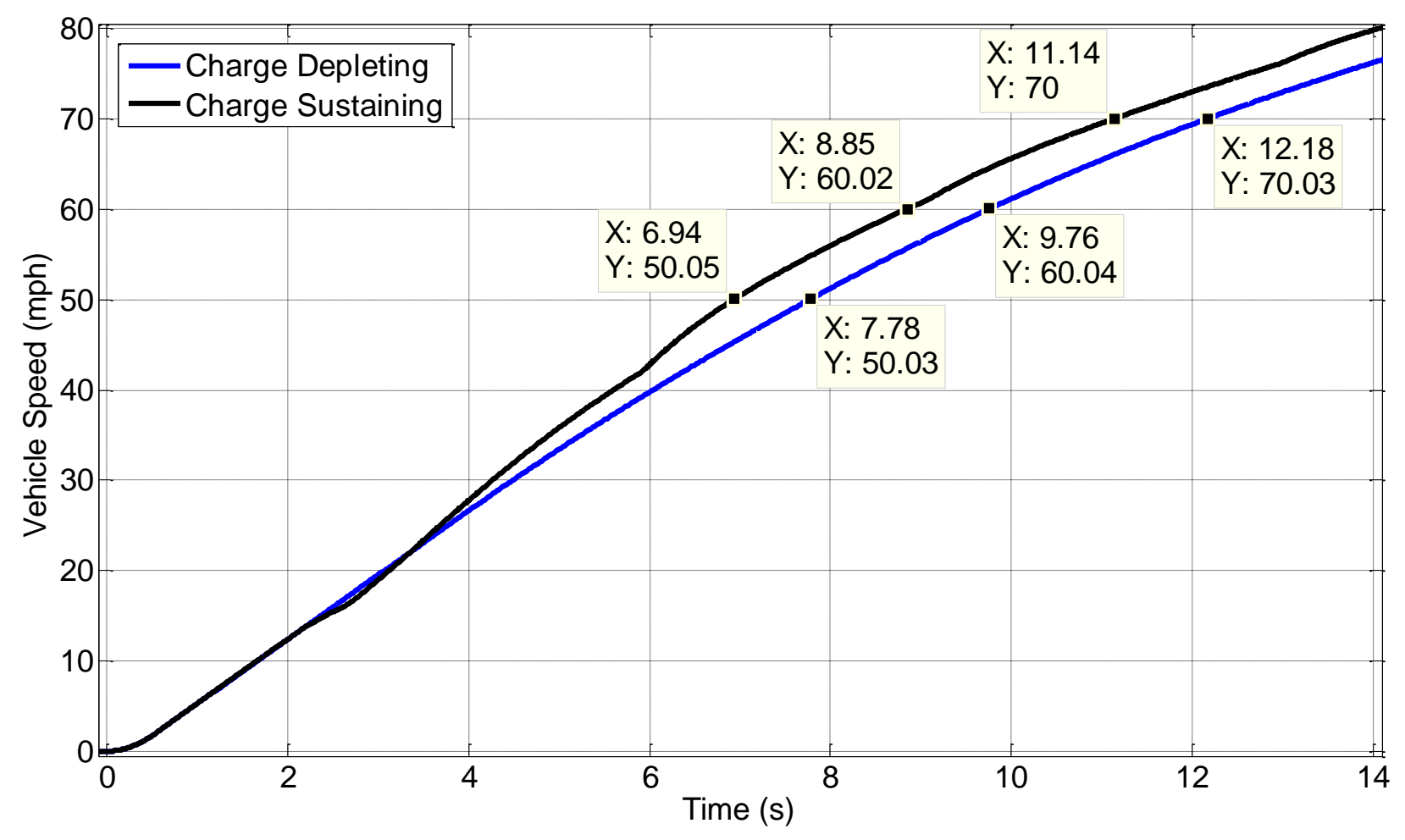

Figure 23: Acceleration data from HIL

The two acceleration runs are equal until the point where the vehicle speed is sufficient to engage parallel mode. At this point the charge sustaining run pulls ahead reaching $60 \mathrm{mph}$ in 8.85 seconds, as opposed to 9.76 seconds for the charge depleting run. 50-70 acceleration time came in at 4.2 seconds for charge sustaining and 4.4 seconds for charge depleting.

One area where the HIL is used to improve drivability is shift quality. Due to the fact that an automatic transmission is being used without a torque converter an algorithm is developed to avoid extra wear on the transmission during shifts. The algorithm commands the transmission to neutral, controls the engine to the correct speed, and then commands the transmission back into gear to execute a shift. During the shift the RTM is used to continue meeting driver demand. When tested on the HIL however a problem is observed. Figure 24 shows vehicle acceleration during a shift from $4^{\text {th }}$ to $5^{\text {th }}$ gear while accelerating with a constant $40 \%$ accelerator pedal input. 


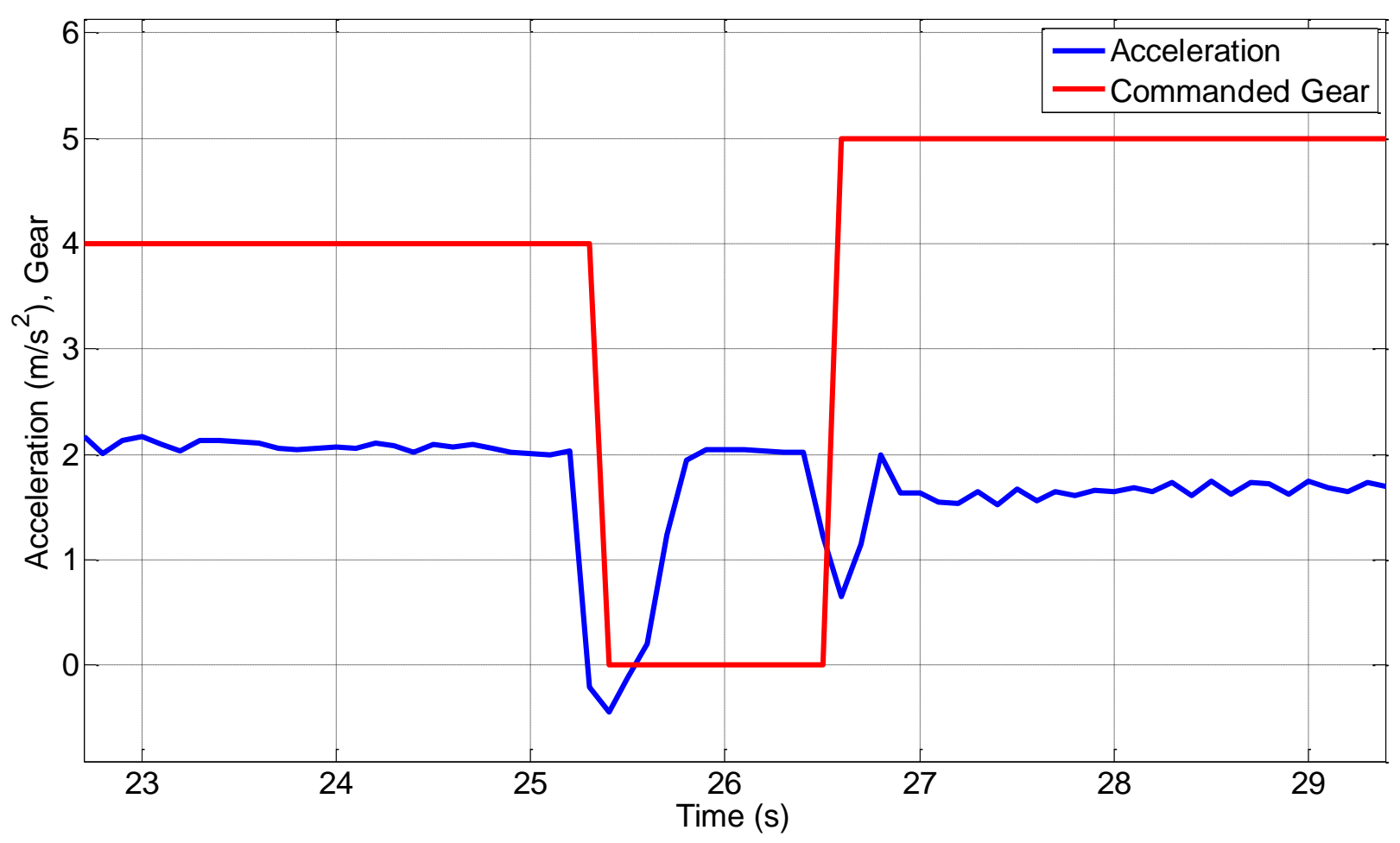

Figure 24: Acceleration gaps during shift

The figure shows the transmission commanded gear in red. A sudden drop in acceleration is observed when the transmission is put in neutral and when put back in gear. The problem occurred because while the RTM was immediately commanded torque when the transmission went to neutral the actual output must be ramped up. This problem is fixed by making the algorithm gradually transfer torque responsibility from the engine to the RTM before commanding the transmission to neutral. The second acceleration drop is due to a drag caused by the transmission as it engaged a gear. This is fixed by commanding extra RTM torque to overcome the drag. Figure 25 shows a shift after the improvements. 


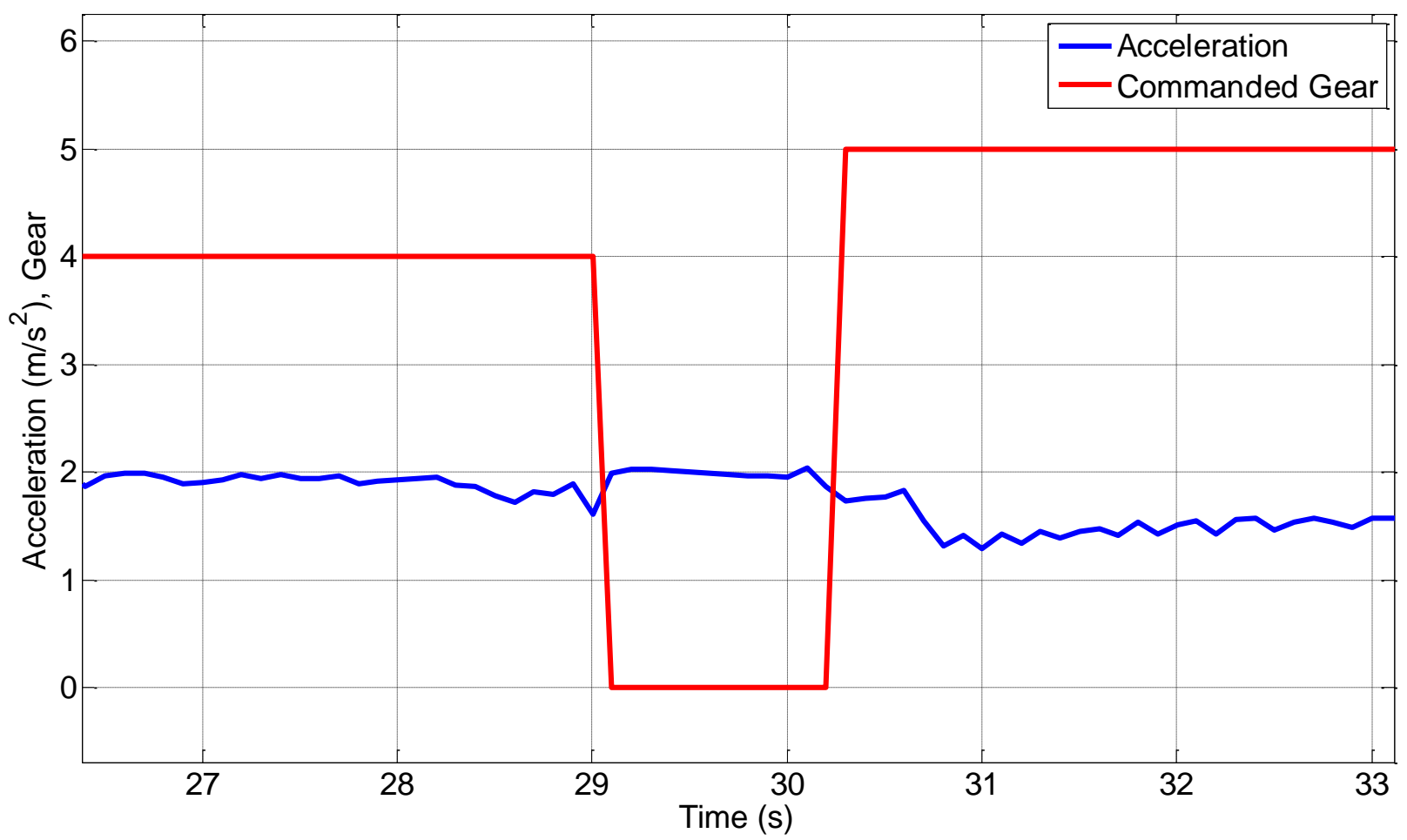

Figure 25: Vehicle acceleration during shift after algorithm changes

\subsubsection{HIL Safety Critical and Diagnostic Testing}

One of the important roles of the HIL is that it can be used to validate the HVSC to ensure it is safe to put in a vehicle and begin on-road testing. This means safety critical functions must be thoroughly tested to ensure safe operation. Safety critical functions include any that have the potential to cause component damage or unintended vehicle operation. This most often relates to algorithms that control torque commands but can relate to other aspects of the control strategy as well. One example of this is the park neutral safety feature of the HVSC. To prevent the vehicle from accelerating unexpectedly when started, the HVSC will not power on the vehicle if the gear shift selector level is not in the "Park" or "Neutral" position. The driver must also depress the brake pedal. This feature can be tested on the HIL before integrating the HVSC for on-road testing.

Another example of a safety critical feature is the HVSC response to ambiguous driver input. In this case the response to simultaneous accelerator pedal and brake pedal input is tested. In this case the HVSC should assume the driver intends to decelerate the vehicle and it should stop commanding torque. Figure 26 shows the results from testing this on the HIL. 


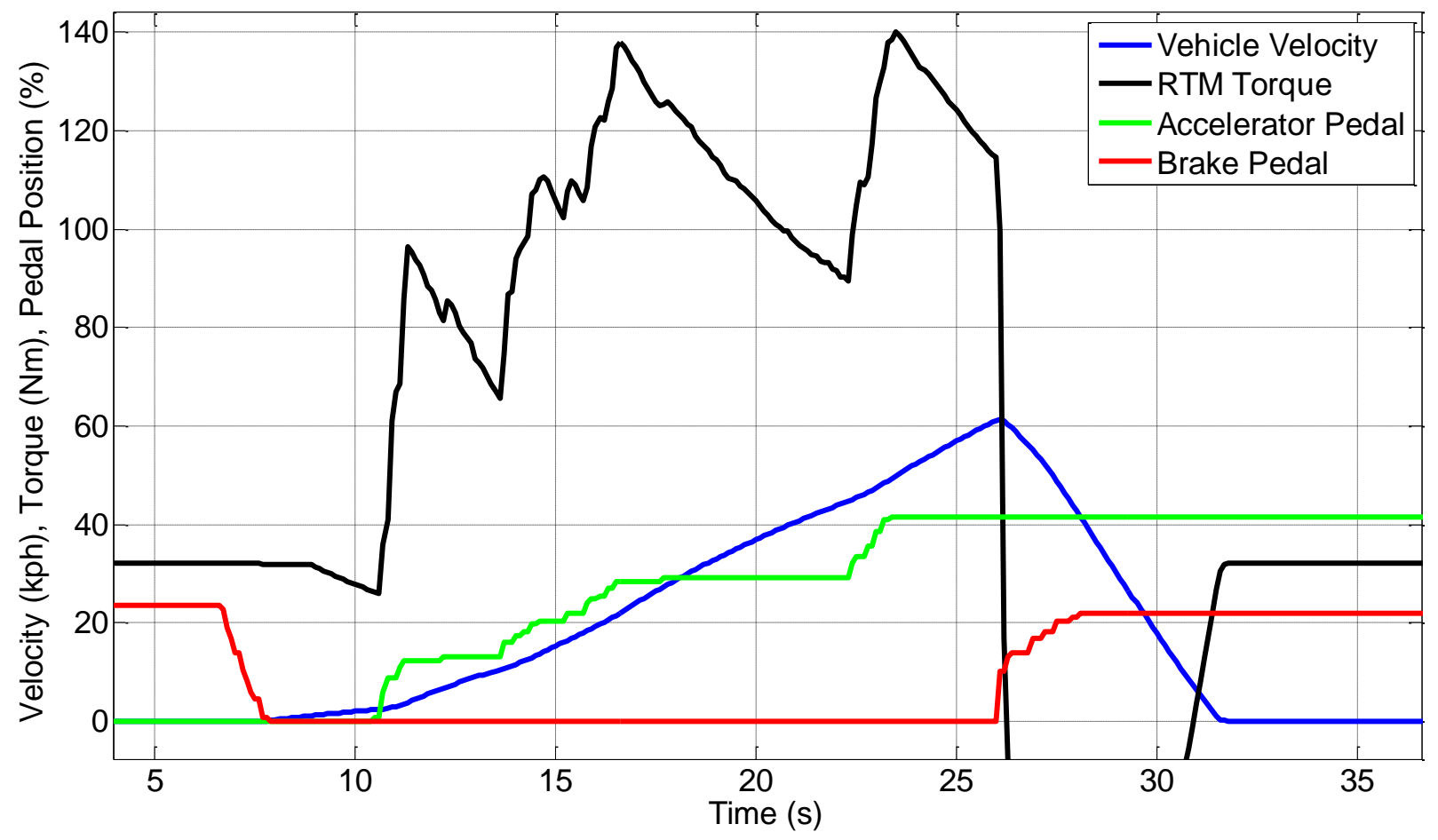

Figure 26: Response to simultaneous accelerator and brake input.

The test starts with the vehicle at rest and the driver pushing the brake. The RTM is being commanded some torque to make vehicle start to "creep" as the driver eases off the brake to give the vehicle a familiar driving dynamic to a conventional vehicle. The driver releases the brake and the vehicle begins to move. The driver then pushes the accelerator pedal to accelerate the vehicle. Next the brake is applied while the accelerator pedal is still being pushed. The HVSC immediately stops commanding RTM torque and allows to vehicle to decelerate. As the vehicle comes to a stop the RTM starts to command a small amount of creep torque again.

Diagnostics are also an important part of validating the HVSC for on-road testing. Working diagnostics are important to ensure the HVSC will protect the safety of the vehicle passengers from unsafe conditions and prevent component damage. As the HVSC assumes a supervisory role in the system it is mostly responsible for detecting system level fault conditions. Each powertrain component has an ECU responsible for detecting faults with that component and reporting those faults to the HVSC. The role of the HVSC is to determine the implications of component level faults on the system and detect system level faults that can arise due to interactions between components even if individually the components are operating correctly.

Two methods that are used determine what fault conditions are important are design failure mode effects analysis (DFMEA) and fault tree analysis (FTA). DFMEA is a top down approach that looks at a component failure and determines what the potential effects it will have on the system are. The goal of DFMEA is to identify high priority failure modes and reduce the likelihood of occurrence, reduce the severity of the failure if it does occur, anr/or improve the method for detecting the failure before it occurs or has serious consequences. FTA is a bottom up approach that looks at failure symptoms and determines what failures could have caused it. Table 12 identifies different categories of faults and some examples of each category. 
Table 12: Summary of different kinds of faults

\begin{tabular}{|l|l|}
\hline Communication Failures & $\begin{array}{l}\bullet \text { Loss of CAN communication with components } \\
\bullet \text { Invalid analog signal }\end{array}$ \\
\hline Component Operation Limits Exceeded & $\begin{array}{l}\text { - Components outside of temperature limits } \\
\text { - Battery over-voltage } \\
- \text { Battery SOC outside safe limits }\end{array}$ \\
\hline Incorrect Component Operation & $\begin{array}{l}\text { - Engine/motor fails to receive torque command } \\
\text { - Transmission engages incorrect gear }\end{array}$ \\
\hline Component Failure & $\begin{array}{l}\text { - Transmission input shaft failure } \\
\bullet\end{array}$ \\
& $\begin{array}{l}\text { DC-DC converter failure } \\
\text { - Drive-shaft failure }\end{array}$ \\
\hline
\end{tabular}

For each of these cases the HVSC must take an appropriate action to protect components and passengers while keeping the vehicle operational if possible. Figure 27 shows an example of testing the diagnostic for losing CAN communication with the RTM on the HIL.

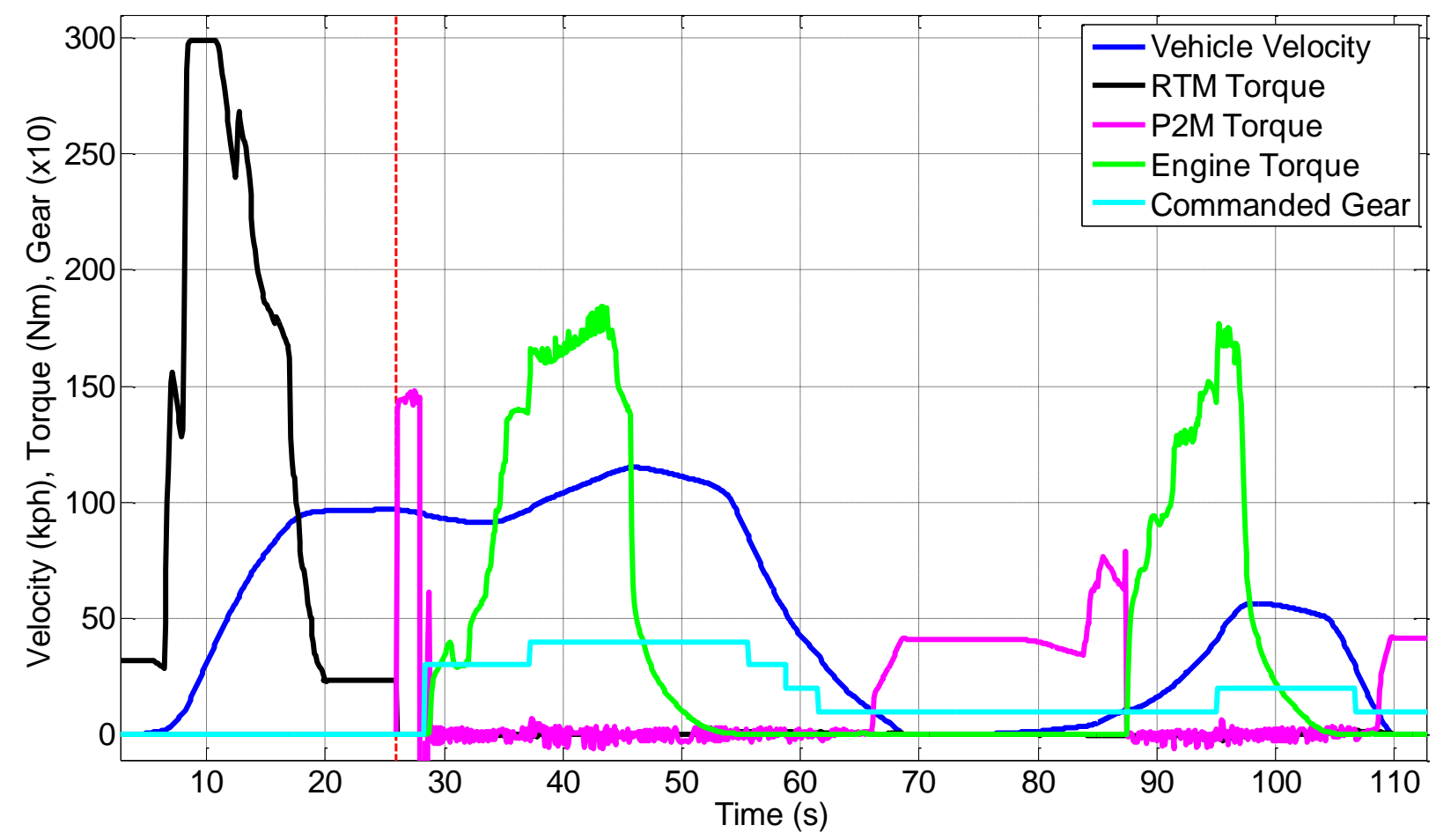

Figure 27: Results from test of RTM CAN communication fault

At the beginning of the test the vehicle is in the charge depleting state and the RTM accelerates the vehicle then maintains a constant speed. At the time indicated by the red line CAN communication with the RTM is cut. Without CAN communication there is no way to know if the RTM is operating correctly. The HVSC therefore immediately stops commanding torque to the RTM and uses the P2M to start the engine. From this point on the engine and P2M are used 
to propel the vehicle in parallel mode. To move from a stop the engine must spin unfueled due to the lack of the torque converter. The test shows that the HVSC can successfully handle a fault that renders the RTM inoperable. This example is a fault condition that has been identified through DFMEA as a high priority fault. Without this diagnostic, loss of communication could mean the motor has shut-off and would lead to a customer walk-home event if not detected. Even more dangerous, the motor could still be operating and could overheat without the HVSC being aware of the problem. This diagnostic improves detection of the failure and reduces the severity of the symptoms. 


\section{CONCLUSIONS}

This paper has provided examples of effective use of model-based design tools throughout the development of a hybrid electric vehicle architecture and control system. In the architecture selection phase, a novel technique was presented for evaluating different architectures based on the system degrees of freedom. This technique was used to show that a series parallel powertrain has the potential for better fuel economy over a series powertrain. Without the need to develop a control strategy drive cycle simulations gave fuel economy estimations. Control system architecture development was then overviewed. This step was important to model-based design because at this point the requirements of the control system and each controller in the system were well defined. These requirements directly drive the requirements and fidelity of models used to validate the control system.

With the vehicle architecture selected and the control system architecture defined, the focus then shifted to development and validation of the hybrid vehicle supervisory controller. The control system architecture was used to systematically outline the specific requirements of the control strategy for the hybrid vehicle supervisory controller. Contol software was then developed using Mathworks Simulink and Stateflow using a modular software architecture to facilitate team work and code reusability. To validate and improve the fuel economy optimization strategy a simple vehicle model was then developed. This low fidelity model was designed to meet the requirements for fuel economy while still allowing fast execution times. Finally a more detailed vehicle model was developed for safety critical validation of the hybrid vehicle supervisory controller software and hardware using hardware-in-the-loop testing. This testing method was demonstrated for fuel economy testing, performance improvement, safety critical testing, and diagnostic validation.

Future work that could build off this thesis could include the implementation of this hybrid vehicle design and collecting real world data to compare results against what was modeled. Also, the control strategy developed for this research can continue to be refined. While the basic strategy is in place more considerations need to be made. While the hardware-in-the-loop testing has been used to improve shift quality, on-road testing may show more improvement is still needed. An important factor in this is how well the transmission model reproduces the behavior of the actual transmission. Another area that can be improved is performance. The current strategy is only optimized for fuel economy and therefore limits engine torque and restrains the engine speed. A performance mode could be added that further opens the engine operating range.

Another important consideration is engine warm-up. Most vehicle emissions during a cold start drive cycle come from the first few minutes while the engine is warming up and the catalyst had not yet lit-off. It is important therefore to keep the load on the engine low during this period to avoid high emissions. Algorithms should therefore be added to the strategy to address engine loading during warm-up. Further work is also needed for validation of the safety critical systems and diagnostics. Individual tests should be automated and run simultaneously to test responses to multiple failures. As the vehicle development goes from design to prototype, model-based design techniques should remain an integral part to the control design process. 


\section{REFERENCES}

1. "U.S. Product Supplied for Crude Oil and Petroleum Products." U.S. Energy Information Administration, 30 July 2012. Web. 05 Aug. 2012.

<http://www.eia.gov/dnav/pet/pet_cons_psup_dc_nus_mbbl_a.htm>.

2. Adams, Becket. "How Much Did The Average American Family Spend On Gas in 2011?" The Blaze. N.p., 20 Dec. 2011. Web. 26 July 2012. <http://www.theblaze.com/stories/how-much-didthe-average-american-family-spend-on-gas-in-2011/>.

3. Green, D., Baker, H., and Plotkin, S., (2011), "Reducing Greenhouse Gas Emissions from U.S. Transportation," Prepared for the Pew Center for Global Climate Change.

4. Robert Jesse Alley, (2012), "VTool: A Method for Predicting and Understanding the Energy Flow and Losses in Advanced Vehicle Powertrains", MS Thesis in Mechanical Engineering, VPI\&SU, Blacksburg, Va.

5. Saurabh Mahapatra, Tom Egel, Raahul Hassan, Rohit Shenoy, and Michael Carone, (2008), "Model-Based Design for Hybrid Electric Vehicle Systems", SAE Paper 2008-01-0085, SAE 2008 International World Congress, April 14-17, Detroit, MI.

6. J. Marco, E. Cacciatori, (2007), "The Use of Model Based Design Techniques in the Design of Hybrid Electric Vehicles", $20073^{\text {rd }}$ Institution of Engineering and Technology Conference on Automotive Electronics, June 28-29, Warwick, UK.

7. Tomaž Katrašnik, Ferdinand Trenc, and Samuel Rodman Oprešnik, (2007), “Analysis of Energy Conversion Efficiency in Parallel and Series Hybrid Powertrains", IEEE Transactions on Vehicular Technology, 56(6).

8. Pierluigi Pisu, Giorgio Rizzoni, (2007), "A Comparative Study Of Supervisory Control Strategies for Hybrid Electric Vehicles”, IEEE Transactions on Control Systems Technology, 15(3).

9. Eric John Schacht, (2011), "Design and Development of the EcoCAR Vehicle and the Vehicle Controls Providing Efficiency and Drivability", MS Thesis in Electrical and Computer Engineering, The Ohio State University, Columbus, Ohio.

10. Deepa Ramaswamy, Ryan McGee, Shiva Sivashankar, Amit Deshpande, Jace Allen, Kevin Rzemien, and Walt Stuart, (2004), "A Case Study in Hardware-In-the-Loop Testing: Development of an ECU for a Hybrid Electric Vehicle", SAE Paper 2004-01-0303, SAE 2004 International World Congress, March 8-11, Detroit, MI.

11. Yuhang Deng, Hui Li, Simon Foo, (2009), "Controller Hardware-In-the-Loop Simulation for Design of Power Management Strategies for Fuel Cell Vehicle with Energy Storage", Vehicle Power and Propulsion Conference, September 7-10, Dearborn, MI. 
12. Robert Jesse Alley, Jonathan King, Douglas J. Nelson, and Eli White, (2012), "Hybrid Architecture Selection and Component Sizing to Reduce Emissions and Petroleum Energy Consumption", SAE Paper 2012-01-1195, SAE 2012 International World Congress, April 24-26, Detroit, MI.

13. P. Christopher Manning, Eli White, R. Jesse Alley, Jonathan King, and Douglas J. Nelson, (2012), "Vehicle System Design Process for a Series-Parallel Plug-in Hybrid Electric Vehicle", SAE Paper 2012-01-1774, SAE 2012 International Powertrains, Fuels \& Lubricants Meeting, September 18-20, Malmo, Sweden.

14. Qing Wang, (2011), "Vehicle System Controls for a Series Hybrid Powertrain", SAE Paper 2011-01-0860, SAE 2011 International World Congress, April 12-14, Detroit MI.

15. Larminie, James, and John Lowry. Electric Vehicle Technology Explained. West Sussex, England: J. Wiley, 2003. Print.

16. "Autonomie." Argonne National Laboratory, Mar. 2012. <http://www.autonomie.net/>. 


\section{APPENDIX A: TABLE OF POWERTRAIN CONTROL MODULES}

Table 13: List of control units for vehicle

\begin{tabular}{|c|c|c|c|}
\hline \multicolumn{4}{|c|}{ Existing Control Units } \\
\hline Component & ECU & Supplier & Primary Roles \\
\hline $\begin{array}{l}\text { Automatic } 6 \\
\text { Speed } \\
\text { Transmission }\end{array}$ & $\begin{array}{l}\text { Transmission } \\
\text { Control Module } \\
(\mathrm{TCM})\end{array}$ & $\begin{array}{l}\text { General } \\
\text { Motors }\end{array}$ & $\begin{array}{l}\text { - Receive gear command from HVSC } \\
\text { - Operate transmission clutches to achieve } \\
\text { desired gear }\end{array}$ \\
\hline Vehicle Chassis & $\begin{array}{l}\text { Integrated Body } \\
\text { Control Module } \\
(\text { IBCM) }\end{array}$ & $\begin{array}{l}\text { General } \\
\text { Motors }\end{array}$ & $\begin{array}{l}\text { - Report key position } \\
\text { - Operate chassis systems (lights, horn, } \\
\text { ect.) }\end{array}$ \\
\hline Brake System & $\begin{array}{l}\text { Electronic } \\
\text { Brake Control } \\
\text { Module } \\
(\text { EBCM) }\end{array}$ & $\begin{array}{l}\text { General } \\
\text { motors }\end{array}$ & $\begin{array}{l}\text { - Report drive applied brake pedal } \\
\text { pressure to HVSC } \\
\text { - Operate ABS } \\
\text { - Report ABS state to HVSC } \\
\end{array}$ \\
\hline $\begin{array}{l}\text { Electric Power } \\
\text { Steering }\end{array}$ & $\begin{array}{l}\text { Power Steering } \\
\text { Control Module } \\
(\mathrm{PSCM})\end{array}$ & $\begin{array}{l}\text { General } \\
\text { Motors }\end{array}$ & $\begin{array}{l}\text { - Operate electric steering assist motor } \\
\text { - Report steering wheel angle to HVSC }\end{array}$ \\
\hline \multicolumn{4}{|c|}{ New Control Units } \\
\hline Component & ECU & Supplier & Primary Roles \\
\hline $\begin{array}{l}\text { 2.4 L Flex Fuel } \\
\text { Engine }\end{array}$ & $\begin{array}{l}\text { Engine Control } \\
\text { Module (ECM) }\end{array}$ & $\begin{array}{l}\text { General } \\
\text { Motors }\end{array}$ & $\begin{array}{l}\text { - Receive torque command from HVSC } \\
\text { - Operate engine fuel delivery, ignition, } \\
\text { and emissions control } \\
\text { - Report engine speed and achieved torque } \\
\text { to HVSC }\end{array}$ \\
\hline $\begin{array}{l}125 \mathrm{~kW} \text { Rear } \\
\text { Traction Motor }\end{array}$ & $\begin{array}{l}\text { Traction Motor } \\
\text { Inverter Module } \\
\text { (TMIM) }\end{array}$ & UQM & $\begin{array}{l}\text { - Receive torque command from HVSC } \\
\text { - Control motor 3-phase current } \\
\text { - Report motor speed and achieved torque } \\
\text { to HVSC }\end{array}$ \\
\hline $\begin{array}{l}30 \mathrm{~kW} \mathrm{P2} \\
\text { Generator } \\
\text { Motor }\end{array}$ & $\begin{array}{l}\text { Generator } \\
\text { Motor Inverter } \\
\text { Module } \\
(\text { GMIM) }\end{array}$ & Kollmorgen & $\begin{array}{l}\text { - Receive torque command from HVSC } \\
\text { - Control motor 3-phase current } \\
\text { - Report motor speed and achieved torque } \\
\text { to HVSC }\end{array}$ \\
\hline $\begin{array}{l}18.9 \mathrm{kWh} \\
\text { Energy Storage } \\
\text { System }\end{array}$ & $\begin{array}{l}\text { Battery Control } \\
\text { Module (BCM) }\end{array}$ & $\begin{array}{l}\text { A123 } \\
\text { Systems }\end{array}$ & $\begin{array}{l}\text { - Receive contactor command from HVSC } \\
\text { - Operate battery contactors } \\
\text { - Report current limits HVSC } \\
\end{array}$ \\
\hline $\begin{array}{l}\text { DC-DC } \\
\text { Converter }\end{array}$ & $\begin{array}{l}\text { Auxiliary } \\
\text { Power Module } \\
\text { (APM) }\end{array}$ & Delphi & $\begin{array}{l}\text { - Receive low voltage system output } \\
\text { command } \\
\text { - Report low voltage system voltage }\end{array}$ \\
\hline $\begin{array}{l}\text { High Voltage } \\
\text { Battery Charger }\end{array}$ & $\begin{array}{l}\text { High Voltage } \\
\text { Charger Module } \\
\text { (HVCM) }\end{array}$ & BRUSA & $\begin{array}{l}\text { - Report AC power availability to HVSC } \\
\text { - Communicate with BCM to facilitate } \\
\text { battery charging }\end{array}$ \\
\hline
\end{tabular}




\section{APPENDIX B: CONTROLLER INTERACTION DIAGRAM}

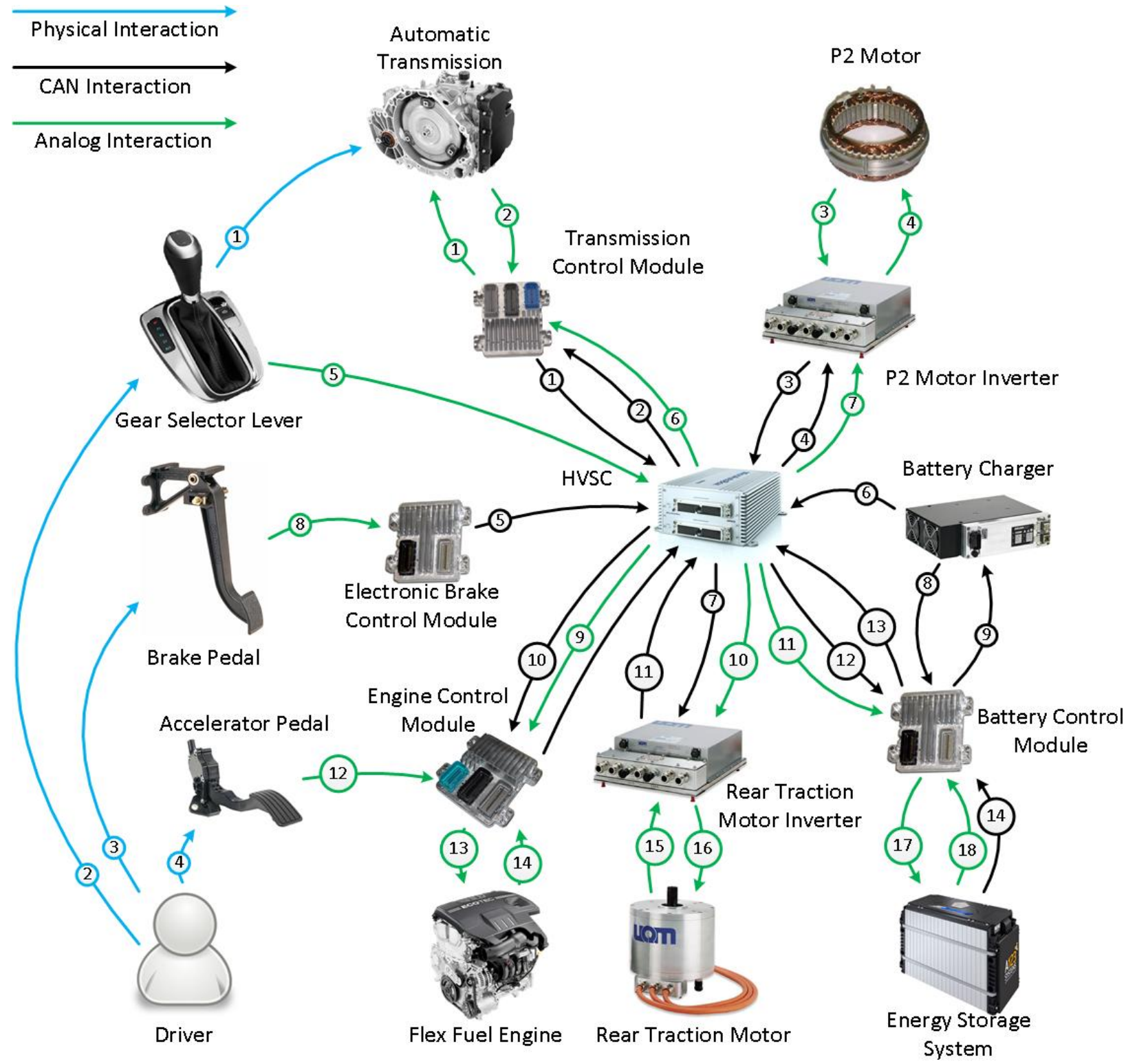

Figure 28: Controller interaction diagram

Table 14: Physical interactions

\begin{tabular}{|l|l|}
\hline $\mathbf{1}$ & Gear shift lever mechanically operates park pawl and enables fluid passages \\
\hline $\mathbf{2}$ & Driver operates gear shift lever \\
\hline $\mathbf{3}$ & Driver operates brake pedal \\
\hline $\mathbf{4}$ & Driver operates accelerator pedal \\
\hline
\end{tabular}


Table 15: CAN signal interactions

\begin{tabular}{|c|l|}
\hline $\mathbf{1}$ & $\begin{array}{l}\text { Transmission input/output speeds, oil pressure, oil temperature, current gear, gear shift lever } \\
\text { position (interpretation of signal from HVSC) }\end{array}$ \\
\hline $\mathbf{2}$ & Gear command \\
\hline $\mathbf{3}$ & $\begin{array}{l}\text { P2M speed, torque request received, actual torque, current, motor stator and rotor } \\
\text { temperatures, inverter circuit temperatures }\end{array}$ \\
\hline $\mathbf{4}$ & P2M torque command, direction command \\
\hline $\mathbf{5}$ & Brake pedal applied pressure, ABS state, wheel speeds \\
\hline $\mathbf{6}$ & AC voltage availability, AC current in, DC current out, DC voltage out \\
\hline $\mathbf{7}$ & P2M torque command, direction command \\
\hline $\mathbf{8}$ & Contactor command \\
\hline $\mathbf{9}$ & Current request, voltage request \\
\hline $\mathbf{1 0}$ & Engine torque command \\
\hline $\mathbf{1 1}$ & $\begin{array}{l}\text { RTM speed, torque request received, actual torque, current, motor stator and rotor } \\
\text { temperatures, inverter circuit temperatures }\end{array}$ \\
\hline $\mathbf{1 2}$ & Contactor command \\
\hline $\mathbf{1 3}$ & $\begin{array}{l}\text { Battery voltage, current, high voltage isolation resistance, max/min cell voltage, max/min } \\
\text { cell temperature, state of charge }\end{array}$ \\
\hline $\mathbf{1 4}$ & Module/cell temperatures, currents, voltages \\
\hline
\end{tabular}

Table 16: Analog signal interactions

\begin{tabular}{|l|l|}
\hline $\mathbf{1}$ & Clutch solenoid control signals \\
\hline $\mathbf{2}$ & Input speed sensor, output speed sensor, oil pressure sensors, oil temperature sensors \\
\hline $\mathbf{3}$ & Encoder, temperature sensors \\
\hline $\mathbf{4}$ & 3-phase current control \\
\hline $\mathbf{5}$ & Range selector position sensor \\
\hline $\mathbf{6}$ & Modified range selector position sensor signal \\
\hline $\mathbf{7}$ & Enable signal \\
\hline $\mathbf{8}$ & Brake pedal hydraulic pressure sensor \\
\hline $\mathbf{9}$ & 12 V starter control signal, ignition signal \\
\hline $\mathbf{1 0}$ & Enable signal \\
\hline $\mathbf{1 1}$ & Wakeup signal, charge enable signal \\
\hline $\mathbf{1 2}$ & Accelerator pedal position sensor \\
\hline $\mathbf{1 3}$ & $\begin{array}{l}\text { Throttle control signal, fuel pump control signal, injector control signals, cam phasing } \\
\text { control signals, ignition control signals }\end{array}$ \\
\hline $\mathbf{1 4}$ & $\begin{array}{l}\text { Throttle position sensor, airflow sensor, manifold pressure sensor, oxygen sensors, coolant } \\
\text { temperature sensor }\end{array}$ \\
\hline $\mathbf{1 5}$ & Encoder, temperature sensors \\
\hline $\mathbf{1 6}$ & 3-phase current control \\
\hline $\mathbf{1 7}$ & Contactor control \\
\hline $\mathbf{1 8}$ & Voltage sensors, current sensor \\
\hline
\end{tabular}




\section{APPENDIX C: RESULTS FOR SIL TESTING PARAMETER VARIATION}

Table 17: SIL parameter variation UDDS results

\begin{tabular}{|l|l|l|l|l|}
\hline $\boldsymbol{\eta}_{\text {Gen,Chg }}$ & $\boldsymbol{\eta}_{\text {Dis,Gen }}$ & Fuel Economy & Average Engine Efficiency & Battery Losses \\
\hline 0.2 & 0.2 & 35.9 & $36.1 \%$ & 63.91 \\
\hline 0.2 & 0.3 & 34.5 & $34.3 \%$ & 18.25 \\
\hline 0.2 & 0.4 & 34.3 & $34.2 \%$ & 15.63 \\
\hline 0.3 & 0.2 & 35.1 & $35.0 \%$ & 203.15 \\
\hline 0.3 & 0.3 & 36.5 & $36.6 \%$ & 68.65 \\
\hline 0.3 & 0.4 & 34.5 & $34.4 \%$ & 18.32 \\
\hline 0.4 & 0.2 & 34.8 & $34.7 \%$ & 246.45 \\
\hline 0.4 & 0.3 & 35.5 & $35.8 \%$ & 236.51 \\
\hline 0.4 & 0.4 & 35.2 & $35.0 \%$ & 29.16 \\
\hline
\end{tabular}

Table 18: SIL parameter variation HWFET results

\begin{tabular}{|l|l|l|l|l|}
\hline $\boldsymbol{\eta}_{\text {Gen,Chg }}$ & $\boldsymbol{\eta}_{\text {Dis,Gen }}$ & Fuel Economy & Average Engine Efficiency & Battery Losses \\
\hline 0.2 & 0.2 & 37.7 & $36.7 \%$ & 52.67 \\
\hline 0.2 & 0.3 & 37.1 & $35.5 \%$ & 7.82 \\
\hline 0.2 & 0.4 & 37.1 & $35.4 \%$ & 7.54 \\
\hline 0.3 & 0.2 & 37.2 & $34.9 \%$ & 155.54 \\
\hline 0.3 & 0.3 & 37.9 & $36.7 \%$ & 59.05 \\
\hline 0.3 & 0.4 & 37.2 & $35.5 \%$ & 7.85 \\
\hline 0.4 & 0.2 & 36.9 & $34.8 \%$ & 194.83 \\
\hline 0.4 & 0.3 & 37.5 & $35.4 \%$ & 154.10 \\
\hline 0.4 & 0.4 & 37.3 & $35.7 \%$ & 10.22 \\
\hline
\end{tabular}

Table 19: SIL parameter variation US06 City results

\begin{tabular}{|l|l|l|l|l|}
\hline $\boldsymbol{\eta}_{\text {Gen,Chg }}$ & $\boldsymbol{\eta}_{\text {Dis,Gen }}$ & Fuel Economy & Average Engine Efficiency & Battery Losses \\
\hline 0.2 & 0.2 & 22.2 & $35.1 \%$ & 118.75 \\
\hline 0.2 & 0.3 & 22.4 & $35.3 \%$ & 90.47 \\
\hline 0.2 & 0.4 & 22.3 & $34.8 \%$ & 91.29 \\
\hline 0.3 & 0.2 & 21.7 & $35.4 \%$ & 206.35 \\
\hline 0.3 & 0.3 & 22.3 & $35.7 \%$ & 116.44 \\
\hline 0.3 & 0.4 & 22.3 & $34.8 \%$ & 91.98 \\
\hline 0.4 & 0.2 & 21.2 & $35.0 \%$ & 278.60 \\
\hline 0.4 & 0.3 & 21.5 & $36.0 \%$ & 244.00 \\
\hline 0.4 & 0.4 & 22.2 & $34.8 \%$ & 95.31 \\
\hline
\end{tabular}


Table 20: SIL parameter variation US06 Highway results

\begin{tabular}{|l|l|l|l|l|}
\hline $\boldsymbol{\eta}_{\text {Gen,Chg }}$ & $\boldsymbol{\eta}_{\text {Dis,Gen }}$ & Fuel Economy & Average Engine Efficiency & Battery Losses \\
\hline 0.2 & 0.2 & 28.2 & $35.2 \%$ & 94.87 \\
\hline 0.2 & 0.3 & 28.3 & $35.3 \%$ & 89.64 \\
\hline 0.2 & 0.4 & 28.2 & $35.2 \%$ & 92.03 \\
\hline 0.3 & 0.2 & 28.1 & $35.2 \%$ & 125.61 \\
\hline 0.3 & 0.3 & 28.3 & $35.4 \%$ & 91.56 \\
\hline 0.3 & 0.4 & 28.2 & $35.2 \%$ & 92.06 \\
\hline 0.4 & 0.2 & 27.9 & $35.2 \%$ & 123.91 \\
\hline 0.4 & 0.3 & 28.2 & $35.3 \%$ & 114.23 \\
\hline 0.4 & 0.4 & 28.3 & $35.2 \%$ & 91.89 \\
\hline
\end{tabular}

